\title{
Lean-Burn Characteristics of a Gasoline Engine Enriched with Hydrogen from a Plasmatron Fuel Reformer
}

By

Edward J. Tully

B.S., Chemical Engineering

Case Western Reserve University, 1997

Submitted to the Department of Mechanical Engineering in Partial Fulfillment of the

Requirements for the Degree of

Master of Science in Mechanical Engineering

at the

Massachusetts Institute of Technology

BARKER

June 2002

(C2002 Massachusetts Institute of Technology

All Rights Reserved

MASSACHUSETTS WMSTITUTE

OF TECHNOLOGY

OCT 252002

LIBRARIES

Signature of Author

Department of Mechanical Engineering

June 10, 2002

I

Certified by

John B. Heywood

Sun Jae Professor of Mechanical Engineering

Thesis Advisor

Accepted By

Ain A. Sonin

Professor, Department of Mechanical Engineering

Chairman, Department Graduate Committee 


\section{DISCLAIMER OF QUALITY}

Due to the condition of the original material, there are unavoidable flaws in this reproduction. We have made every effort possible to provide you with the best copy available. If you are dissatisfied with this product and find it unusable, please contact Document Services as soon as possible.

Thank you.

\section{The images contained in this document are of the best quality available.}





\title{
Lean-Burn Characteristics of a Gasoline Engine Enriched with Hydrogen from a Plasmatron Fuel Reformer
}

\author{
By
}

\author{
Edward J. Tully
}

\author{
Submitted to the Department of Mechanical Engineering \\ June 2002 in Partial Fulfillment of the Requirements for the Degree of \\ Master of Science in Mechanical Engineering
}

\begin{abstract}
If a small amount of hydrogen is added to a gasoline fueled spark ignition engine the lean limit of the engine can be extended. Lean running engines are inherently more efficient, and have the potential for significantly lower NOx emissions. Hydrogen addition reduces the combustion variability. In this engine concept supplemental hydrogen is generated on-board the vehicle by diverting a small fraction of the gasoline to a plasmatron where it is partially oxidized into a stream containing hydrogen, carbon monoxide, nitrogen, and carbon dioxide. It is then mixed in the intake port with the main fuel/air charge to provide hydrogen enhanced lean operation
\end{abstract}

A series of experiments were performed to study the feasibility of this engine concept. Since the plasmatron is still under development the final composition of the plasmatron gas is not yet known. Therefore, two different bottled gases were used to simulate the plasmatron output. An ideal plasmatron gas $\left(\mathrm{H}_{2}, \mathrm{CO}\right.$, and $\left.\mathrm{N}_{2}\right)$ was used to represent the output of the theoretically best plasmatron. In addition, a typical plasmatron gas $\left(\mathrm{H}_{2}, \mathrm{CO}\right.$, $\mathrm{N}_{2}$, and $\mathrm{CO}_{2}$ ) was used to represent the current output of the plasmatron. In addition, a series of hydrogen only addition experiments were performed to quantify the impact of the non-hydrogen components in the plasmatron gas.

Various amounts of plasmatron gas were used, ranging from the equivalent of $10 \%-30 \%$ of the gasoline being converted in the plasmatron. At each of these fractions a sweep of the relative air/fuel ratio was performed, starting at stoichiometic and slowly increasing lambda until the engine began to misfire. At each operating point data was collected to quantify efficiency, emissions, and combustion stability.

All of the data was compared to a baseline case of the engine operating stoichiometrically on gasoline only. It was found that the peak net indicated fuel conversion efficiency of the system increased $12 \%$ over the baseline case. In addition, at this peak efficiency point the engine out NOx emissions decrease by $94 \%$ (165ppm vs. $2800 \mathrm{ppm}$ ) while the hydrocarbon emissions decreased by 6\% (2210ppm vs. 2350ppm). NOx emissions reductions of $99 \%$ were possible although they occured at slightly lower overall efficiency points. 
In the analysis the relative air/fuel ratio was found to be an inadequate measure of mixture dilution. Two new dilution parameters were defined. The Volumetric Dilution Parameter, VDP, represents the heating value per unit volume of the air/fuel mixture. Pumping work reductions due to dilution correlate with VDP. The Thermal Dilution Parameter, TDP, represents the heating value per unit heat capacity of the fuel/air mixture. Combustion and emissions parameters correlate with TDP. 


\section{ACKNOWLEDGEMENTS}

The end.

At times I thought this day would never come.

Sixteen months ago I become a member of the Sloan Automotive Lab. Since then I have felt excitement, frustration, surprise, failure, and ultimately success. Throughout the entire process I have had the support of many people that have made my experience at MIT invaluable. Without them none of this would have been possible.

First I would like to thank Professor John Heywood for being my thesis advisor. Professor Heywood encouraged me every step of the way, providing direction when necessary but also giving me the freedom to contribute my own ideas to the research project. His continuous support has greatly enhanced my time spent at MIT.

In addition I would like to thank Professor Wai K. Cheng. Professor Cheng provided creative solutions for dealing with equipment problems that caused havoc with my data collection. Without his help I would probably still be standing in my test cell, pulling my hair out in frustration.

Grant number DE-AC03-99EE50565 from the US Department of Energy supported this work. I would like to thank the Dr. Rogelio Sullivan and Sidney Diamond of the US Department of Energy for this support.

The assistance in the lab has been excellent. Thane Dewitt helped with all types of technical issues while Alexis Rozantes provided solutions to my administrative questions. In addition, Karla Stryker always somehow managed to squeeze me into Professor Heywood's busy schedule. Without this group my research would have been much more difficult to complete.

Every single student in the Sloan Auto Lab has had a positive impact on my stay at MIT. Several have done a tremendous amount to help me along the way. Andreas Lengwiler preceded me on the plasmatron project and helped in setting up much of the necessary experimental hardware. Jenny Topinka worked closely with me for the past academic year and performed many hours of analysis and simulation in support of this project. Additionally, Brian Hallgren helped in many ways from equipment setup to data analysis, not to mention the many hours of laughter he provided. Many more remain unnamed but are no less important.

Finally I would like to thank my employer, General Motors. Their backing has been substantial and they have gone out of their way to provide both financial and administrative support. Without their assistance I would not have had this incredible opportunity. 


\section{TABLE OF CONTENTS}

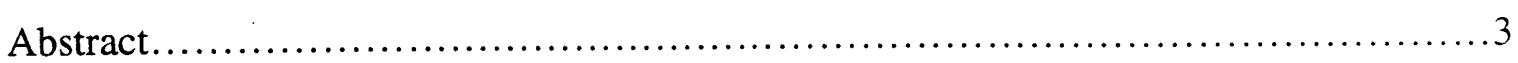

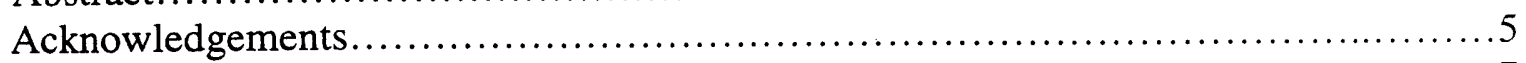

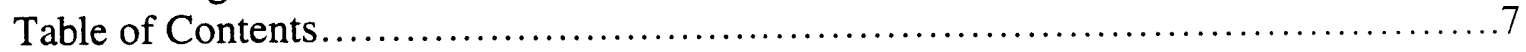

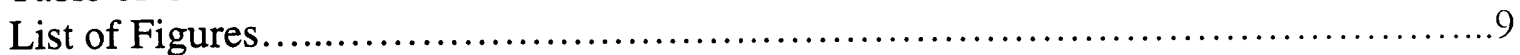

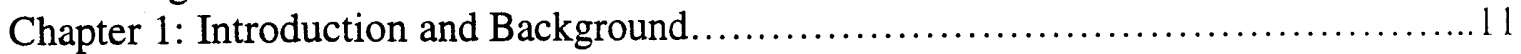

1.1: Current State of Gasoline SI and Diesel Engines.................... 1

1.2: Supplemental Hydrogen Addition Concept.......................... 12

1.3: Plasmatron Engine Concept...................................... 13

1.4: Plasmatron Operation........................................... 15

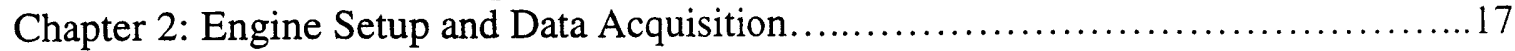

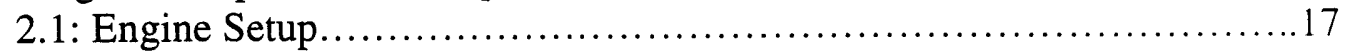

2.2: Engine Control................................................ 17

2.3: Fuel Data........................................................ 18

2.4: Data Acquisition................................................. 18

2.4.1: Test Setup.................................................... 18

2.4.2: Airflow Measurement........................................ 19

2.4.3: Indolene Flow Rate Control................................. 19

2.4.4: Plasmatron Flow Rate Control................................ 19

2.4.5: Lambda Measurement.......................................21

2.4.6: In-Cylinder Pressure Measurement............................ 21

2.4.7: Hydracarbon Emissions Measurement.........................21

2.4.8: NOx Emissions Measurement...............................21

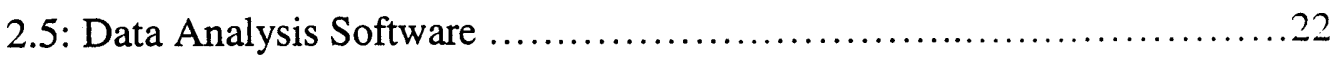

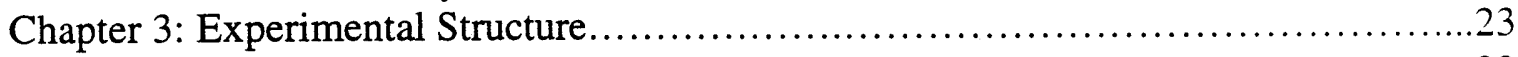

3.1: Increasing Burn Rate........................................... 23

3.2: Plasmatron and Hydrogen Addition Experiments..................... 25

3.2.1: Experimental Procedure.....................................25

3.2.2: Equivalent Percent Plasmatron Definition....................27

3.2.3: Dilution Parameters....................................... 30

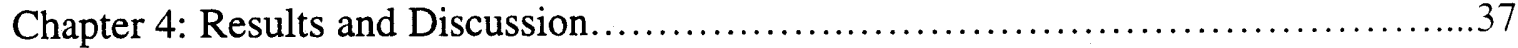

4.1: Error Analysis....................................................... 37

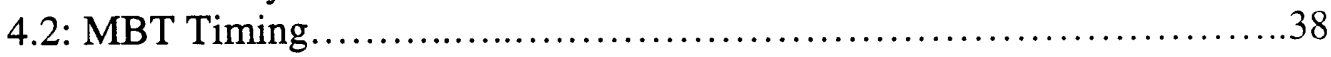

4.3: Burn Duration.................................................... 38

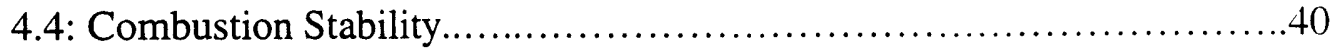

4.5: Hydrocarbon Combustion Efficiency.............................. 43

4.6: NOx Emissions............................................... 46

4.7: Fuel Conversion Efficiency ..................................... 48

4.7.1: Engine Only Fuel Conversion Efficiency .....................49

4.7.2: Overall System Fuel Conversion Efficiency ...................5 51

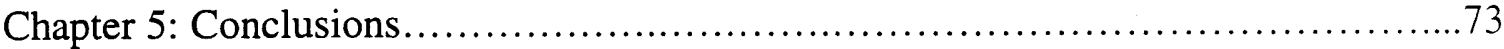

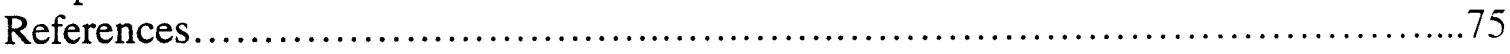

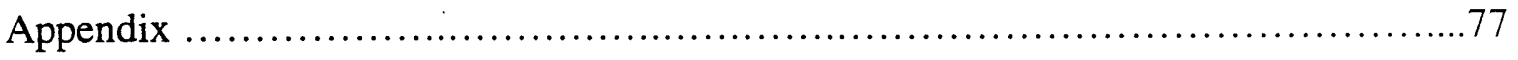




\section{LIST OF FIGURES}

Figure 1.1 - Flame Speed and Dilution Limit Data for Selected Compounds............12

Figure 1.2 - Plasmatron Engine Concept......................................... 13

Figure 1.3 - Schematic of a Plasmaton Fuel Reformer............................. 15

Figure 1.4 - Ideal and Typical Plasmatron Composition and Efficiency...................16

Figure 2.1 - Basic Engine Data................................................. 17

Figure 2.2 - Selected Fuel Properties........................................... 18

Figure 2.3 - Schematic of the Experimental Setup.................................. 18

Figure 3.1 - Intake Plate Designs..........................................24

Figure 3.2 - MBT Spark Timing vs. Lambda for Different Intake Plates Designs.........35

Figure 3.3 - Plasmatron Engine Schematic: Airflow and Fuel Flow ...................26

Figure 3.4 - Experimental Setup for Plasmatron and Hydrogen Addition.................27

Figure 3.5 - Energy Balance on System Using a Plasmatron.........................28

Figure $3.6-0 \%-10 \%$ Burn Angles vs. Lambda - Ideal Plasmatron and Hydrogen

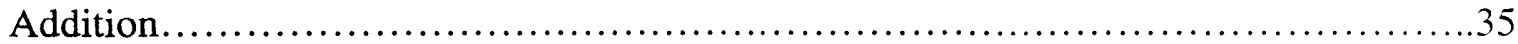

Figure 3.7 - 0\%-10\% Burn Angles vs. VDP - Ideal Plasmatron and Hydrogen

Addition............................................................... 36

Figure 3.8 - 0\%-10\% Burn Angles vs. TDP for Ideal Plasmatron and Hydrogen

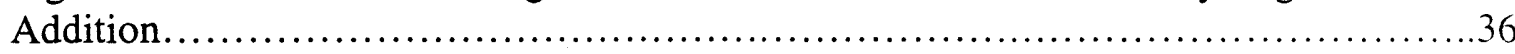

Figure 4.1 - Calculated Lambda vs. UEGO Lambda.............................. 54

Figure 4.2 - Absolute Error in Lambda vs. UEGO Lambda............................54

Figure 4.3 - MBT Spark Timing vs. Lambda - Typical and Ideal Plasmatron

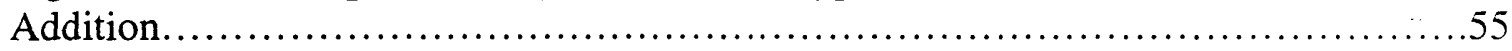

Figure 4.4 - MBT Spark Timing vs. TDP - Typical and Ideal Plasmatron Addition.....55

Figure 4.5 - MBT Spark Timing vs. Lambda - Ideal Plasmatron and Hydrogen

Addition.................................................................... 56

Figure 4.6 - MBT Spark Timing vs. TDP - Ideal Plasmatron and Hydrogen

Addition................................................................. 56

Figure 4.7 - 0\%-10\% Burn Duration Angle vs. Lambda - Typical and Ideal

Plasmatron Addition.............................................................57

Figure 4.8 - 0\%-10\% Burn Duration Angle vs. TDP - Typical and Ideal

Plasmatron Addition....................................................... 57

Figure 4.9 - 10\%-90\% Burn Duration Angle vs. Lambda - Typical

Plasmatron and Ideal Plasmatron................................................ 58

Figure 4.10 - 10\%-90\% Burn Duration Angle vs. TDP - Typical

Plasmatron and Ideal Plasmatron............................................... 58

Figure 4.11 - 10\%-90\% Burn Duration Angle vs. Lambda - Ideal

Plasmatron and Hydrogen Addition.................................................59

Figure 4.12 - 10\%-90\% Burn Duration Angle vs. TDP - Ideal Plasmatron

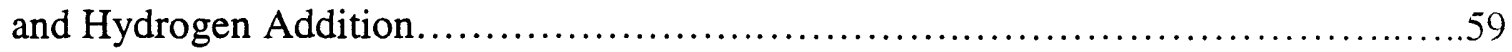

Figure 4.13 - COV of IMEP vs. Lambda - Typical Plasmatron and Ideal Plasmatron...60

Figure 4.14 - COV of IMEP vs. TDP - Typical Plasmatron and Ideal Plasmatron........60

Figure 4.15 - COV of IMEP vs. Lambda - Ideal Plasmatron and Hydrogen Addition....61

Figure 4.16 - COV of IMEP vs. TDP - Ideal Plasmatron and Hydrogen Addition........61 
Figure 4.17 - Percent Unburned Hydrocarbons vs. Lambda - Typical and

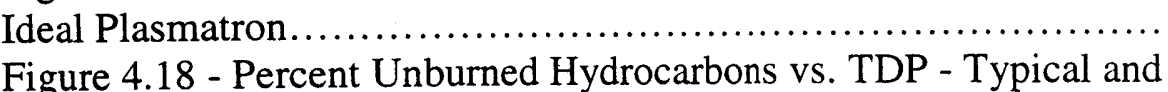

Ideal Plasmatron...............................................................

Figure 4.19 - Percent Unburned Hydrocarbons vs. Lambda - Ideal Plasmatron

and Hydrogen Addition.

Figure 4.20 - Percent Unburned Hydrocarbons vs. TDP - Ideal Plasmatron

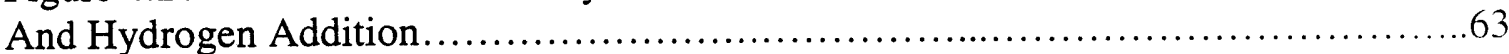

Figure 4.21 - NOx emissions vs. Lambda - Typical and Ideal Plasmatron...............64

Figure 4.22 - Log Scale of NOx emissions vs. Lambda - Typical and

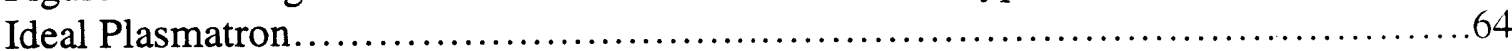

Figure 4.23 - NOx emissions vs. TDP - Typical and Ideal Plasmatron.................65

Figure 4.24 - Log Scale of NOx emissions vs. TDP - Typical and Ideal Plasmatron......65

Figure 4.25 - NOx emissions vs. Lambda - Ideal Plasmatron and

Hydrogen Addition........................................................66

Figure 4.26 - Log Scale of NOx emissions vs. Lambda - Ideal Plasmatron

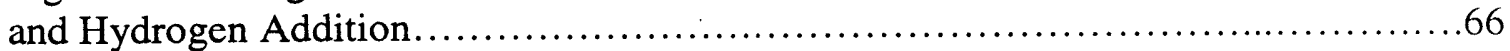

Figure 4.27 - NOx emissions vs. TDP - Ideal Plasmatron and Hydrogen Addition.......67

Figure 4.28 - Log Scale of NOx emissions vs. TDP - Ideal Plasmatron

and Hydrogen Addition.

Figure 4.29 - Engine only Fuel Conversion Efficiency vs. Lambda - Typical

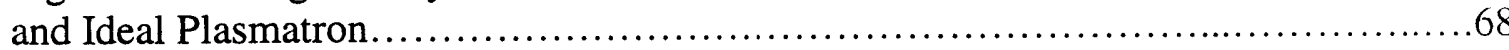

Figure 4.30 - Engine only Fuel Conversion Efficiency vs. VDP - Typical

and Ideal Plasmatron.

Figure 4.31 - Engine only Fuel Conversion Efficiency vs. Lambda - Ideal

Plasmatron and Hydrogen....

Figure 4.32 - Engine only Fuel Conversion Efficiency vs. VDP - Ideal

Plasmatron and Hydrogen

Figure 4.33 - Overall Fuel Conversion Efficiency vs. Lambda - Typical

and Ideal Plasmatron.............................................................. 70

Figure 4.34 - Overall Fuel Conversion Efficiency vs. VDP - Typical

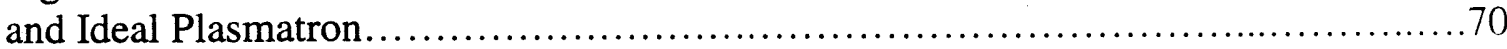

Figure 4.35 - Overall Fuel Conversion Efficiency vs. Lambda - Ideal

Plasmatron and Hydrogen Addition............................................ 71

Figure 4.36 - Overall Fuel Conversion Efficiency vs. VDP - Ideal

Plasmatron and Hydrogen Addition.......................................... 71

Figure 4.37 - Overall Net Indicated Fuel Conversion Efficiency vs. Relative

NOx emissions - All Data.................................................... 72

Figure 4.38 - Overall Net Indicated Fuel Conversion

Efficiency vs. COV - All Data.............................................. 72 


\section{Chapter 1: - Introduction and Background}

\section{1 - Current State of Gasoline Spark Ignition and Diesel Engines}

Currently the two dominant engine technologies in the automotive industry are the diesel engine and the gasoline spark ignition (SI) engine operating stoichiometrically. A promising third engine technology is the hydrogen enriched lean operating gasoline spark ignition engine.

Because diesel engines are designed to operate globally lean the throttle can be eliminated which significantly reduces pumping losses. In addition, the diesel engine can operate at a significantly higher compression ratio then the stoichiometrically operated spark ignition engine, which provides an additional efficiency benefit. Globally the diesel engine operates lean of stoichiometric although the air/fuel mixture inside the cylinder is not homogeneous. Locally, the charge can be fuel rich, stoichiometric, or lean. Combustion that occurs near stoichiometric results in high flame temperatures. which drives nitric oxide (NO) formation. In addition, the combustion that occurs in the fuel rich region is less complete and results in soot formation. An additional problem is that diesel exhaust is very difficult to treat. The exhaust gas is a highly oxidizing environment which makes the reduction of nitrogen oxides (NOx) to nitrogen and oxygen an especially challenging problem. Most diesel engines are currently sold without aftertreatment systems installed, resulting in high tailpipe out emissions of NOx and particulates.

The gasoline engine typically operates with a charge that is both homogeneous and stoichiometric. The main benefits to operating stoichiometrically are that a highly efficient three-way catalyst can be used, and the turbulent premixed flame combustion process is fast. Although the engine out NOx emissions are relatively high due to the high burnt gas temperatures, the use of exhaust gas recirculation (EGR) and a highly efficient three-way catalyst results in very low tailpipe emissions. The main drawback is that the engine must be throttled at part load, resulting in significant pumping losses. In addition, the knock limits are lowest near stoichiometric operation, necessitating lower compression ratios. 


\section{2 - Supplemental Hydrogen Addition Concept}

An alternative engine concept is the gasoline engine which operates both lean and with a homogeneous air/fuel mixture. Studies have shown that the addition of a small amount of hydrogen can greatly increase the lean limit of the engine [1]. By operating with excess air the engine is inherently more efficient and is less throttled, which greatly reduces the pumping losses and further increases efficiency. By operating with a homogeneous lean charge the peak combustion temperatures are much lower than in diesel or SI engines, resulting in much lower engine-out NOx emissions. At very lean conditions the NOx emissions may be low enough to eliminate aftertreatment. The largest obstacle to overcome with this concept is in achieving fast and stable combustion at very lean conditions. As excess air is added the flame speed slows, causing burn durations and combustion variability to increase. Eventually, the mixture becomes so dilute that it will no longer support stable combustion. Gasoline has a relatively low dilution limit with combustion deteriorating rapidly as excess air is added. One solution is to add a small amount of a fuel that has much faster combustion characteristics.

Hydrogen $\left(\mathrm{H}_{2}\right)$ is an excellent candidate because it has a much higher dilution limit and flame speed than typical hydrocarbons [2].

\begin{tabular}{|l|r|r|r|}
\hline & \multicolumn{2}{|c|}{ Laminar Flame Speed (cm/sec) } & \multicolumn{2}{c|}{ Lean Limit in Air } \\
\hline & Stoichiometric & Maximum & Relative AFR (Lambda) \\
\hline Hydrogen & 170.0 & 325.0 & 10.0 \\
\hline Carbon Monoxide & 28.5 & 52.0 & 2.9 \\
\hline Benzene & 47.6 & 47.6 & 2.2 \\
\hline Propane & 45.6 & 46.4 & 1.8 \\
\hline
\end{tabular}

Figure 1.1 - Flame Speed and Dilution Limit Data for Selected Compounds

Benzene and propane were chosen as representative straight chained and cyclic hydrocarbons. Although indolene is a mixture of many different hydrocarbons most of them have very similar burn properties to benzene and propane. The carbon monoxide (CO) data is included because it is present in the plasmatron engine concept, which is

NOTE: Figures showing experimental data are presented at the end of each chapter. All other figures are contained within the body of the paper. 
dicussed in the next section.

Although hydrogen has some very good combustion characteristics it is not widely used as a fuel for several reasons. First, hydrogen is a gas at room temperature and therefore must be stored in high pressure tanks on the vehicle which poses significant safety risks. In addition, there is no infrastructure available to distribute hydrogen and the construction of one would be expensive. Finally, hydrogen is not widely available in nature and if large quantities were needed it would have to be made from either the electrolysis or water or from the partial oxidation of a hydrocarbon. For these reasons it is unlikely that hydrogen will be widely available as a vehicle fuel source.

\section{3 - Plasmatron Engine Concept}

One alternative to storing hydrogen on the vehicle is to generate hydrogen on board the vehicle using a partial oxidation fuel reformer. Several studies have shown that the use of an on-board fuel reformer can significantly reduce emissions and potentially increase efficiency [3,4]. In this concept gasoline and air enter the reformer and the fuel is partially oxidized to form a stream that consists primarily of hydrogen, carbon monoxide, and nitrogen.

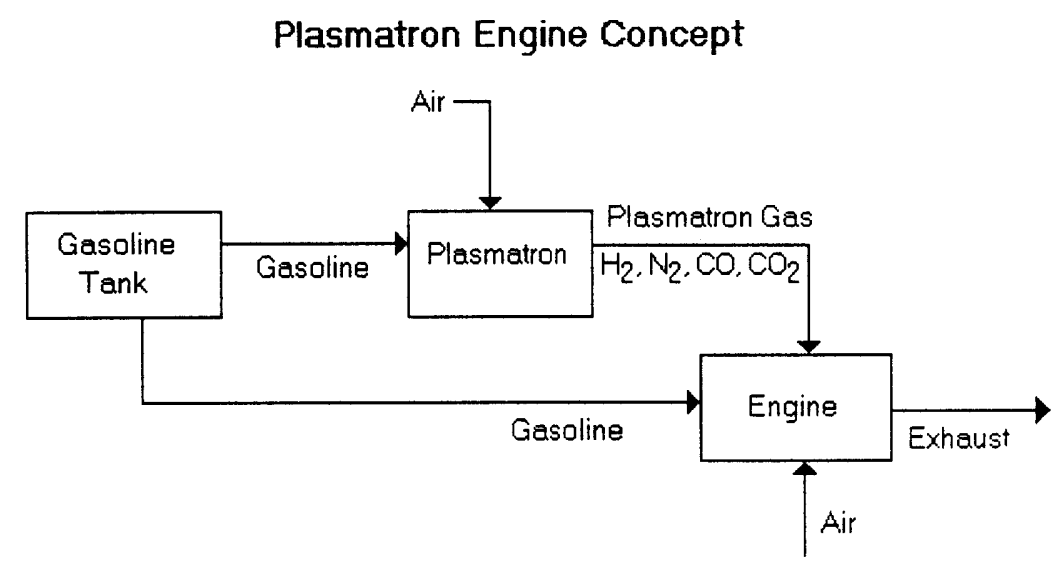

Figure 1.2 - Plasmatron Engine Concept 
The process is exothermic, with approximately $15 \%-20 \%$ of the chemical energy of the indolene being converted to waste heat during the conversion process. This hydrogen rich stream is then combined with the indolene and air to form a homogeneous mixture prior to combustion. Due to the losses in the reformer the fraction of the fuel that is reformed should be minimized.

A series of experiments were performed to investigate this engine concept. Because the plasmatron is still in development, bottled gases were used to simulate the plasmatron output gas. Three different reformed fractions of fuel were investigated: $10 \%, 20 \%$, and $30 \%$. The reformed fraction is defined as the fraction of the gasoline that is sent through the plasmatron. Two different mixes of bottled gases were used, one representing the current output of a prototype plasmatron design, and one representing a best case or ideal plasmatron. In addition, while it is known that hydrogen addition will increase the lean combustion limits of the engine, it was unclear as to the impact of the nitrogen $\left(\mathrm{N}_{2}\right)$ and $\mathrm{CO}$ in the plasmatron gas. To assess this, experiments were performed with straight hydrogen addition. In total there were 3 fuels, each with 3 different reformed fractions, plus the baseline case of gasoline only for a total of 10 different fueling combinations. Comparisons between the typical and ideal plasmatron gas at a fixed reformed fraction could show the potential benefit of improving the actual plasmatron. Comparisons between the ideal plasmatron and hydrogen addition could assess the impact of the other components in the plasmatron gas. Finally, all of these cases were compared to a baseline case of the engine run on indolene only.

All of the experiments were performed at a fixed load and speed on a modified Ricardo single-cylinder research engine. For each case a sweep of the relative air/fuel ratio (lambda) was performed, starting at stoichiometric and stepping lambda until the engine began to misfire. Lambda at the misfire limit varied from 1.8 to 2.1 depending on the fuel. At each point the following measurements were taken: in-cylinder pressure, fuel flow, airflow, and hydrocarbon and NOx emissions data. 


\section{4 - Plasmatron Operation}

\section{Plasmatron Schematic}

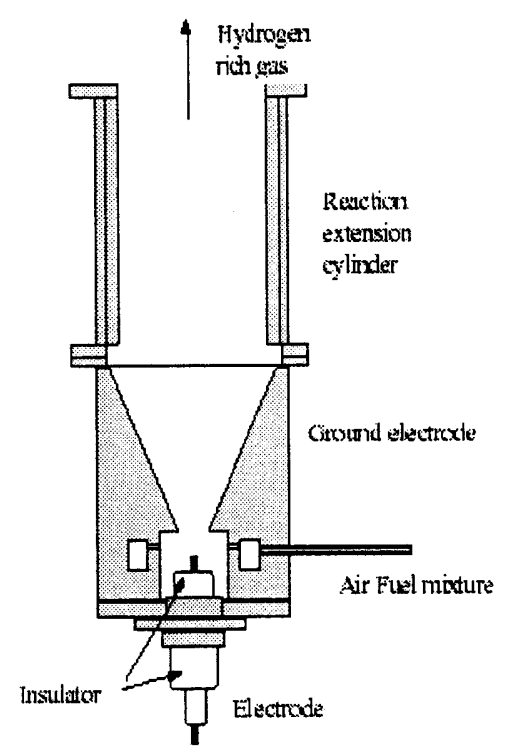

Figure 1.3 - Schematic of a Plasmaton Fuel Reformer

The plasmatron is currently in development at the MIT Plasma Fusion Lab. A fuel rich mixture of indolene and air is passed through the plasmatron fuel reformer where a high voltage spark is used to initiate a partial oxidation reaction [5]. The ideal reaction is:

$C_{m} H_{n}+\frac{m}{2}\left(O_{2}+3.773 N_{2}\right) \rightarrow m C O+\frac{n}{2} H_{2}+\frac{m}{2} \cdot 3.773 N_{2}$

This defines the best case or ideal plasmatron output. In reality some of the $\mathrm{CO}$ is overoxidized to carbon dioxide $\left(\mathrm{CO}_{2}\right)$, resulting in additional chemical energy losses. In addition, a small fraction of the fuel is either unoxidized or is oxidized into short-chained hydrocarbons such as methane. Since the plasmatron is still in development all of the experiments were carried out using bottled gas that contained a representative plasmatron 
output. One gas, which will be referred to as the ideal plasmatron gas, is based on the above reaction. A second gas, referred to as the typical plasmatron gas, contains some $\mathrm{CO}_{2}$ to represent the overoxidation of $\mathrm{CO}$ into $\mathrm{CO}_{2}$. This typical plasmatron gas is representative of the current output that is achievable with a plasmatron.

\begin{tabular}{|l|r|r|}
\hline & Ideal Plasmatron & Typical Plasmatron \\
\hline Hydrogen & $25 \%$ & $23 \%$ \\
\hline Carbon Monoxide & $26 \%$ & $21 \%$ \\
\hline Nitrogen & $49 \%$ & $52 \%$ \\
\hline Carbon Dioxide & $0 \%$ & $4 \%$ \\
\hline Efficiency & $85.74 \%$ & $77.01 \%$ \\
\hline
\end{tabular}

Figure 1.4: Ideal and Typical Plasmatron Composition and Efficiency

Since the plasmatron is exothermic, the chemical energy of the plasmatron gas will be less than the chemical energy of the indolene used to generate the plasmatron gas. The plasmatron efficiency quantifies these losses and is defined as the Lower Heating Value (LHV) of the plasmatron gas divided by the LHV of the indolene used to generate the gas:

$$
\begin{gathered}
\eta_{\text {Plas }}=\frac{\dot{m}_{H 2} \cdot L H V_{H 2}+\dot{m}_{C O} \cdot L H V_{C O}}{\dot{m}_{\text {indolene }} \cdot L H V_{\text {indolene }}} \\
\eta_{\text {Plas }}=\text { Plasmatron Efficiency } \\
\dot{m}_{x} \quad=\text { Mass Flow Rate of component } \mathrm{x} \\
L H V=\text { Lower Heating Value }
\end{gathered}
$$




\section{Chapter 2: Engine Setup and Data Aquisition}

\section{1 - Engine Setup}

A modified Ricardo test engine was used to perform the experiments. The original cylinder head was replaced with a modern cylinder head from a Volvo production engine while the base engine was unchanged. The following sheet summarizes the basic engine data:

\begin{tabular}{|l|c|}
\hline Type & Single-Cylinder Dual Overhead Cam \\
\hline Bore & $83 \mathrm{~mm}$ \\
\hline Stroke & $90 \mathrm{~mm}$ \\
\hline Displacement & $0.49 \mathrm{~L}$ \\
\hline Valves per Cylinder & 4 \\
\hline Compression Ratio & $10.1: 1$ \\
\hline
\end{tabular}

Figure 2.1 - Basic Engine Data

In addition, the burn rate of the engine was increased by adding a plate into the intake system which partially obstructed the intake, thereby increasing the velocity and turbulence of the air entering the engine. Details of this modification are presented in Section 3.1 - Increasing Burn Rate.

\section{2 - Engine Control}

A Motec M4 Engine Control Unit (ECU) model 9806 was used to control the fuel injector pulse width (IPW) and the spark timing. The ECU was connected to a dedicated computer that was running Motec Engine Management Program Version 4.22. This setup allowed the IPW and spark timing to be varied in real time. IPW could be varied in increments of $0.1 \mathrm{msec}$ and the spark timing could be varied in increments of 1 crank angle degree. 


\section{3 - Fuel Data}

Indolene was used as the reference fuel. The specific blend used in these experiments was Phillips Chevron UTG-96 [6]. A brief summary of the important fuel properties is listed below:

\begin{tabular}{|l|r|}
\hline Phillips Chevron UTG-96 & \\
\hline Lower Heating Value (MJ/kg) & 43.1 \\
\hline H/C ratio (molar) & 1.93 \\
\hline Carbon Wt \% & 86.07 \\
\hline Hydrogen Wt\% & 13.93 \\
\hline Research Octane Number & 96.7 \\
\hline Motor Octane Number & 87.9 \\
\hline Antiknock Index & 92.3 \\
\hline
\end{tabular}

Figure 2.2 - Selected Fuel Properties

\section{4 - Data Acquisition}

\subsection{1 - Test Setup}

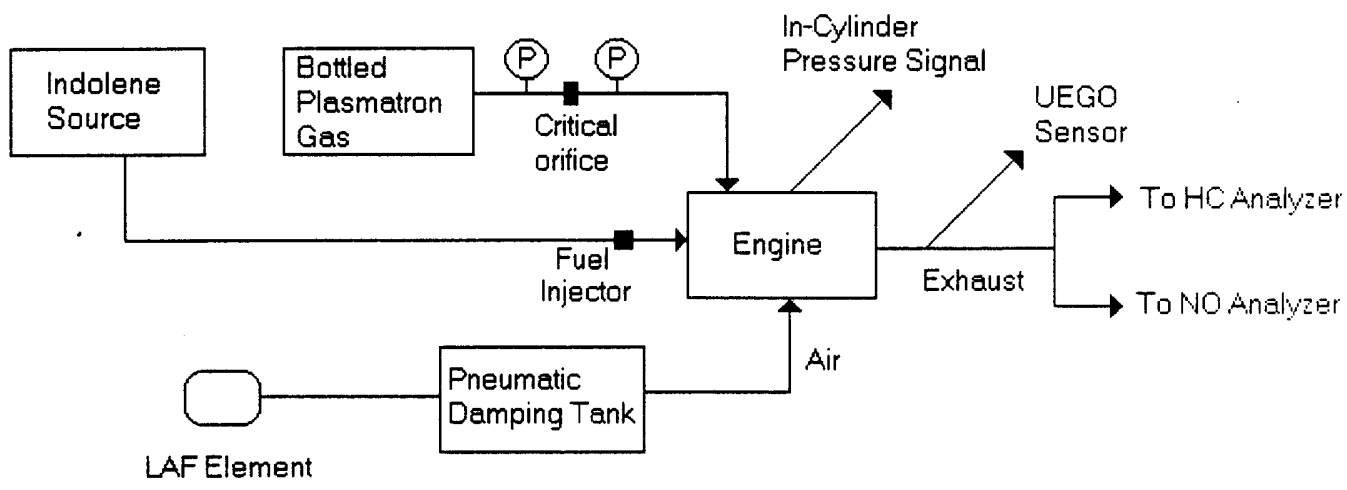

Figure 2.3 - Schematic of the Experimental Setup

The schematic in figure 2.3 shows the overall test cell layout. This section will discuss each of the individual methods used to measure airflow, plasmatron flow, indolene flow. in-cylinder pressure, and hydrocarbon and NOx emissions. 


\subsection{2 - Airflow Measurement}

A Ricardo Instruments Viscous Flow Meter Model \#P.7021-1025S was used to measure the airflow. This flow meter is a laminar flow type. In the laminar flow regime the volumetric flowrate is simply proportional to the pressure drop across the element, with the constant of proportionality provided by Ricardo Instruments. A custom built digital pressure transducer was used to measure the pressure drop across the element and to convert the pressure drop into a flowrate.

\subsection{3 - Indolene Flow Rate Control}

A production Volvo fuel injector, Model \#280-150779, was used in the engine. The injector was of the single-hole type emitting a conical spray. If the pressure drop across a fuel injector is held constant then the flow rate is determined by the injector pulse width. To establish this relationship the injector was removed from the engine and mounted above a chilled graduated cylinder. The Motec ECU software has a calibration mode where the user can enter the number of cycles to fire and the IPW. The injector was fired several thousand times at each pulse width and the fuel was collected in the graduated cylinder and weighed. This was repeated for a range of pulse widths from $2.0 \mathrm{msec}$ to 20 msec and the relationship between pulse width and fuel flow per pulse was found to be linear over the range of interest. Since the manifold air pressure changes with operating conditions a fuel backpressure regulator was used to maintain a constant pressure drop across the injector.

\subsection{4 - Plasmatron Flow Rate Control}

To control the plasmatron flow a calibrated critical flow orifice was used. For high upstream pressures the flow through the orifice is choked and the flow is simply proportional to the upstream pressure [7]. Choked flow occurs when the upstream pressure exceeds the critical pressure, which can be found from: 


$$
\frac{P_{2}}{P_{C R}}=\gamma \cdot\left(\frac{2}{\gamma+1}\right)^{\frac{\gamma}{(\gamma-1)}}
$$

$P_{2}=$ Pressure Downstream of the Orifice

$P_{C R}=$ Critical Pressure, Upstream of the Orifice

$\gamma=$ Ratio of Specific Heats

Evaluating (3) gives the minimum upstream pressure that is necessary to guarantee choked flow. All experiments were run with the upstream pressure well above this minimum. In the choked flow regime, the flow through the orifice becomes independent of the downstream pressure and can be calculated from:

$$
\begin{gathered}
\dot{m}=\frac{C_{D} A_{T} P_{1}}{\sqrt{R T}} \gamma^{\frac{1}{2}}\left(\frac{2}{\gamma+1}\right)^{\frac{\gamma+1}{2 \cdot(\gamma-1)}} \\
C_{D}=\text { Discharge Coefficient } \\
A_{T}=\text { Area of Orifice Opening } \\
P_{1}=\text { Pressure Upstream of Orifice } \\
R=\text { Gas Constant } \\
T=\text { Temperature }
\end{gathered}
$$

By setting the upstream pressure of the plasmatron gas the mass flow rate could be controlled. Type B and Type E precision orifices from Fluid Control Products were used to control the flow rate of the plasmatron and hydrogen gases. 


\subsection{5 - Lambda Measurement}

A heated, wide-band, universal exhaust gas oxygen senser (UEGO) was used to directly measure the relative fuel air ratio in the exhaust stream. The sensor was a Horiba MEXA-110 $\lambda$ sensor.

\subsection{6 - In-Cylinder Pressure Measurement}

A piezo-electric crystal was used for in-cylinder pressure measurement. A National Instruments BNC-2090 board was connected to a Labview PCI-6025E data acquisition board that was installed in a PC running a Labview data acquisition interface. A shaft encoder was used to provide the trigger for the pressure measurement. In-cylinder pressure was sampled once per crank angle.

\subsection{7 - Hydrocarbon Emissions Measurement}

The hydrocarbon measurement was taken using a Rosemont Analytical Model 402 Hydrocarbon Analyzer. The Rosemont is a Flame Ionization Detector (FID) type analyzer [8]. A FID has a small burner that is fueled by hydrogen gas. The exhaust sample is sent to this burner and during the combustion process the hydrocarbon is ionized. An electrode above the flame captures the ions and causes a current to flow through the electrode. This current is amplified and converted to a voltage signal. The amplitude of the signal is proportional to the concentration of the hydrocarbon components. The FID is calibrated using a certified reference gas containing propane. The FID only counts emissions based on $\mathrm{C} 1$ and cannot give the breakdown of the hydrocarbon composition.

\subsection{8 - NOx Emissions Measurement}

The NOx analyzer was a Thermo Environment Instruments Model 10

Chemiluminescence $\mathrm{NO}-\mathrm{NO}_{2}-\mathrm{NOx}$ detector. The exhaust sample is first run through a dessicant to remove any water vapor in the sample. The sample then enters a reaction chamber where any NOx is converted to NO [9]. The NO is then sent to a chamber where it is reacted with ozone to form $\mathrm{NO}_{2}$ which is in an excited state. A photon is released when this molecule rev-erts to the ground state. A photodetector measures the 
intensity of the signal, which is proportional to the concentration of NO. The NO analyzer is calibrated using a certified reference gas of known NO concentration.

\section{5 - Data Analysis Software}

An MIT proprietary burn rate analysis code was used to analyze the raw pressure data $[10,11]$. Using the pressure vs. crankangle data and the geometry of the engine. a pressure vs. volume relationship is established. The numerical integration of the P-V data then determines the gross and net indicated mean effective pressure (IMEP). In addition, if many cycles are used each cycle can be analyzed separately and a coefficient of variation (COV) of the NIMEP can be calculated. The coefficient of variation is simply defined as the standard deviation divided by the mean. Finally, by incorporating a heat transfer model the pressure data can be used to back calculate the burned fraction as a function of crank angle. 


\section{Chapter 3 - Experimental Structure}

This section will discuss how the experiments were structured. This chapter is organized into two main sections. The first addresses the experiments that were performed to increase the burn rate of the engine. The second section looks at the design of the plasmatron and hydrogen addition experiments.

\section{1 - Increasing Burn Rate}

As an engine is operated under increasingly dilute conditions the burn duration increase due to the effect of the diluents on flame speed [12]. This has a negative impact on efficiency. Since the experiments were exploring lean combustion limits it was important to have an engine with a fast burning combustion system. One of the most effective ways of increasing the burn rate of an engine is to increase the turbulence level in the engine. A restrictor plate was used on the intake port of the engine to create additional turbulence. This method of increasing turbulence was chosen because it offered the most flexibility. All of the other methods of increasing turbulence, such as altering the valve profile or port shape, would result in permanent changes to the engine. By using swappable plates many different turbulence concepts could be quickly tested. In addition, by removing the plate the engine could easily be returned to the base state. 


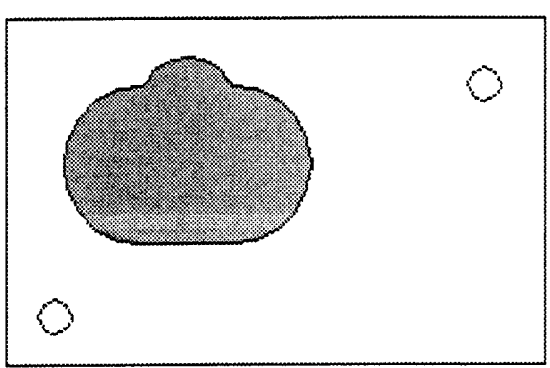

No Plate

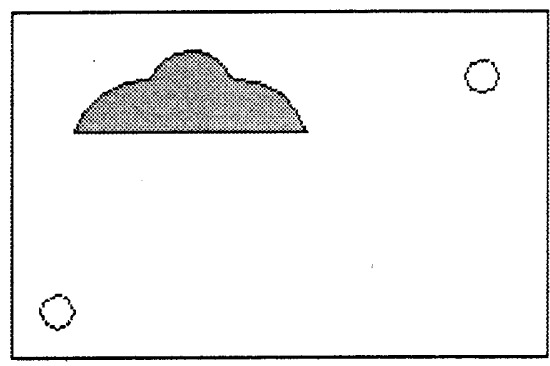

Plate \#2 - 2/3 Blocked Symmetric

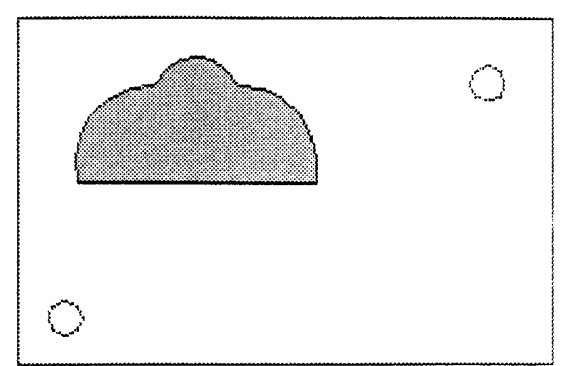

Plate \#1-1/3 Blocked Symmetric

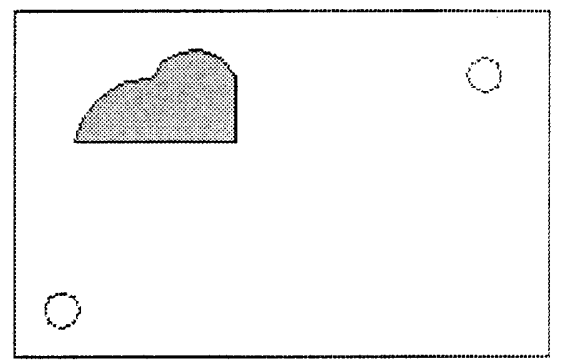

Plate \#3 - 2/3 Blocked Asymmetric

Figure 3.1 - Intake Plate Designs

All of the plates increase the velocity of the air by decreasing the cross sectional area that the air flows through. The shaded area shows the cross sectional area through which air: can flow. The white area is blocked off. The first two designs are intended to increase the amount of tumble introduced into the cylinder. Plate \#1 reduces the cross sectional flow area by $1 / 3$, thereby increasing the average velocity of the air by $50 \%$. Plate \#2 is a more aggressive version of the first design and reduces the cross sectional area by $2 / 3$. This results in the average velocity increasing by a factor of three. Plate \#3 not only reduces the cross sectional area by $2 / 3$, but it also biases the airflow to one on the two intake valves, introducing both tumble and swirl into the cylinder.

To test the different plate concepts a series of experiment were performed. All of the experiments were performed using indolene as the fuel without any plasmatron or hydrogen addition. First, the engine was operated without the plate and a sweep of increasing lambda was performed. At each lambda a spark sweep was performed to find the Maximum Brake Torque (MBT) engine timing. The data was collected at MBT 
timing and then lambda was increased and the process was repeated. This was done until the engine began to misfire.

Figure 3.2 shows the MBT spark timing vs. lambda for the unmodified engine as well as with each of the three plates in place. The MBT spark timing is a measure of the relative burn rates, where faster burning engines should have an MBT timing that is closer to top dead center (TDC). It is clear that all of the plates decrease the burn duration and increase the lean combustion limit of the engine. The unmodified engine is the slowest burning. Plate \#1, which blocks $1 / 3$ of the intake cross sectional area, shows a slight improvement in burn rate although the impact is modest. On average the MBT timing moves about 2 degrees closer to TDC. Both of the plates that block $2 / 3$ of the intake result in the MBT timing moving significantly. Either of these plates would be a good choice for increasing the burn rate of the engine. Plate $\# 3$ was chosen because it resulted in the fastest burning rate. The main impact on burn rate seems to be from the decrease in cross sectional area and the shape of the plate seems to only have a modest secondary effect. All further experiments were performed with Plate \#3 installed.

\section{2 - Plasmatron and Hydrogen Addition Experiments}

\subsection{1 - Experimental Procedure}

All of the experiments in this section were performed in the same manner. Initially the engine was operated stoichiometrically and a spark sweep was performed to find MBT timing. Once MBT timing was found the following data was taken: in-cylinder pressure. fuel flow, airflow, and hydrocarbon and NOx emissions concentration. Lambda was increased and a spark sweep was again performed to find MBT timing and the relevant data was collected at MBT timing. This processed was repeated, slowly increasing lambda, until the engine began to misfire. All experiments were performed at 1500RPM and at a NIMEP of $350 \mathrm{kPa}$.

For each experiment the engine was run on one of 4 possible fuel combinations. To establish a baseline case the first sweep of lambda was performed using indolene only: 
Next the engine was run on a combination of indolene with one of the plasmatron gases presented in figure 1.4. Although bottled gases were uses in lieu of an actual plasmatron. flow rates and compositions were matched to the case of using an actual plasmatron. Therefore, the following schematic is useful in defining an equivalent percent plasmatron:

Plasmatron Engine Concept

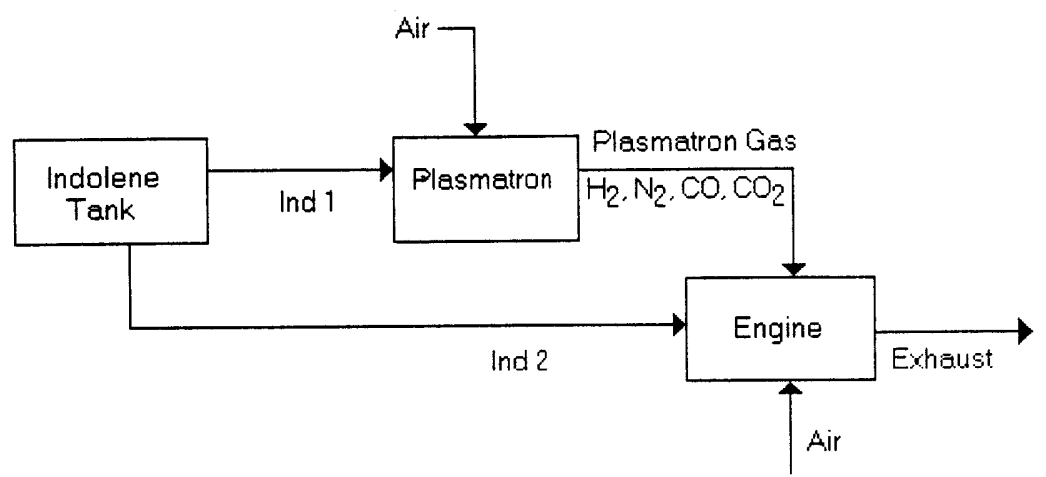

Figure 3.3 - Plasmatron Engine Schematic: Airflow and Fuel Flow

$$
\text { Plas } \%=\frac{\dot{Q}_{\text {ind } 1}}{\dot{Q}_{\text {ind } 1}+\dot{Q}_{\text {ind } 2}}=\frac{\dot{m}_{\text {ind } 1} \cdot L H V_{\text {ind }}}{\dot{m}_{\text {ind } 1} \cdot L H V_{\text {ind }}+\dot{m}_{\text {ind } 2} \cdot L H V_{\text {ind }}}=\frac{\dot{m}_{\text {ind } 1}}{\dot{m}_{\text {ind } 1}+\dot{m}_{\text {ind } 2}}
$$

From (5) it is clear that the equivalent percent plasmatron is simply the mass fraction of the indolene that is sent through the plasmatron. Three sweeps of lambda were performed for the typical plasmatron gas, matching the flows appropriately to represent $10 \% .20 \%$. and 30\% reformed plasmatron gas. The next experiment was done using the ideal plasmatron gas at $10 \%, 20 \%$, and $30 \%$ reformed fractions. This would provide a way to quantify the potential gains that could come from optimizing the plasmatron. Finally. experiments were performed substituting hydrogen for plasmatron gas to separate out the 
impact of the carbon monoxide, carbon dioxide, and nitrogen present in the plasmatron gas.

\subsection{2 - Equivalent Percent Plasmatron Definition}

Before any hydrogen addition experiments could be performed an appropriate definition of the equivalent percent hydrogen had to be formed so that the hydrogen experiments would be comparable to the plasmatron experiments. Figure 3.4 helps explain the rational used in defining the equivalent percent plasmatron for the direct hydrogen addition experiments.

\section{Experimental Setup - Equivalent}

a)

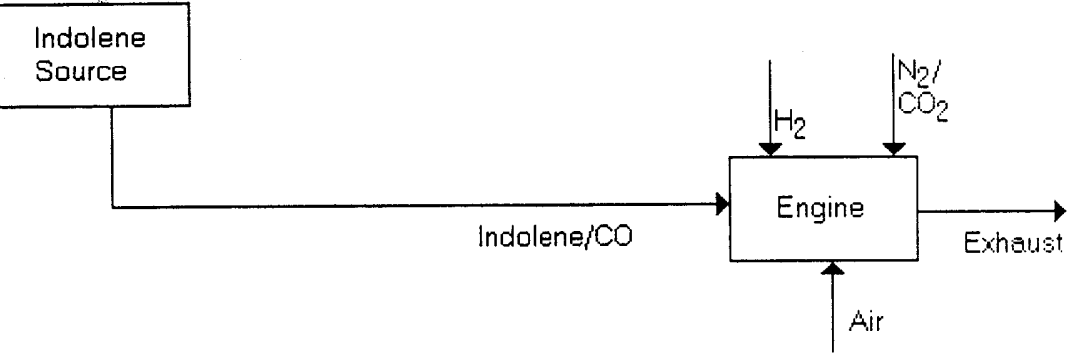

b)

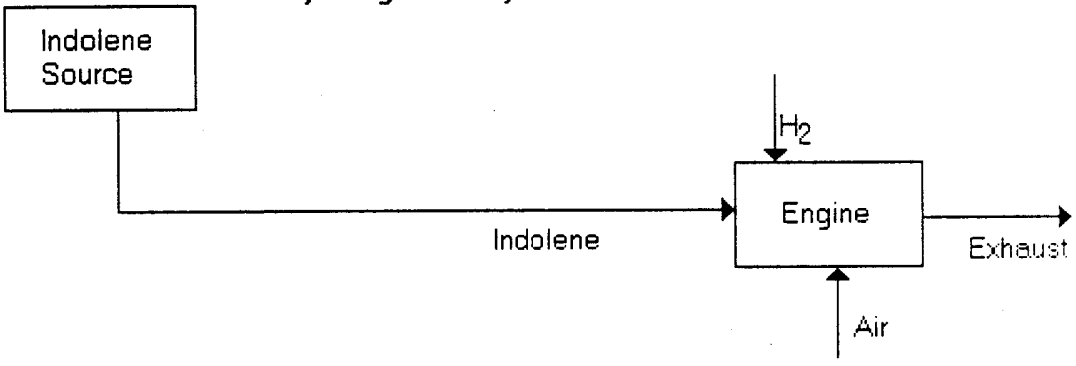

Figure 3.4 - Experimental Setup for Plasmatron and Hydrogen Addition

Figure 1.2 introduced a schematic of the experimental setup. Since the indolene. air. and plasmatron gas are homogeneously mixed prior to entering the engine the schematic in $3.4 \mathrm{a}$ is an equivalent representation. The only reason the schematic is shown in this new configuration is to highlight the similarities between the plasmatron and hydrogen addition experiments. Figure 1.1 presented data on the burn characteristics of $\mathrm{CO}$. At 
stoichiometric conditions the laminar flame speed of $\mathrm{CO}$ is somewhat slower than a typical hydrocarbon. However, the maximum flame speed and the dilution limit are both somewhat higher. Therefore it is unclear whether the $\mathrm{CO}$ will have positive or a negative impact on combustion when compared to a hydrocarbon. Since the burn characteristics of $\mathrm{CO}$ are similar to a hydrocarbon it will be grouped with the indolene in the schematic and for the purpose of analysis. The analysis of the data will show that this is a reasonable assumption. The equivalent percent hydrogen should be defined in such a way that a direct comparison between the plasmatron and hydrogen only cases quantifies the effect of the plasmatron components other than the hydrogen. From Figure 3.4 it is clear that matching the fraction of the total energy that is provided by the hydrogen will allow for a valid comparison. Figure 3.5 is an energy balance on the plasmatron and will aid in deriving the equations for the equivalent percent plasmatron. Although bottled gases were used all flow rate were matched so that a comparison to the figure 3.5 is valid.

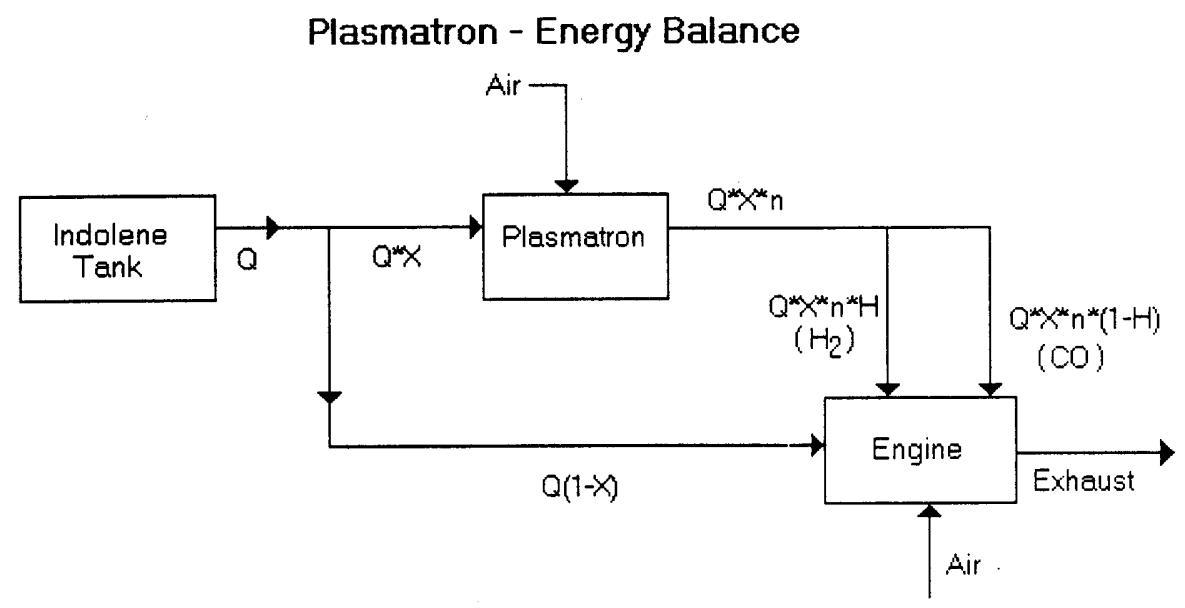

Figure 3.5 - Energy Balance on System Using a Plasmatron

From figure 3.5 we can form a ratio of the energy provided by the engine to the total energy entering the engine:

$$
\frac{Q_{H 2}}{Q_{\text {engine }}}=\frac{Q_{H 2}}{Q_{P L A S}+Q_{I N D O L E N E}}=\frac{Q \cdot \mathrm{X} \cdot \eta_{P L A S} \cdot H}{Q \cdot \mathrm{X} \cdot \eta_{P L A S}+Q \cdot(1-\mathrm{X})}=\frac{\mathrm{X} \cdot \eta_{P L A S} \cdot H}{1+\mathrm{X}\left(\eta_{P L A S}-1\right)}
$$


Where:

$\mathrm{Q}=$ heating value

$\eta_{P L A S}=0.8574 \quad$ (see Figure 1.4)

$\mathrm{H}=$ fraction of the energy in the plasmatron gas that is supplied by hydrogen

$\mathrm{X}=$ Equivalent Percent Plasmatron

$H=\frac{n_{H 2} \cdot M W_{H 2} \cdot L H V_{H 2}}{n_{C O} \cdot M W_{C O} \cdot L H V_{C O}}$

All of the variables on the right hand side of (7) are known and the equation then gives $\mathrm{H}=0.4521$. Finally, inserting the numerical values for $\eta_{P L A S}$ and $\mathrm{H}$ into (6) gives:

$\frac{Q_{H 2}}{Q_{\text {engine }}}=\frac{0.3876 \cdot \mathrm{X}}{1-0.1426 \cdot \mathrm{X}}$

Equation (8) can be used to calculate the fraction of the total energy entering the engine that should be provided by hydrogen to match a certain ideal plasmatron run. For example, $X=10 \%$ gives $3.93 \%$ as the fraction of the total energy provided by hydrogen. In other words, setting the hydrogen energy fraction equal to $3.93 \%$ in a hydrogen addition experiments will provide an equivalent percent plasmatron of $10 \%$.

Notice this derivation makes no mention of lambda, but only discusses equivalent percent plasmatron. From the diagram it can be seen that the extra $\mathrm{N}_{2} / \mathrm{CO}_{2}$ act as an extra diluent. At the same lambda the plasmatron cases will be more dilute than the hydrogen addition only cases. Therefore, lambda no longer reflects the true dilution of the fuel/air mixture in the cylinder. The next section will discuss this issue and will introduce a new dilution parameter that is more appropriate. 


\subsection{3 - Dilution Parameters}

When examining lean combustion lambda is often used as the independent variable against which data is correlated or plotted. Lambda appropriately represents the normalized air/fuel ratio though it does not include the additional dilution of the residual burned gas. If the engine is being run on a single fuel and no EGR is being used then lambda defines the relative dilution. If EGR or multiple fuels are used then lambda will not give the true dilution. In these cases where lambda does not define the dilution. a dilution parameter that represents true dilution of the mixture would be useful.

From Figure 3.4 it is seen that at the same lambda the plasmatron cases will be more dilute then the hydrogen addition case due to the excess $\mathrm{N}_{2}$ and $\mathrm{CO}_{2}$. Burn duration is a basic combustion parameter that can be useful in quantifying the effect of dilution since it is primarily affected by engine operating conditions, fuel type, and dilution. All of the experiments were operated under the same engine operating conditions and the hydrogen levels were matched in such a way as to provide an equivalent percent plasmatron. Therefore, if an appropriate dilution parameter is formed a direct comparison of the burn duration under the ideal plasmatron, typical plasmatron, and hydrogen experiments will be possible. This new dilution parameter should replace lambda and extend to all analysis, not just burn duration.

It is recognized that this discussion is a simplification of the factors that impact burn duration. For example, although all of the experiments were done under the same speed and load conditions the total mass flow rate varied slightly depending on whether plasmatron or hydrogen gas was used. Therefore, the turbulence in the engine will vary slightly, impacting burn duration. Trying to account for these secondary effects would greatly increase the complexity of the analysis. In addition, these secondary affects are often difficult to quantify. It will be shown that ignoring these secondary effects does not have a detrimental impact on the analysis.

Figure 3.6 shows the $0-10 \%$ burn angles for the ideal plasmatron and hydrogen cases vs. lambda. As expected the burn durations at a fixed lambda are longer for the plasmatron cases then for the equivalent hydrogen addition case. The extra dilution supplied by the 
$\mathrm{N}_{2}$ and $\mathrm{CO}_{2}$ in the plasmatron gas slows combustion. An appropriate dilution parameter would account for this extra dilution.

One simple dilution parameter is the heating value of the fuel per unit volume of fuel/air mixture. This will be referred to as the volumetric dilution parameter (VDP*):

$\dot{Q}=\sum_{i} \dot{m}_{i} \cdot L H V_{i}$

$$
\dot{n_{\text {tot }}}=\frac{\dot{m}_{\text {ind }}}{\overline{M W_{\text {ind }}}}+\frac{\dot{m}_{\text {plas }}}{\overline{M W}_{\text {plas }}}+\frac{\dot{m}_{\text {air }}}{\overline{M W_{\text {air }}}}
$$

$$
\begin{aligned}
& \dot{n_{t o t}}=\text { Total molar flow rate into the engine } \\
& \overline{M W}=\text { Average Molecular Weight }
\end{aligned}
$$

From the ideal gas law:

$$
V=\frac{n R T}{P}
$$

Then the energy per unit volume, VDP*, is simply:

$$
V D P^{*}=\frac{\dot{Q}}{V}
$$

For convenience, a dimensionless Volumetric Dilution Parameter (VDP) was defined relative to the stoichiometric, gasoline only case: 
$V D P=\frac{V D P_{\text {indolene_only.tambda }=1}^{*}}{V D P^{*}}$

Figure 3.7 shows the same 0\%-10\% burn angle data plotted against the VDP instead of lambda. The VDP calculation does a good job of collapsing the burn duration data. At the $10 \%$ equivalent plasmatron level the fit between the ideal plasmatron and hydrogen addition is excellent. At the $20 \%$ level and $30 \%$ levels the ideal plasmatron experiments burn faster than the direct hydrogen addition experiments at the same VDP.

One reason for this discrepancy is that the VDP does not take into account the affect of heat capacity. Components that have a high heat capacity will absorb more thermal energy then components that have a low heat capacity and therefore will have a larger dilution effect. Incorporating the heat capacity in the dilution parameter should improve the dilution parameter. If an energy balance is done on the system:

$\dot{Q_{\text {comb }}}=\sum_{i} \dot{m_{i}} \cdot L H V_{i}$

$$
\dot{Q}_{\text {comb }}=\text { Chemical Energy Released During Combustion }
$$

If the combustion process is modeled as constant volume and the change in composition during the combustion process is ignored, then the heat released will be equal to the heat absorbed by the gas:

$\dot{Q}_{\text {comb }}=\dot{m}_{t o t} \cdot \overline{c_{v}} \cdot \Delta T$

Setting (14) equal to (15) and solving for $\Delta T$ gives: 


$$
\Delta T=\frac{\sum_{i} \dot{m}_{i} \cdot L H V_{i}}{\dot{m}_{t o t} \cdot \bar{C}_{v}}
$$

$\Delta \mathrm{T}$ is the chemical energy per unit heat capacity and thus represents the thermal dilution of the mixture. Since the change in specific heat of the gases was ignored $\Delta \mathrm{T}$ is not exactly the adiabatic, constant volume temperature difference between the burned and unburned gases due to combustion. However, it approximates that number. Many of the combustion related processes should scale well with this variable. For example, the flame speed is largely determined by the temperature rise across the flame. Therefore, there should be a strong correlation between burn rate and $\Delta \mathrm{T}$. It is useful to convert the $\Delta \mathrm{T}$ to a dimensionless Thermal Dilution Parameter (TDP) which is defined in the same manner as the VDP.

$T D P=\frac{\Delta T_{\text {indolene_only,lambda=1 }}}{\Delta T}$

Figure 3.8 shows the same burn duration data plotted against TDP. At the $10 \%$ and 20\% levels the ideal plasmatron and hydrogen addition experiments give very similar results. At the $30 \%$ level the plasmatron is faster burning at an equivalent TDP. This implies that the $\mathrm{CO}$ and $\mathrm{N}_{2}$ in the plasmatron gas have a positive impact on the combustion process. This is thought to be due to the higher dilution limit of $\mathrm{CO}$ when compared to a hydrocarbon.

Both the VDP and TDP are straightforward to calculate and provide a better correlation with the data. It is important that the correct dilution parameter is chosen when analyzing the data. Most parameters such as burn duration, combustion stability, combustion efficiency, and NO emissions depend on thermal dilution and therefore will be displayed 
against TDP. However, one important phenomena, the pumping work, is based on the volumetric flowrate of the gas through the engine and therefore should correlate more closely with VDP. Net efficiency is dependent on pumping work and will therefore be plotted against VDP. It is clear that the choice of whether to use TDP or VDP is dependent upon the specific parameter being analyzed. All TDP and VDP graphs that are not presented in the body of the paper are available in the appendix.

To summarize, in order to provide a useful comparison between the typical plasmatron. ideal plasmaton, and hydrogen addition experiments it was necessary to formulate some new parameters. First, an equivalent percent plasmaton was defined for the hydrogen addition cases. In addition, two dilution parameters based on volumetric and thermal dilution were defined. Using the equivalent percent plasmatron along with the VDP or TDP dilution parameter will allow a useful comparison of the data for the different fueling schemes. 


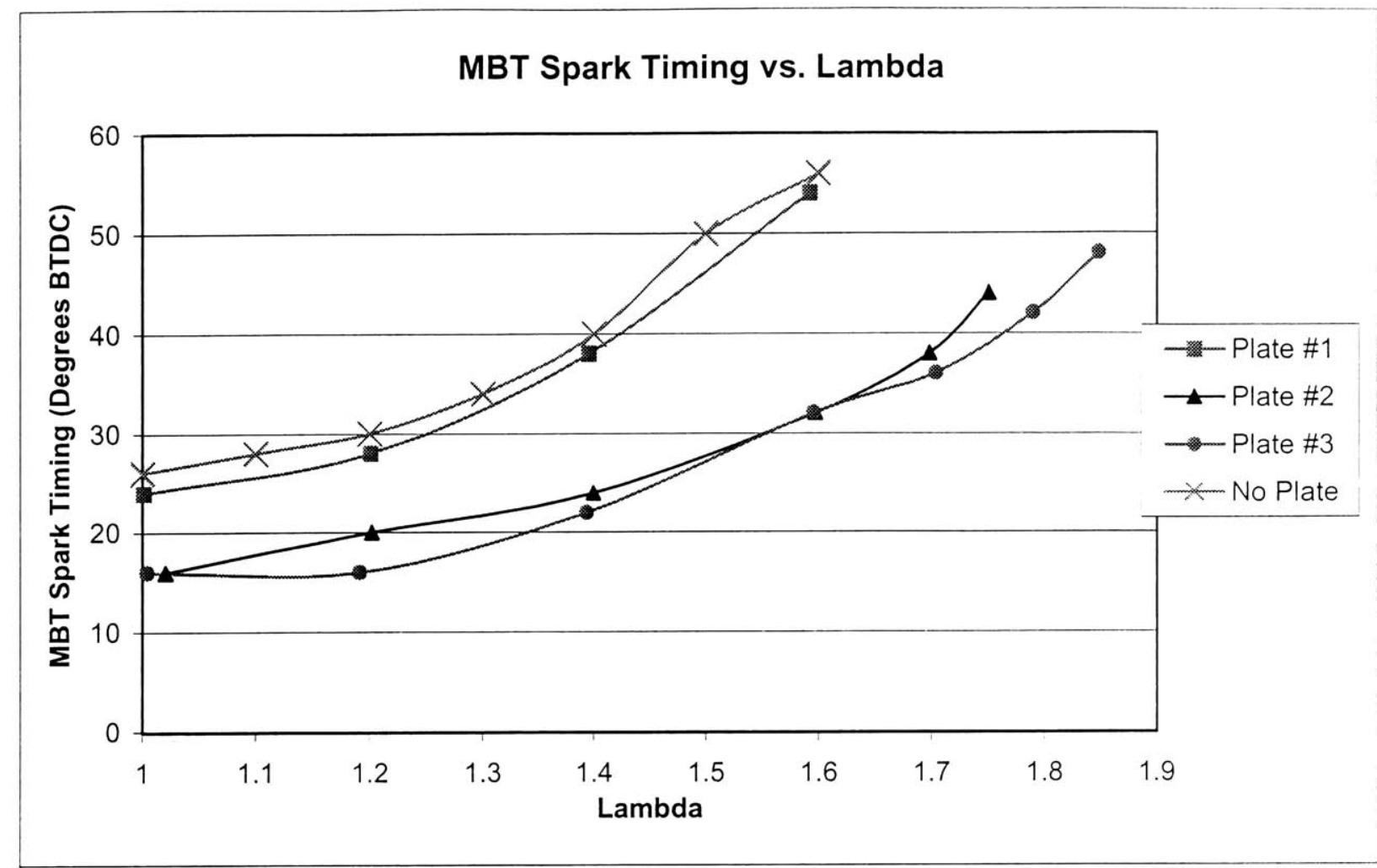

Figure \#3.2 - MBT Spark Timing vs. Lambda for Different Intake Plates Designs

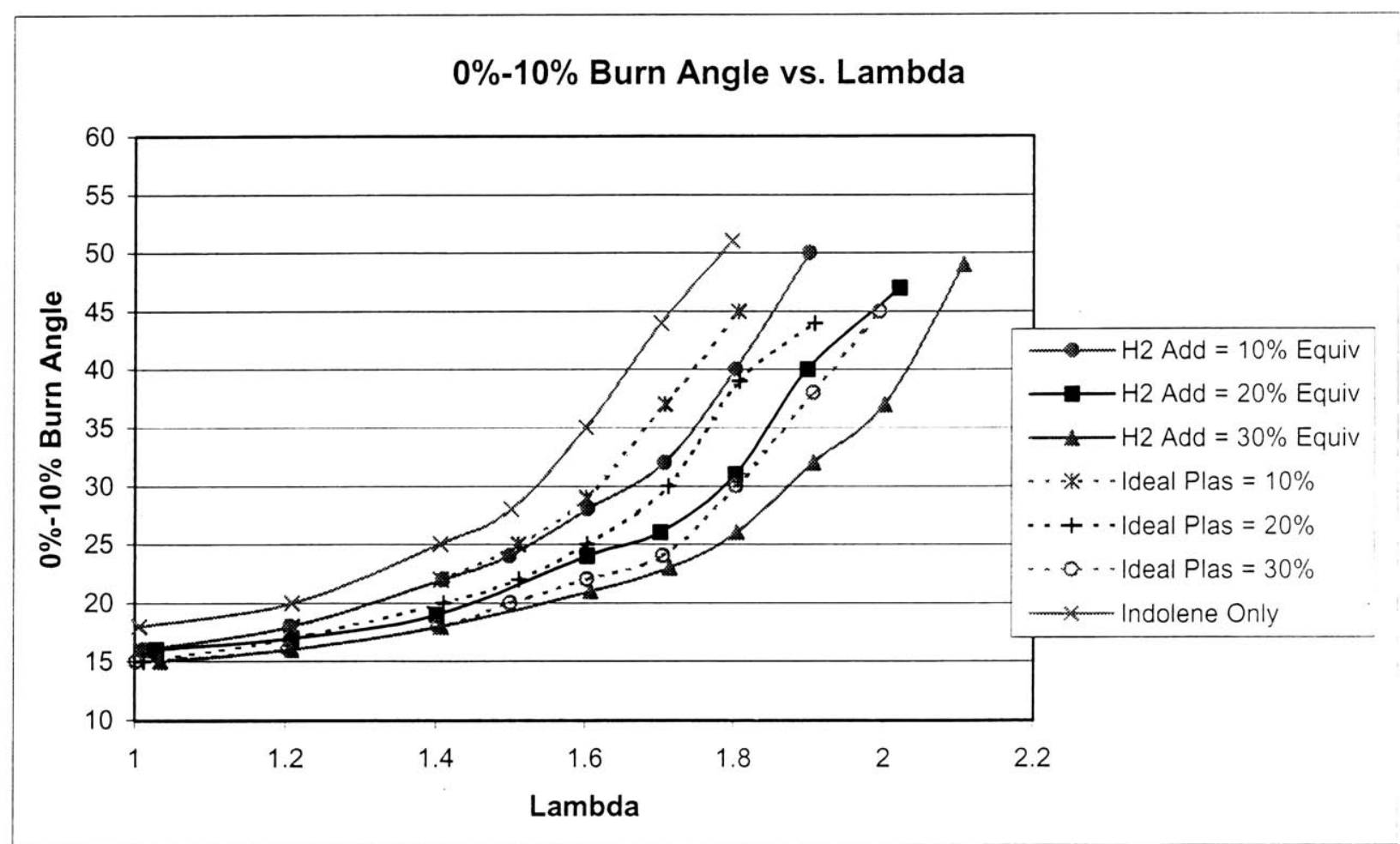

Figure \#3.6 - 0\%-10\% Burn Angles vs. Lambda - Ideal Plasmatron and Hydrogen Addition 


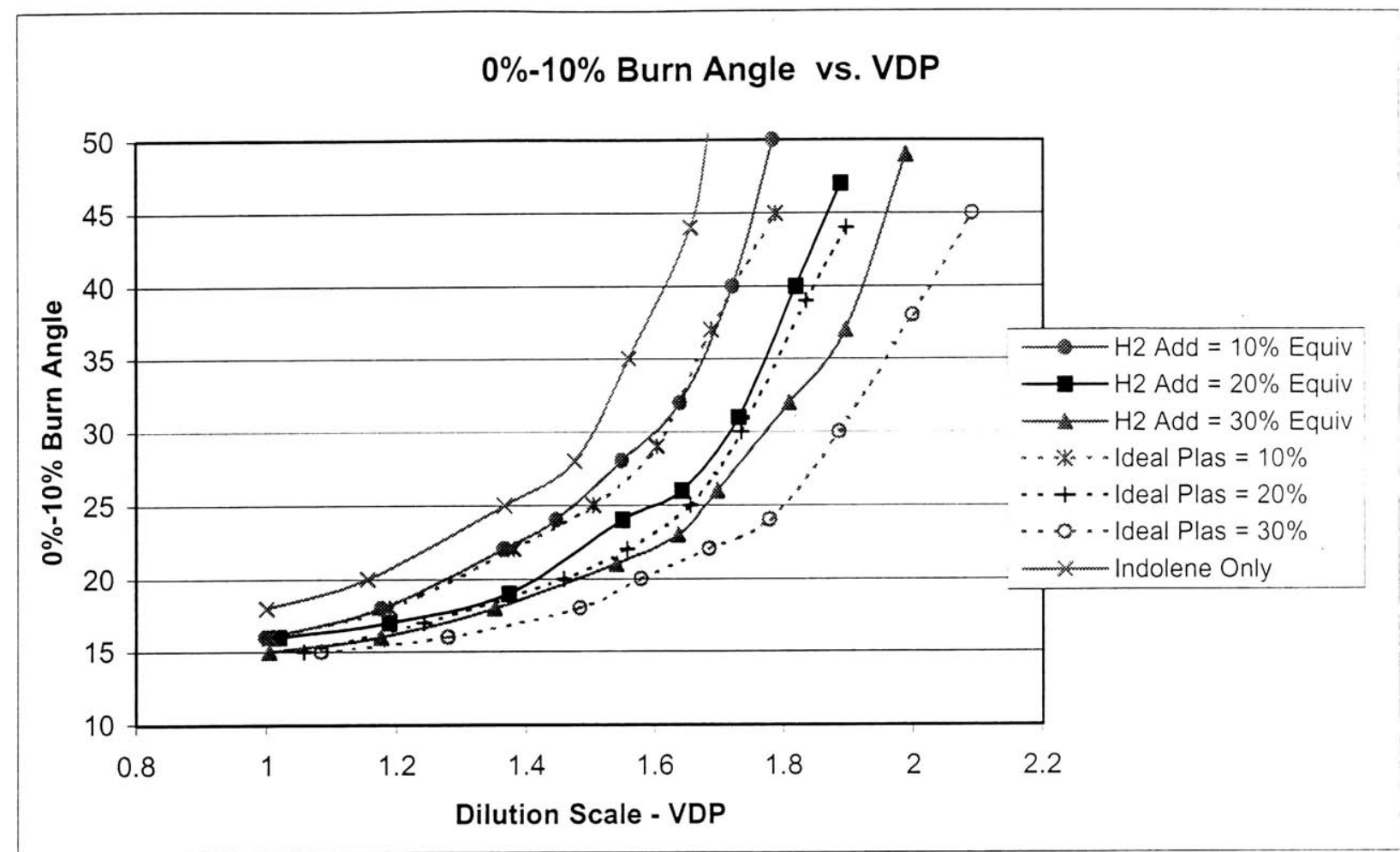

Figure \#3.7 - 0\%-10\% Burn Angles vs. VDP - Ideal Plasmatron and Hydrogen Addition

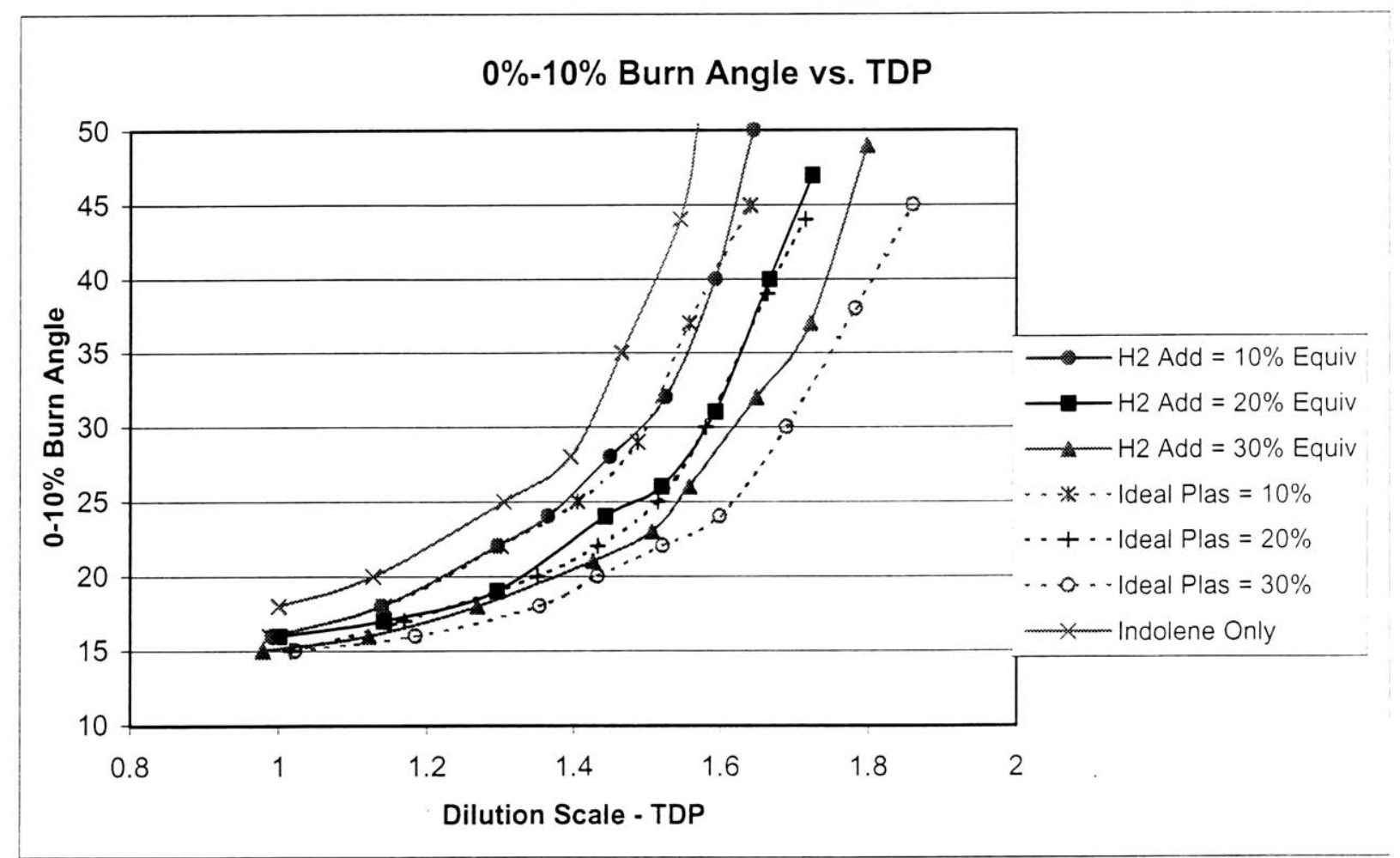

Figure \#3.8 - 0\%-10\% Burn Angles vs. TDP for Ideal Plasmatron and Hydrogen Addition 


\section{Chapter 4 - Results and Discussion}

As stated earlier a total of 10 sets of experiments were performed: ideal plasmatron. typical plasmatron, and hydrogen addition at 10\%, 20\%, and 30\% equivalent percent plasmatron levels as well as one experiment using gasoline only. First, an error analysis will be used to establish the level of accuracy of the fuel and airflow rate. Next the results will be presented for all 10 sets of experiments: MBT spark timing, burn duration data, combustion variability, hydrocarbon emissions, engine only efficiency, overall fuel system efficiency which takes into account the plasmatron losses, and finally NOx emissions. Where it is appropriate the data will be presented on both a traditional lambda scale as well as an appropriate dilution scale.

\section{1 - Error Analysis}

Since one of the primary goals of the experiment was to determine the fuel conversion efficiency under different fueling strategies it was important to perform an error analysis to determine the level of accuracy in the airflow and fuelflow. The mass flow rates of the indolene, plasmatron (or hydrogen), and air were all measured independently. In addition the lambda of the exhaust stream was measured directly. Therefore lambda could be calculated from the flow rates and compared to the lambda measured directly with the UEGO.

Figure 4.1 shows this graphs of UEGO Lambda vs. Calculated Lambda. The UEGO lambda and calculated lambda match up well for all experiments and across the entire operating range.

An absolute percent error can be defined as:

$$
\text { Absolute_\%_Error }=\frac{\left|\lambda_{U E G O}-\lambda_{\text {calculated }}\right|}{\lambda_{U E G O}}
$$


Figure 4.2 is a graph of absolute percent error versus lambda. The error seems to be random and does not exhibit any obvious trends. The average error is $1.51 \%$ and the maximum error is $3.21 \%$.

\section{2 - MBT Timing}

MBT timing is a familiar variable and is a good indicator of relative burn durations.

Figure 4.3 shows the MBT spark timing for the typical and ideal plasmatron experiments. At a fixed lambda the MBT timing moves closer to top dead center as more plasmatron gas is added. The match between the ideal and typical plasmatron data is excellent at all equivalent percent plasmatron levels. Figure 4.4 shows the same MBT spark timing data plotted against TDP. As expected the correlation between the data is better when plotted against TDP.

Figures 4.5 and 4.6 compare the MBT spark timing of the ideal plasmatron and hydrogen addition cases. Figure 4.5 shows that at the same lambda the hydrogen addition experiments burn significantly faster than the plasmatron addition experiments. This is due to the extra dilution caused by the $\mathrm{N}_{2}$ in the ideal plasmatron gas, which is not present in the hydrogen addition experiments. When shown on the TDP scale, which more accurately represents dilution, the $10 \%$ and $20 \%$ curves align almost perfectly. In addition, at the $30 \%$ equivalent plasmatron level the ideal plasmatron is slightly faster burning than the direct $\mathrm{H}_{2}$ addition. This shows that using a plasmatron to produce the $\mathrm{H}_{2}$ onboard does not have a detremental effect on combustion, but instead results in combustion that is at least as fast and is some cases faster than the direct hydrogen addition.

\section{3 - Burn Duration}

In section 3.2.3 it was argued that burn duration should be should be strongly dependent on thermal dilution. Figure 4.7 shows the $0 \%-10 \%$ burn duration for the typical and ideal plasmatron plotted against lambda. At low values of lambda the combustion process is both fast and stable and the addition of plasmatron gas has only a small impact on burn duration. For example, at a lambda of 1.0 the spread in the $0 \%-10 \%$ burn duration is only 
3 degrees. As the dilution level increases the curves begin to separate as the hydrogen in the plasmatron has an increasingly positive effect on the combustion process. At a lambda of 1.6 the spread is 13 degrees. The impact of burn duration on efficiency is expected to grow as lambda is increased. Looking at the typical and ideal plasmatron trials the match in burn duration is good although as lambda is increased the ideal plasmatron burns faster than the typical plasmatron. This can again be explained through dilution since the typical plasmatron is more dilute than the ideal plasmatron at an equivalent lambda. Figure 4.8 shows the same data plotted against TDP, which properly accounts for dilution. The typical and ideal plasmatron data now match up better than they had when plotted against lambda.

Althought the $10 \%-90 \%$ burn rate data is a less stable parameter and therefore more difficult to draw conclusions from, it is clear from figure 4.9 that at a fixed lambda the burn durations for the ideal plasmatron gas are generally shorter than for the typical plasmatron gas. In figure 4.10, when plotted against TDP, the ideal plasmatron no longer exhibits a shorter burn duration at the same equivalent percent plasmatron.

The burn rate data suggests that efficiency should increase with increasing plasmatron amounts, although the effect will be small at low dilution levels and increasingly important as dilution levels increase.

The $0 \%-10 \%$ ideal plasmatron vs. hydrogen data was already discussed when deriving the dilution parameters. It was shown that the plasmatron addition was slightly faster burning than the hydrogen addition when compared at a fixed TDP. The 10\%-90\% burn duration is shown in figures 4.11 and 4.12. A similar conclusion can be drawn from this data. The hydrogen addition is significantly better at decreasing burn duration at a fixed lambda. When dilution is properly accounted for the plasmatron addition seems to result in slightly faster combustion although variability in the data makes it difficult to interpret.

In conclusion the TDP parameter has proven to be useful in analyzing the burn duration data. When the burn rate data is plotted vs. lambda each burn profile forms a separate curve and a direct comparison between the hydrogen addition and the plasmatron 
addition cannot be made due to the fact that lambda does not fully account for dilution. By switching over to TDP a direct comparison could be made and it was found that the $\mathrm{CO}$ and $\mathrm{N}_{2}$ have a small but positive impact on the $0 \%-10 \%$ burn rate. The $10 \%-90 \%$ burn rate is more variable and therefore harder to draw conclusion from although it was clear that the plasmatron addition resulted in 10\%-90\% burn rates that were at least as fast as the hydrogen addition at the same TDP.

\section{4 - Combustion Stability}

The second parameter which impacts engine efficiency directly is combustion stability. If every cycle burned at the same rate then every cycle would give the same NIMEP. In addition, when operating at MBT timing every cycle would give the same NIMEP. which would be the maximum attainable under the operating conditions. In reality combustion varies from cycle-to-cycle and thus burn rates vary from cycle-to-cycle. At a set operating condition the spark timing is fixed regardless of the burn rate for that particular cycle. Therefore, when combustion variability is present the MBT timing is actually the spark timing where the average NIMEP is maximized. However, this does not produce the maximum NIMEP for each individual cycle. Cycles that burn faster than the average will produce a NIMEP that is less than what would have been achieved with retarded spark timing. Similarly, cycles which burn slow would have a NIMEP that is lower then what could have been achieved with advanced spark timing. When cycle-to-cycle variability is small the impact on the average NIMEP is negligible. However, as variability increases this effect becomes large.

At each operating condition in-cylinder pressure data was taken for 400 cycles. The pressure was sampled once per crank-angle, for a total of 720 samples per cycle. This pressure vs. crank angle data was converted to pressure vs. volume by using the following geometric relationship between volume and crank angle [7]:

$$
V=V_{c}\left[1+\frac{1}{2}\left(r_{c}-1\right)\left(R+1-\cos \theta-\sqrt{R^{2}-\sin ^{2} \theta}\right)\right]
$$




$$
\begin{aligned}
& \mathrm{V}=\text { Volume } \\
& \mathrm{V}_{\mathrm{c}}=\text { Clearance Volume } \\
& \mathrm{r}_{\mathrm{c}}=\text { Compression Ratio } \\
& \mathrm{R}=\text { Bore/Stroke Ratio } \\
& \theta=\text { Crank Angle measured clockwise from TDC }
\end{aligned}
$$

The Pressure vs. Volume data can now be numerically integrated to give the net indicated work per cycle, $\mathrm{W}_{\mathrm{i}}$.

$$
W_{i}=\oint P d V
$$

The net indicated mean effective pressure is defined as the net indicated work per cycle divided by the displaced volume of the cylinder.

$$
N I M E P=\frac{W_{i}}{V_{d}}
$$

A more widely used measure of combustion stability is the coefficient of variation (COV) of the NIMEP. The COV is defined as:

$C O V=\frac{\sigma_{\text {NIMEP }}}{\overline{N I M E P}}$

$$
\begin{aligned}
& \overline{\text { NIMEP }}=\text { Average NIMEP of all cycles } \\
& \sigma_{\text {NIMEP }}=\text { Standard Deviation of the NIMEP }
\end{aligned}
$$

Figure 4.13 shows the COV of NIMEP for the typical and ideal plasmatron cases as a function of lambda. The COV of NIMEP is a measure of the cycle-to-cycle variability in 
the NIMEP. Near the misfire limit the COV increases very rapidly. High levels of COV will result in a noticeable roughness in the engine operation. Comparing the 10\%, $20 \%$. and $30 \%$ equivalent percent plasmatron shows that the lambda at which COV exceeds this limit increases as more plasmatron gas is added. The ideal plasmatron gas experiments can consistently reach a higher lambda before deterioration occurs. However, the ideal plasmatron gas is less dilute then the typical plasmatron gas because it does not contain $\mathrm{CO}_{2}$. If this is a correct explanation then the same data plotted vs. TDP will show that the TDP where the COV deteriorates is the same for both plasmatron gases. Another observation to note is that the $10 \%$ plasmatron cases deteriorate at almost the same lambda as the indolene only case. Again, dilution is though to offer an explanation.

Figure 4.14 shows the same data on the TDP scale. The TDP at which the COV begins to increase rapidly is well behaved. As expected, the indolene only case deteriorates rapidly first, at a TDP of 1.57. Both the typical and ideal plasmatron deteriorate at a TDP of 1.64. At the $20 \%$ reformed fraction the typical and ideal plasmatron case both deteriorate rapidly near 1.73 on the TDP scale. At the $30 \%$ equivalent plasmatron level the typical and ideal plasmatron case do not match as closely although they both deteriorate near a TDP 1.85. The COV is independent of whether typical or ideal plasmatron gas is used and instead is only a function of equivalent percent plasmatron and TDP. The increase in dilution limit is linear with equivalent percent plasmatron, with each $10 \%$ increase in the equivalent percent plasmatron resulting in an increase in the dilution limit of approximately $0.1 \mathrm{TDP}$.

Figure 4.15 shows the COV of NIMEP vs. lambda for the ideal plasmatron and the hydrogen addition on the lambda scale. The addition of hydrogen increases the lean combustion limit in a very predicitable manner. For the hydrogen experiments each step from indolene only up to $30 \%$ equivalent plasmatron results in the lambda at the lean limit increasing by 0.1 . The combustion deterioration occurs at a significantly higher lambda for the hydrogen addition case vs. the ideal plasmatron. For the plasmatron addition increasing the amount of plasmatron gas also increases the lambda at which 
combustion deteriorates although the increases are not as much as for the hydrogen addition cases.

Figure 4.16 shows the same data on the TDP scale. At the $10 \%$ level the ideal plasmatron and hydrogen deteriorate at almost the exact same level. At the 20\% and 30\% levels the ideal plasmatron has a higher dilution limit then the hydrogen addition cases. Going from indolene only to $30 \%$ equivalent plasmatron for the hydrogen case only increases the dilution limit from 1.57 to 1.80 for a total increase of 0.23 TDP. This is significantly less than the increase of 0.29 (1.57 to 1.86) for the ideal plasmatron addition. This suggests that the $\mathrm{N}_{2} / \mathrm{CO}$ present in the ideal plasmatron gas increases the upper limit for COV. This is due to the higher dilution limit of $\mathrm{CO}$.

\section{5 - Hydrocarbon Combustion Efficiency}

Incomplete combustion has a direct impact on engine efficiency. The mass flow rate of air and fuel into the engine can be used along with the hydrocarbon emissions data to calculate hydrocarbon combustion efficiency:

$$
\begin{aligned}
& m_{\text {tot.e.xh }}=\sum_{i} m_{i} \\
& n_{\text {tot } e x \mathrm{xh}}=\frac{m_{\text {tot } e x h}}{\overline{M W}_{\text {exh }}} \\
& n_{H C . \mathrm{exh}}=C_{H C} \cdot n_{t o t . \mathrm{exh}} \\
& m_{H C, e x h}=n_{H C, e x h} \cdot \overline{M W}_{H C, e x h} \\
& \eta_{\text {comb. } H C}=\frac{m_{H C, \text { exh }}}{m_{H C, \text { engine }}}
\end{aligned}
$$


The average molecular weight of the exhaust can be calculated from the exhaust composition. The hydrocarbon concentration, $C_{H C}$, is known from the FID hydrocarbon analyzer. Since the $\mathrm{HC}$ analyzer reports the $\mathrm{HC}$ concentration in PPM C1 the chemical formula used to determine the average molecular weight of the hydrocarbon in the exhaust should be $\mathrm{CH}_{1.93}$.

Figure 4.17 shows the percent unburned hydrocarbons vs. lambda for the typical and ideal plasmatron trials. At a fixed lambda and a fixed reformed fraction the ideal plasmatron case has slightly lower unburned hydrocarbons then the typical plasmatron case although the difference is small. The unburned $\mathrm{HC}$ fraction at stoichiometric conditions is approximately $1.5 \%$ for all cases. As lambda is increased the unburned hydrocarbon level increases steadily which can be explained by examining the combustion process. During the combustion process the flame propagates away from the center of the cylinder toward the wall. As the flame grows the heat released by the combustion process initiates the combustion reaction in the unburned fuel/air mixture that is entering the flame. As the flame approaches the wall of the cylinder the lower temperature and large heat capacity of the cylinder wall act as a thermal sink and quenches the flame. The thin layer of fuel near the cylinder wall never reaches the temperature required for combustion chemistry reactions, leaving some unburned fuel/air mixture near the wall. More dilute mixtures will have lower burnt gas temperatures. which will result in the flame quenching sooner. In other words, higher levels of dilution will leave more unburned fuel/air mixture near the combustion chamber walls.

In addition to the unburned hydrocarbons near the wall of the cylinder there are hydrocarbons that are trapped in the crevices of the combustion chamber. As the pressure rises due to the compression stroke and the beginning of combustion some of the fuel/air mixture is forced into the crevices of the combustion chamber. Once the main combustion process is completed the pressure in the cylinder drops due to the continued expansion process and finally the exhaust blowdown process. As the pressure drops the gases in the crevices expand and enter the main combustion chamber. 
Both the unburned fuel/air mixture near the cylinder wall and in the crevices will be oxidized when they mix with the burnt gases if the temperature of the burnt gas is hot enough to initiate the reaction. As the engine is run at increasingly dilute levels the incylinder exhaust and burned gas temperatures drop, resulting in reduced post-flame oxidation.

As the dilution level is further increased the engine will begin to operate with high variability, resulting in cycles that only partially burn or will misfire completely. This will result in a very steep increase in both the COV and the hydrocarbon emissions.

If this model is correct then hydrocarbon combustion efficiency should primarily be a function of burnt gas temperatures and combustion stability. At a fixed lambda the ideal plasmatron burnt gases will be higher than the typical plasmatron burnt gases because the heating value of the ideal plasmatron is greater than that of the typical plasmatron. In addition, when the COV was plotted against lambda the COV was lower for the ideal plasmatron then for the typical plasmatron. Since hydrocarbon combustion efficiency increases with both combustion stability and burnt gas temperatures the ideal plasmatron gas should have lower hydrocarbon emissions than the typical plasmatron gas when plotted against lambda. This agrees well with the data presented in figure 4.17.

The TDP parameter was defined in such a way that it represents a simplified burnt gas temperature. Because of this the ideal and typical plasmatron cases should have the same burnt gas temperatures at the same TDP. In addition, when COV was plotted against TDP it was found to be essentially independent of whether typical or ideal plasmatron gas was used. The COV was only a function of the equivalent percent plasmatron and the TDP. If the hydrocarbon combustion efficiency is primarily determined by the burnt gas temperature and COV then a plot of percent unburned hydrocarbon vs. TDP should show that the hydrocarbon emissions are only a function of equivalent plasmatron percent and TDP. Figure 4.18 confirms this, showing that the when plotted against TDP the hydrocarbons are largely independent of whether the typical or ideal plasmatron gas is used. 
The above arguments for using dilution instead of lambda also hold for this data. Figure 4.19 shows the percent unburned hydrocarbons vs. lambda for the ideal plasmatron and the hydrogen addition. At high levels of lambda the combustion deteriorated more rapidly for the plasmatron addition then it does for the hydrogen addition. Figure 4.29 shows the data plotted against the TDP. Here it is clear that the hydrogen and plasmatron data match up well. At the same equivalent percent plasmatron and the same TDP the percent unburned hydrocarbons match very closely.

It is interesting that in the stable combustion regime the percent unburned hydrocarbons is independent of the amount of plasmatron gas used. Only near the lean limit does the addition of plasmatron or hydrogen affect combustion efficiency. In other words, the presence of hydrogen and $\mathrm{CO}$ at a fixed dilution only results in a more complete combustion process near the lean limit.

\section{6 - NOx Emissions}

NOx formation is strongly effected by two parameters, peak combustion temperatures and oxygen concentration [7]. Near stoichiometric the NO formation process is complex. A small increase in excess air will drive the NO equilibrium, resulting in a large increase in NO emissions. However, excess air will also reduce the combustion temperatures, which reduces the rate of formation of NO. Since the impact of excess air affects the chemical equilibrium as well as the peak combustion temperatures, the net effect in not obvious. Once the mixture is sufficiently lean the addition of more air will only impact NO fomation through the diluent effect it has by reducing burnt gas temperatures. Thus from stoichiometric to slightly lean conditions the effect of both oxygen concentration and peak temperatures are expected to be important and it is not clear if lambda or TDP will better explain the data. At more dilute conditions TDP is expected to collapse the data since in this area the primary impact on NO formation will be thermal, which TDP represents.

Figures 4.21 and 4.22 show the plasmatron NO emissions vs. lambda plotted on a linear as well as a logarithmic scale. As the percentage of plasmatron gas is increased the 
impact on $\mathrm{NO}$ emissions is significant. For example, looking at lambda $=1.0$, going form $10 \%$ - 30\% ideal plasmatron gas reduces the NO emissions by approximately $40 \%$. This is though to be due to the extra thermal dilution of the $\mathrm{N}_{2}$ in the plasmatron gas. Looking at Figure 4.22 it is clear that at a fixed lambda the regular plasmatron consistently has lower NO emissions. Again, this is thought to be due to the fact that the lambda scale does not properly account for dilution.

Figures 4.23 and 4.24 show the NO emissions data vs. TDP. Near stoichiometric the ideal and typical plasmatron NO emissions differ by a large amount. This is probably due to the importance of oxygen conentration, which is not explicitly accounted for in TDP. Above dilution of approximately 1.3 the TDP does a much better job. In this highly dilute regime neither the ideal nor typical plasmatron cases consistently exhibits a higher NO level. In other words, the TDP parameter allows the NO emissions to be expressed as a function of dilution and reformed fraction only and is independent of whether the ideal or the typical plasmatron gas is used. Again, this is because in the highly dilute regime $\mathrm{NO}$ formation is primarily a thermal phenomena driven by peak combustion temperatures.

Figures 4.25 and 4.26 show the NO data for the ideal plasmatron and hydrogen experiments plotted vs. lambda. Both a linear as well as a logarithmic plot are shown. Again at a fixed lambda the addition of more plasmatron gas results in greatly reduce NO emissions due to the thermal effect of the nitrogen in the plasmatron gas.

Figure 4.27 and 4.28 show the NO data vs. TDP. Figure 4.27 shows that at low dilution levels the TDP only does a marginal job of collapsing the data because it does not account for oxygen concentration. At higher dilution levels, where the thermal effects dominate, TDP does an excellent job of collapsing the data. Above a TDP of approximately 1.2 all of the trials essentially collapse to a single line where NO emissions can be described as a function of only TDP. 


\section{7 - Fuel Conversion Efficiency}

The net indicated fuel conversion efficiency is defined as [7]:

$\eta_{f}=\frac{W_{i}}{Q_{c y c l e}}$

The flow rate of fuel is known so to convert to $Q_{c y c l e}$ the following relationship can be used:

$$
Q_{\text {cycle }}=\frac{n_{R}}{N} \dot{Q}=\frac{n_{R}}{N} \sum_{i} \dot{m}_{i} L H V_{i}
$$

The burn rate analysis software was used to calculate the NIMEP from the pressure data. The NIMEP relationship from (21) can be rearranged to:

$W_{i}=V_{d} \cdot N I M E P$

Substituting (29) and (30) into (28) gives:

$$
\eta_{f}=\frac{N I M E P \cdot V_{d} \cdot N}{n_{R} \cdot \dot{Q}}
$$

For the engine only efficiency:

$$
\eta_{f, \text { engine }}=\frac{N I M E P \cdot V_{d} \cdot N}{n_{R} \cdot \dot{Q}_{\text {engine }}}
$$

For the overall efficiency:

$$
\eta_{f, \text { overall }}=\frac{N I M E P \cdot V_{d} \cdot N}{n_{R} \cdot \dot{Q}_{\text {overall }}}
$$


Dividing (32) by (33) gives:

$\frac{\eta_{f, \text { overall }}}{\eta_{f, \text { engine }}}=\frac{\dot{Q}_{\text {engine }}}{\dot{Q}_{\text {overall }}}$

So the overall and engine only efficiency are simply related by the energy flows.

Looking at the energy flows set up in Figure 3.4 it is possible to do some analysis. Since engine only efficiency is based on energy entering the engine:

$\dot{Q}_{\text {engine }}=\dot{Q} \cdot X \cdot \eta_{\text {plas }}+\dot{Q} \cdot(1-X)$

For the overall efficiency:

$\dot{Q}_{\text {overall }}=\dot{Q}$

$\frac{\eta_{f, \text { overall }}}{\eta_{f, \text { engine }}}=\frac{\dot{Q}_{\text {engine }}}{\dot{Q}_{\text {overall }}}=1-X\left(1-\eta_{\text {plus }}\right)$

This ratio, which represents the loss in efficiency due to the plasmatron losses, scales with both the reformed fraction and the plasmatron efficiency. If either the reformed fraction increases or the plasmatron efficiency decreases the overall system efficiency is decreased. The plasmatron losses can be significant. For example using the typical plasmatron gas at a $20 \%$ reformed fraction, these losses will reduce the system efficiency by almost $5 \%$.

\subsection{1 - Engine Only Fuel Conversion Efficiency}

Figure 4.29 shows the engine only efficiency for the typical and ideal plasmatron cases plotted against lambda. The efficiency will be negatively impacted by 3 parameters as the engine is run lean: burn duration, combustion inefficiency, and combustion variation. Since the efficiency data is the net and not the gross efficiency, the data directly includes the effect of pumping losses. The burn duration data was calculated directly while the 
combustion inefficiency was analyzed using the percent unburned hydrocarbons data and the combustion variation was represented by the COV data. Offsetting these negative impacts on efficiency is the reduction of pumping losses under lean conditions, which will have a positive impact on efficiency. The data showed that initially the negative impact of burn duration, combustion inefficiency, and combustion variability are small and are not strongly impacted by the equivalent percent plasmatron. However, they became more important at leaner conditions and all three increased dramatically as the lean limit was approached. The expected result is that the reduced pumping losses will initially dominate, resulting in a nearly linear rise in efficiency until the negative impact of increased burn duration, combustion inefficiency, and worsening combustion stability become large. At this point the efficiency will peak and begin to decline as these continue to increase rapidly. Figure 4.29 is consistent with this trend, with the efficiency increasing initially for all cases and then peaking and dropping off rapidly. Looking at a fixed lambda the addition of plasmatron gas results in higher efficiency. This is primarily due to the fact that as more plasmatron gas is added the total molar flow rate into the engine is increased and therefore the pumping losses are reduced. In addition the peak efficiency occurs at a higher lambda due to the extention of the lean limit from the plasmatron gas. The combined impact of the reduced pumping losses and the extended lean limit results in the addition of plasmatron causing the curve to shift up and to the right.

Pumping work will correlate well with the total molar flow rate into the engine. Lambda will not correlate directly with changes in pumping work since at a fixed lambda the molar flow rate varies depending upon the amount of plamatron gas used. If the data were plotted against a dilution parameter that represents pumping losses then the chart could be used to test the statement that the increase in efficiency with more plasmatron gas at a fixed lambda was due to reduced pumping losses. TDP is not the appropriate dilution variable since it represents thermal dilution, not molar dilution. The VDP. which was defined in section 3.2.2, represents the energy per unit mole and should scale well with the reduction in pumping losses. 
Figure 4.30 shows the engine only efficiency for the typical and ideal plasmatron vs. VDP. At low values of VDP the curves tend to collapse to a single curve. This is because the difference in burn duration, combustion inefficiency, and combustion variability is small for all trials at a low dilution. The only variable that is significantly different is the pumping losses, but those are captured in the VDP. At higher dilution levels the difference between the burn duration, combustion inefficiency, and combustion variability for the various amounts of plasmatron gas becomes significant and the efficiency curves begin to separate. As expected, increasing amounts of plasmatron gas both increases the efficiency and causes it to peak at a higher dilution.

Figure 4.31 shows the engine only efficiency vs. lambda for the ideal plasmatron and hydrogen addition experiments. The curves follow a similar trend to this in figure 2.29, resulting in efficiency increasing as the amount of plasmatron is increased due to the impact of dilution. Figure 4.32 shows the same data plotted against VDP. The data again collapses to a single line near the lower dilution levels indicating that dilution is the appropriate explanation for the higher efficiency of the plasmatron runs at the same lambda.

\subsection{2 - Overall System Fuel Conversion Efficiency}

Equation (38) established a simple relationship between the engine only and overall system fuel conversion efficiency. The overall system efficiency is not expected to correlate with either lambda, TDP, VDP, or any other dilution parameter since it is a function of the plasmatron characteristics which are independent of the engine operation. However, for consistency the data will be shown plotted against both lambda and VDP. For the hydrogen addition case there is no plasmatron so the overall fuel conversion efficiency is the same as what was already presented for the engine only efficiency.

Figure 4.33 and 4.34 show the overall fuel conversion efficiency for the ideal and typical plasmatron cases plotted against lambda and VDP. The ideal plasmatron has a higher efficiency and therefore has a higher overall system efficiency compared to the typical plasmatron. In addition, all of the ideal plasmatron data sets peak out at about the same efficiency of $32.2 \%$. In other words, the engine only efficiency gains made by running at 
higher reformed fractions were approximately offset by greater losses in the plasmatron at the higher reformed fractions. The peak efficiency for the ideal plasmatron run achieves an efficiency improvement of approximately $12.3 \%$ over the indolene only, stoichiometric case. The typical plasmatron runs have a lower efficiency than the ideal plasmatron runs due to the lower plasmatron efficiency. As the reformed fraction increases the peak efficiency of the typical plasmatron runs decreases. It is clear that improving the plasmatron efficiency or designing the engine to run on lower plasmatron fractions would both significantly boost efficiency. It is interesting to note that the indolene only experiment has the highest peak efficiency. In other words, the efficiency gains made by using a plasmatron are more than offset by losses in the plasmatron. However, engines fueled by gasoline only are typically restricted to the stoichiometric operating point and cannot be run at this peak efficiency point due to combustion variability issues, emissions restrictions and the inability to use a three-way catalyst in this regime.

From an efficiency standpoint it is desirable to operate the engine where the overall net indicated fuel conversion efficiency is maximized. Drivability requirements will limit the maximum value of COV that is acceptable. In addition, since NOx aftertreatment is difficult in a lean environment the engine out NOx emissions are also going to place a limitation on what operating conditions are acceptable. Therefore, it is useful to understand the tradeoff between COV, NOx, and efficiency. Figure 4.37 shows the tradeoff between NOx and efficiency. The relative NOx is defined as:

$N O x_{\text {relative }}=\frac{N O x_{\text {indolene_only.:Lambdal }=1}}{N O x}$

The trendline shows that NOx emissions can be reduce by approximately 95\% (Relative NOx $=0.05$ ) without an efficiency penalty. To further reduce the NOx level below this amount there is an efficiency penalty. For example, going from the $95 \%$ NOx reduction level to the $99 \%$ NOx reduction level cuts the efficiency gain by more than half.

Figure 4.38 shows the COV vs. efficiency for all experiments. The experiments that have the maximum efficiency also have low values of $\mathrm{COV}$, in the $1 \%-2 \%$ range. Conversely. 
experiments where the COV was high are not points where the efficiency is a maximum This is expected as high COV signals combustion variability and poor combustion efficiency. Unlike with NOx emissions, there is never a tradeoff between COV. 


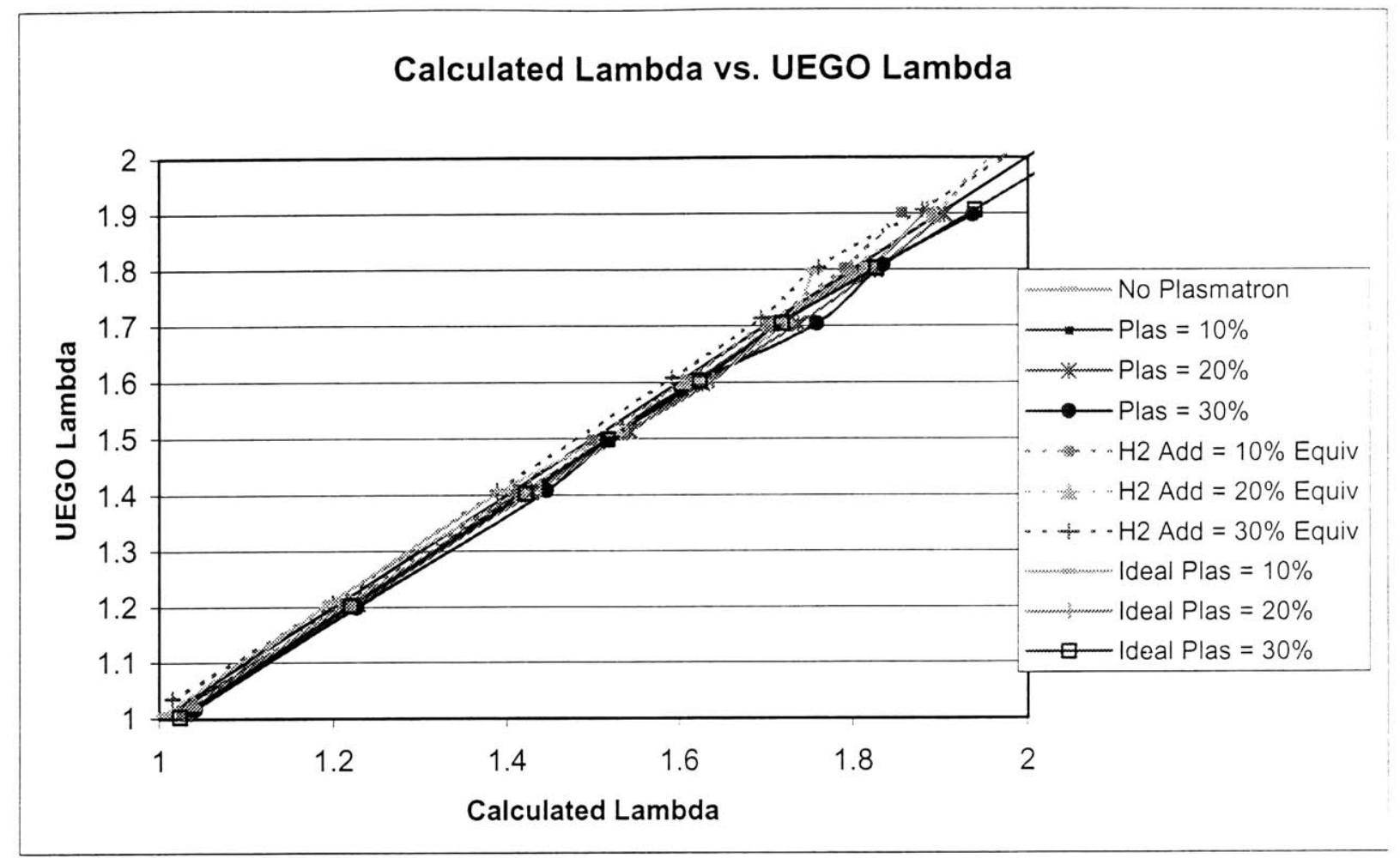

Figure 4.1 - Calculated Lambda vs. UEGO Lambda

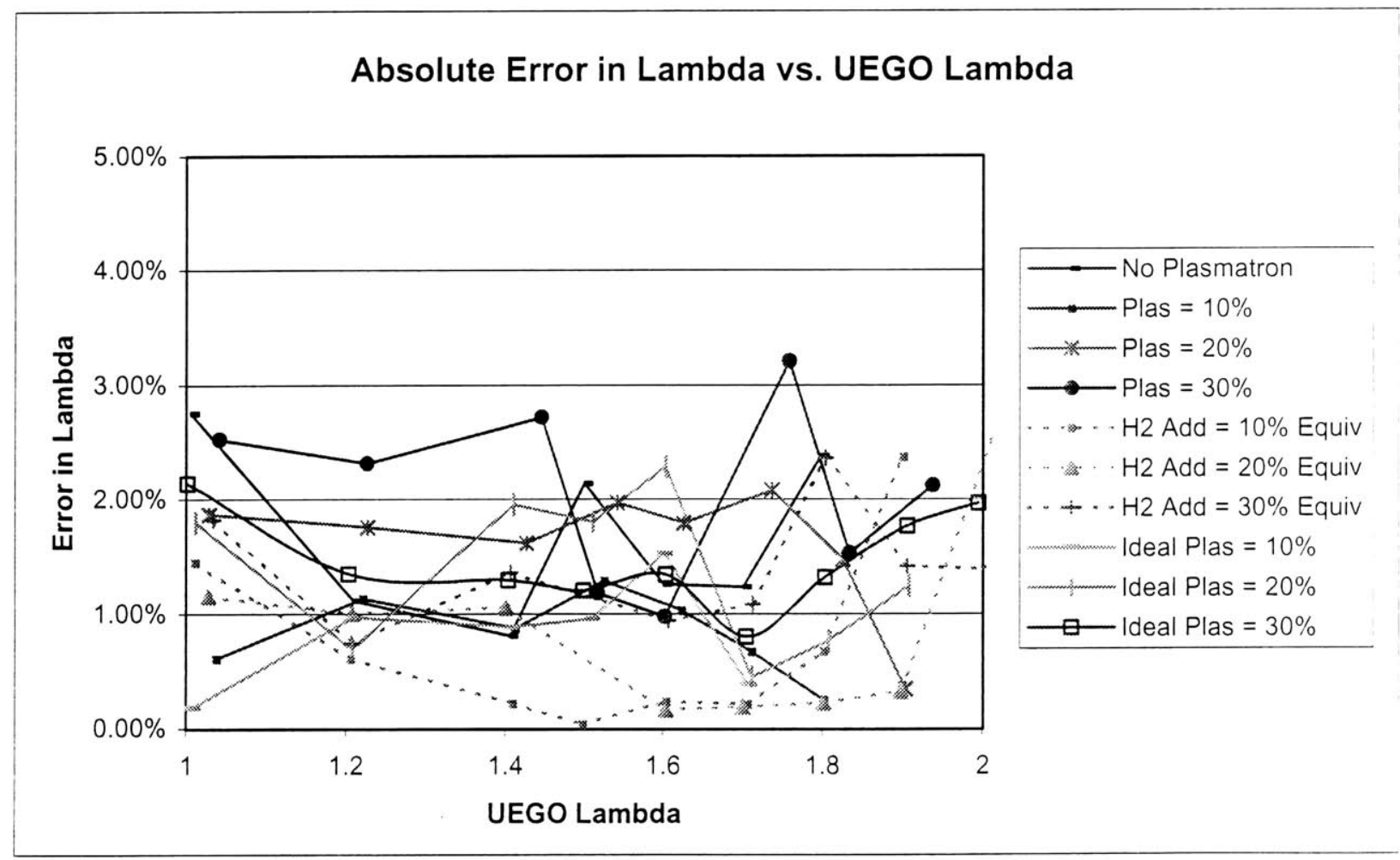

Figure 4.2 - Absolute Error in Lambda vs. UEGO Lambda 


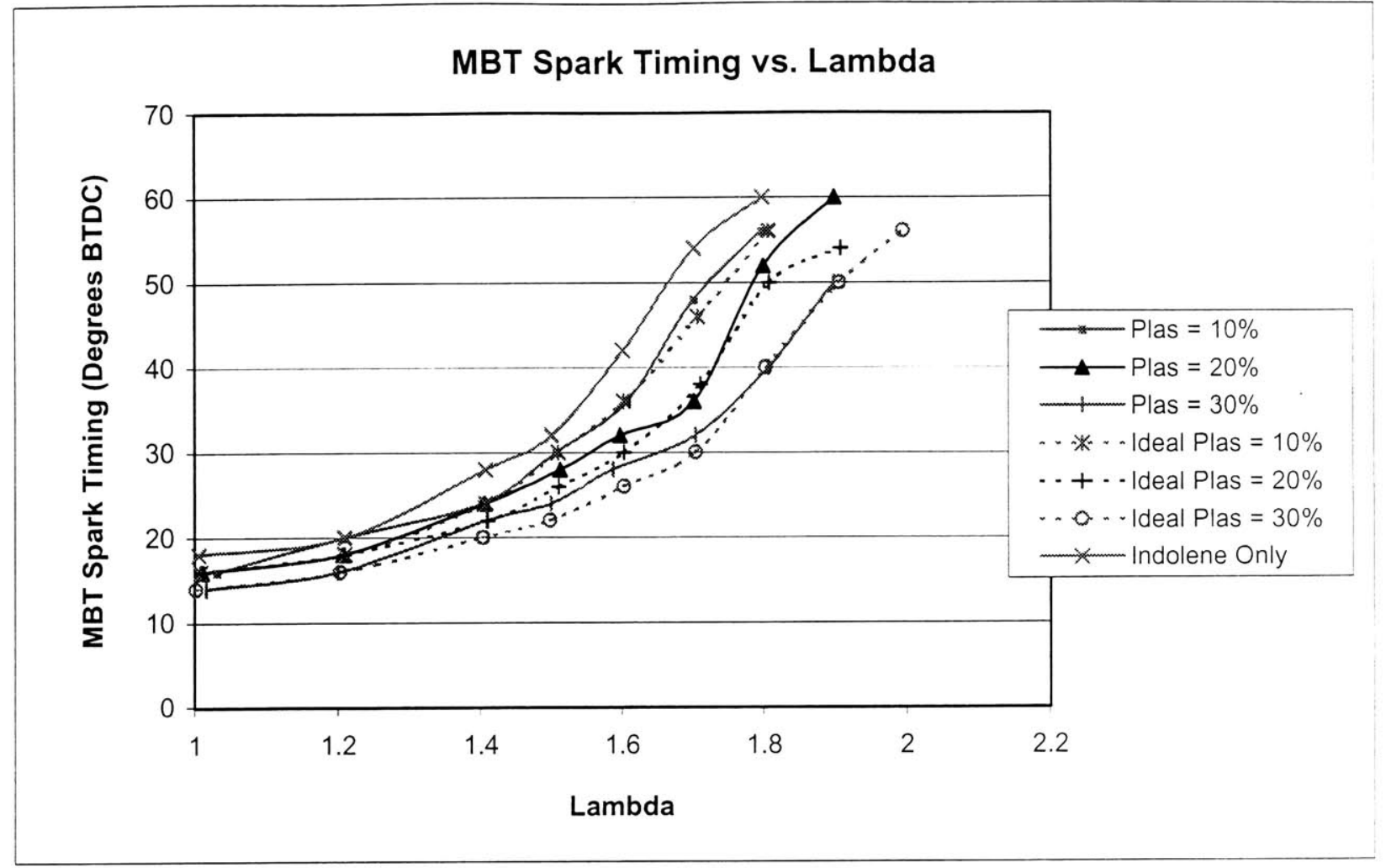

Figure 4.3 - MBT Spark Timing vs. Lambda - Typical and Ideal Plasmatron Addition

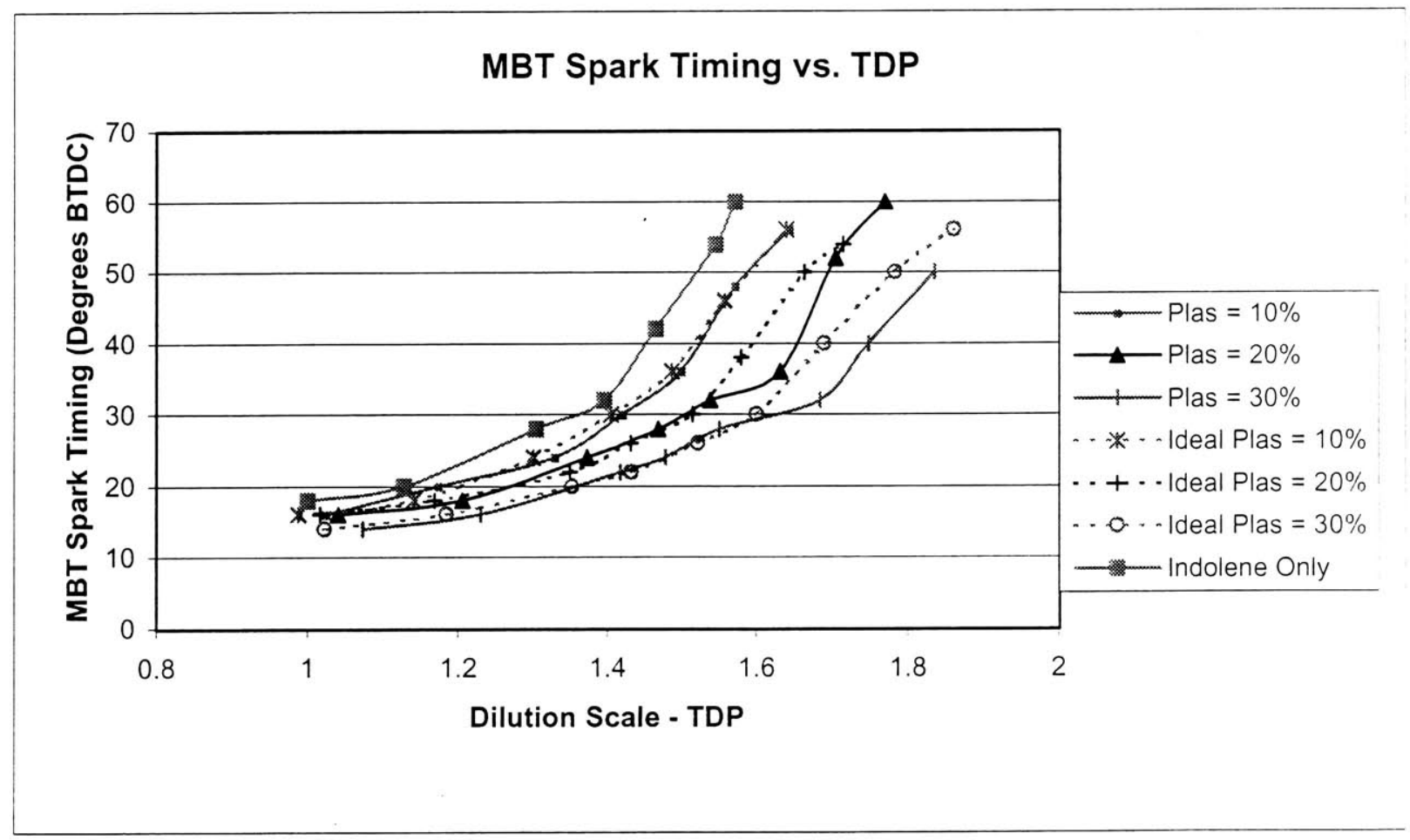

Figure 4.4 - MBT Spark Timing vs. TDP - Typical and Ideal Plasmatron Addition 


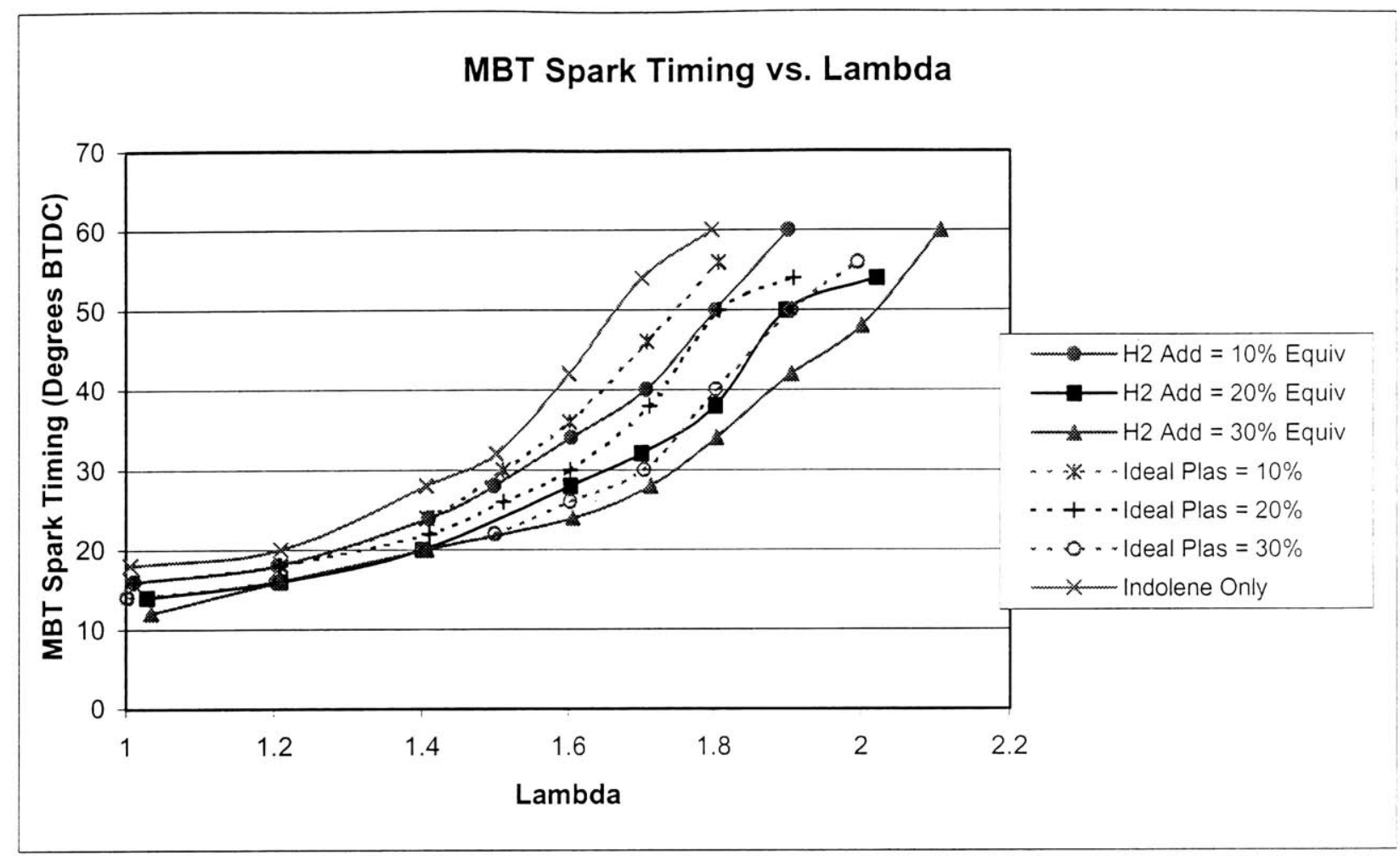

Figure 4.5 - MBT Spark Timing vs. Lambda - Ideal Plasmatron and Hydrogen Addition

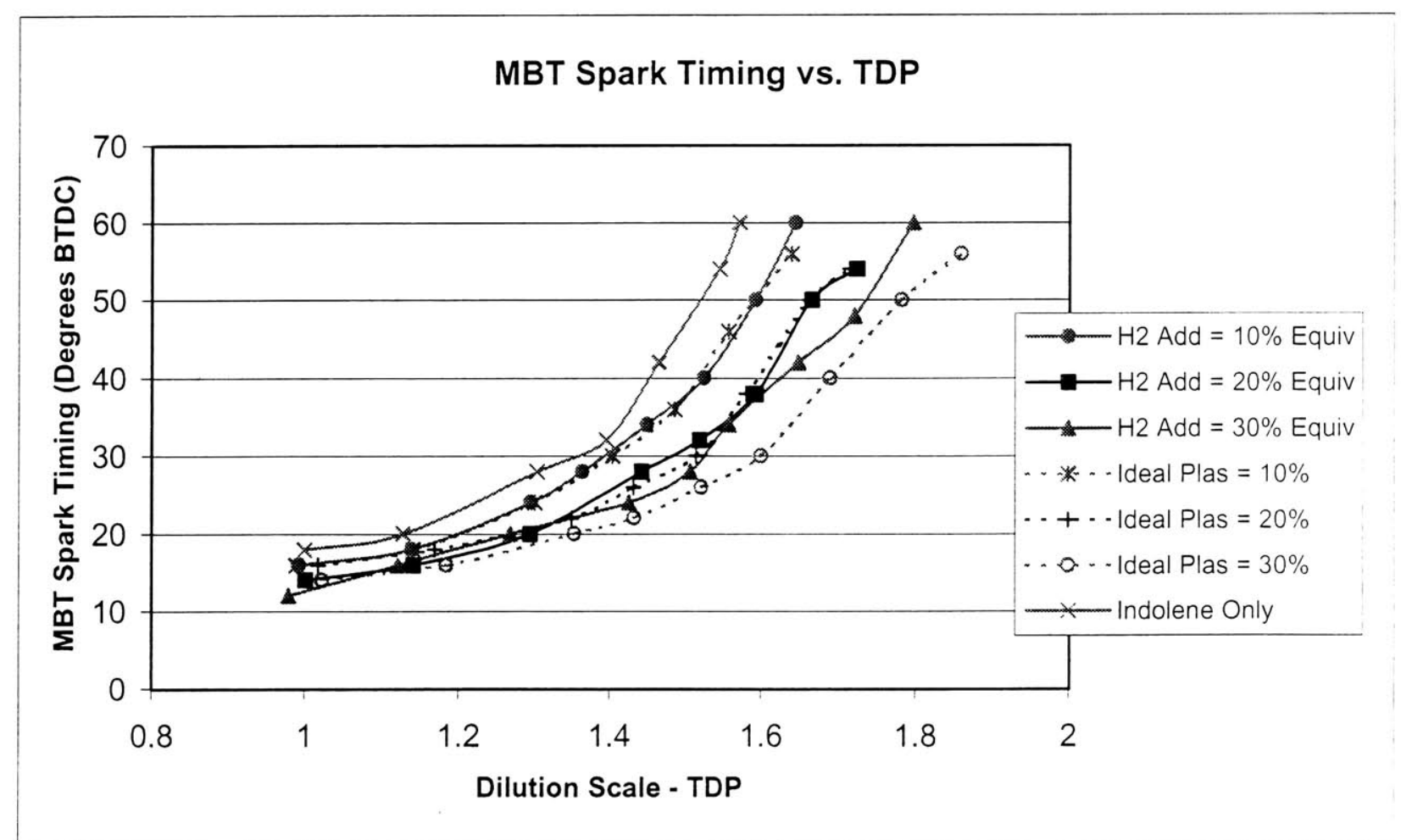

Figure 4.6 - MBT Spark Timing vs. TDP - Ideal Plasmatron and Hydrogen Addition 


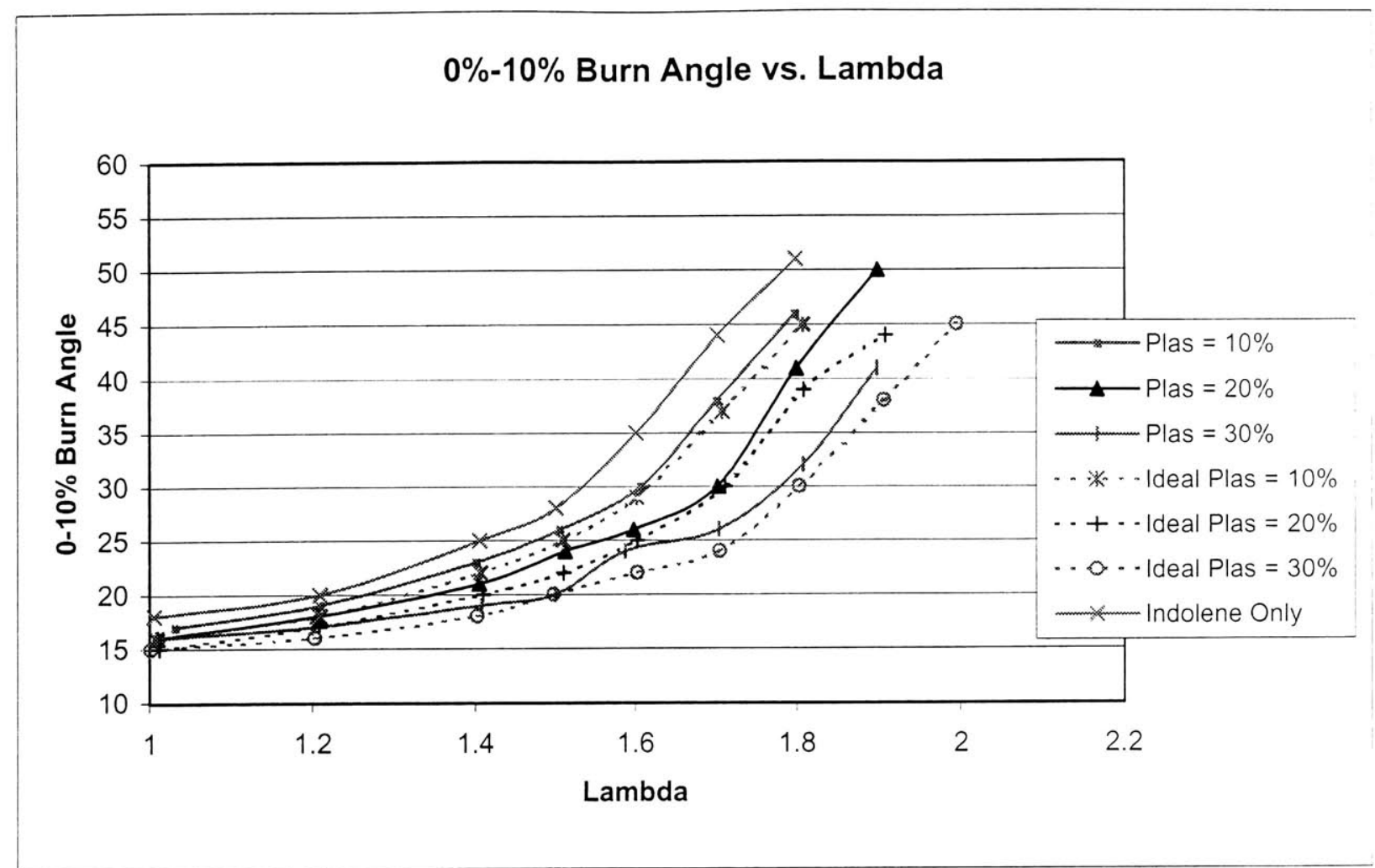

Figure 4.7 - 0\%-10\% Burn Duration Angle vs. Lambda - Typical and Ideal Plasmatron Addition

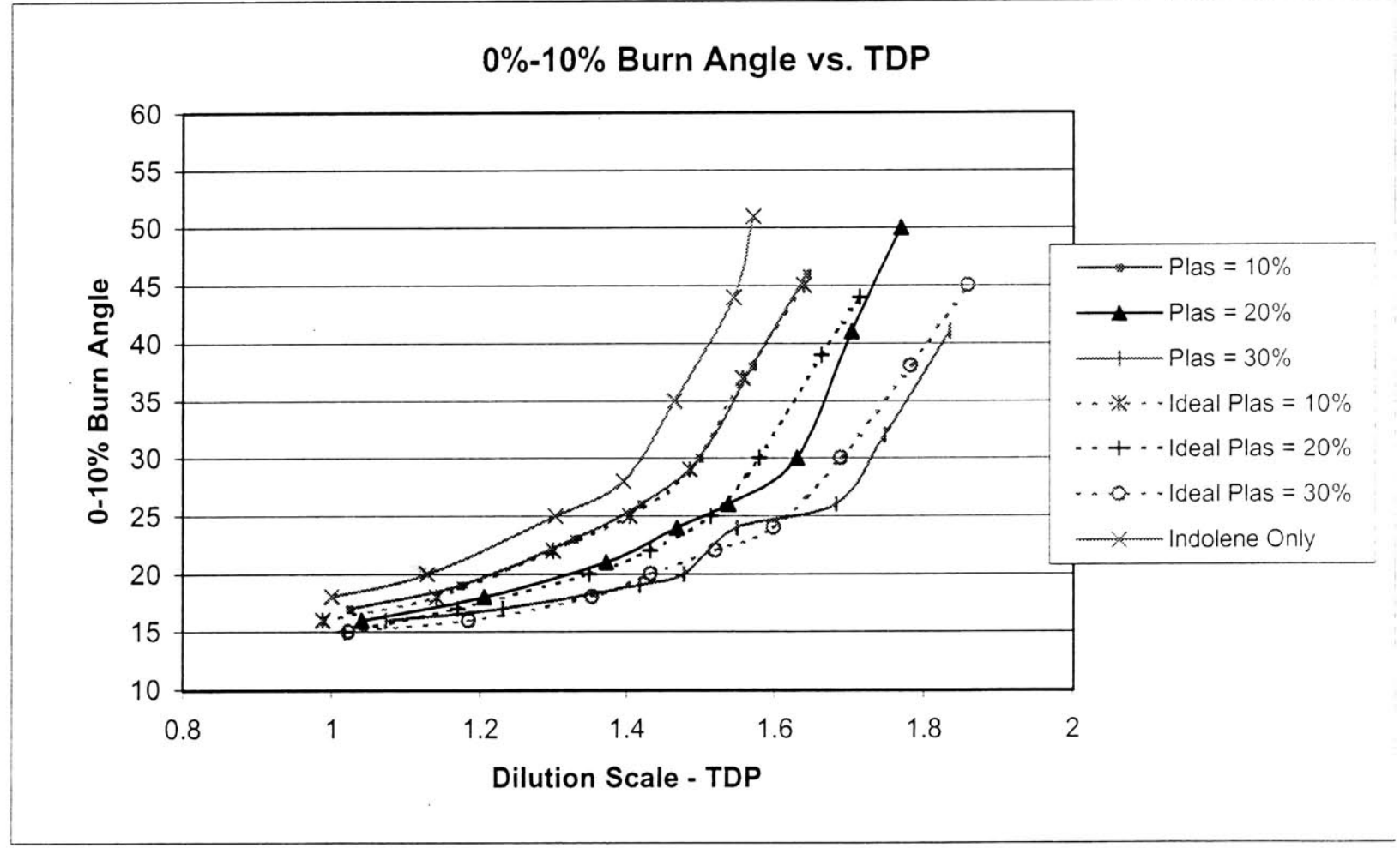

Figure 4.8 - 0\%-10\% Burn Duration Angle vs. TDP - Typical and Ideal Plasmatron Addition 


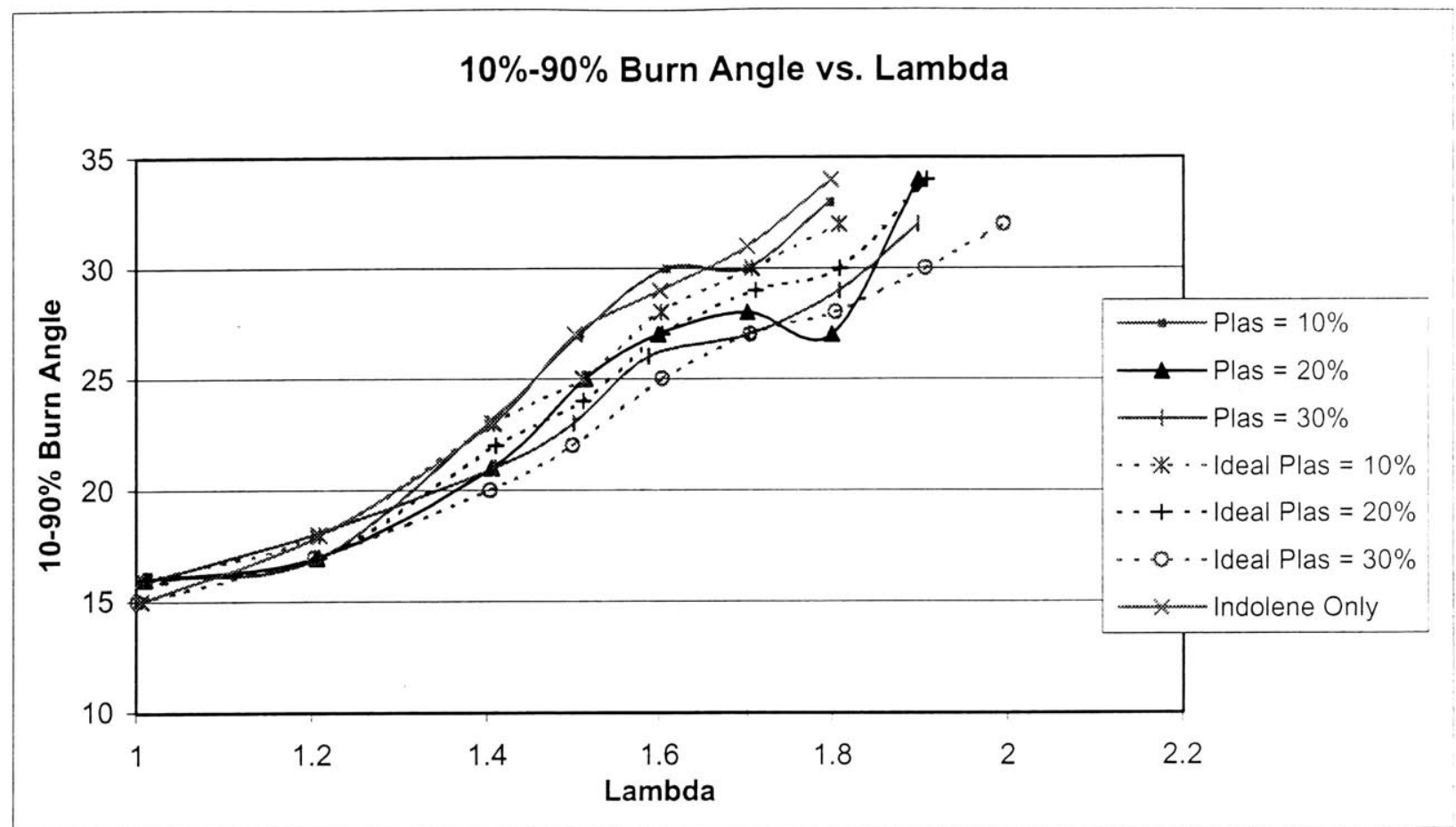

Figure 4.9 - 10\%-90\% Burn Duration Angle vs. Lambda - Typical Plasmatron and Ideal Plasmatron

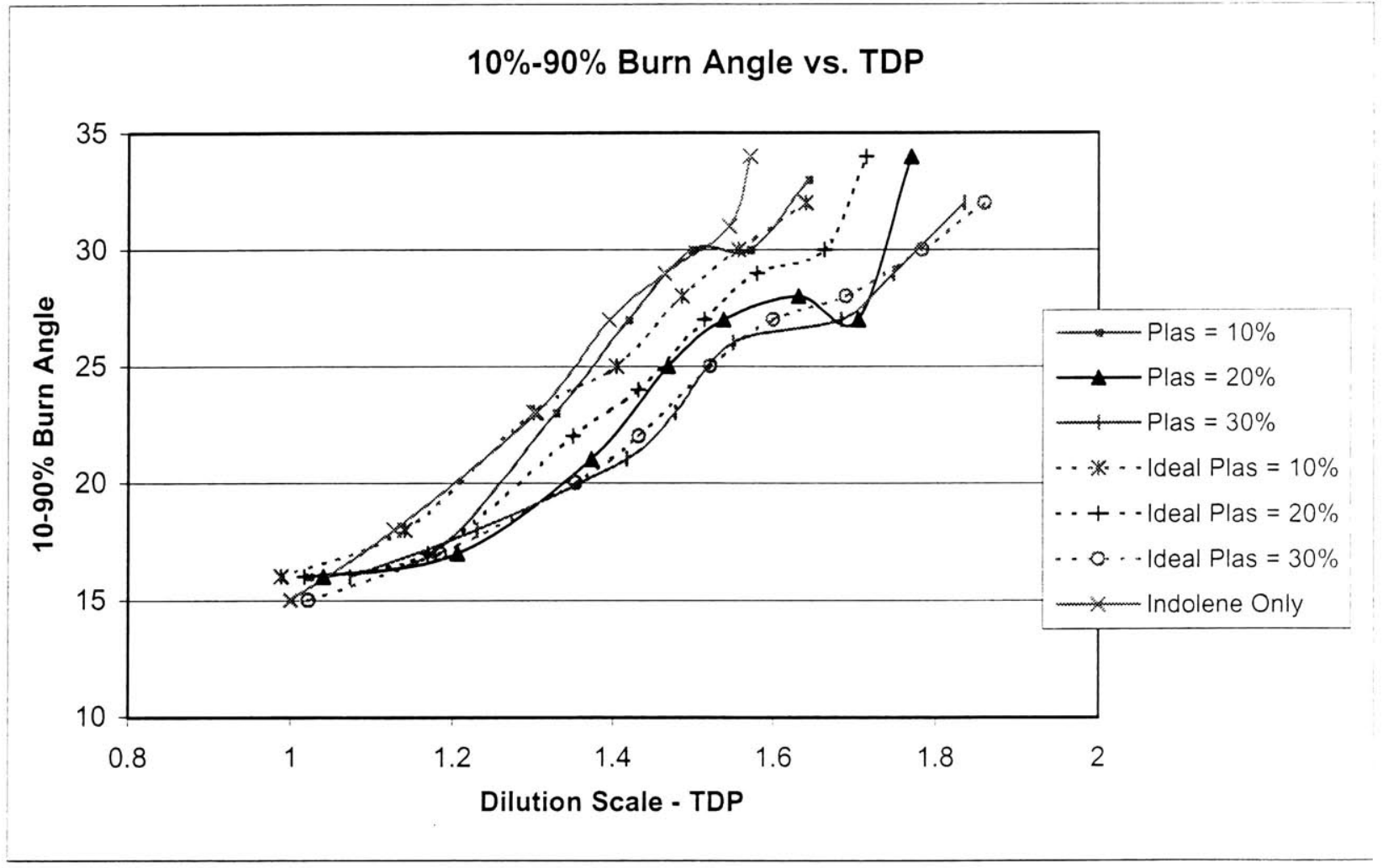

Figure 4.10 - 10\%-90\% Burn Duration Angle vs. TDP - Typical Plasmatron and Ideal Plasmatron 


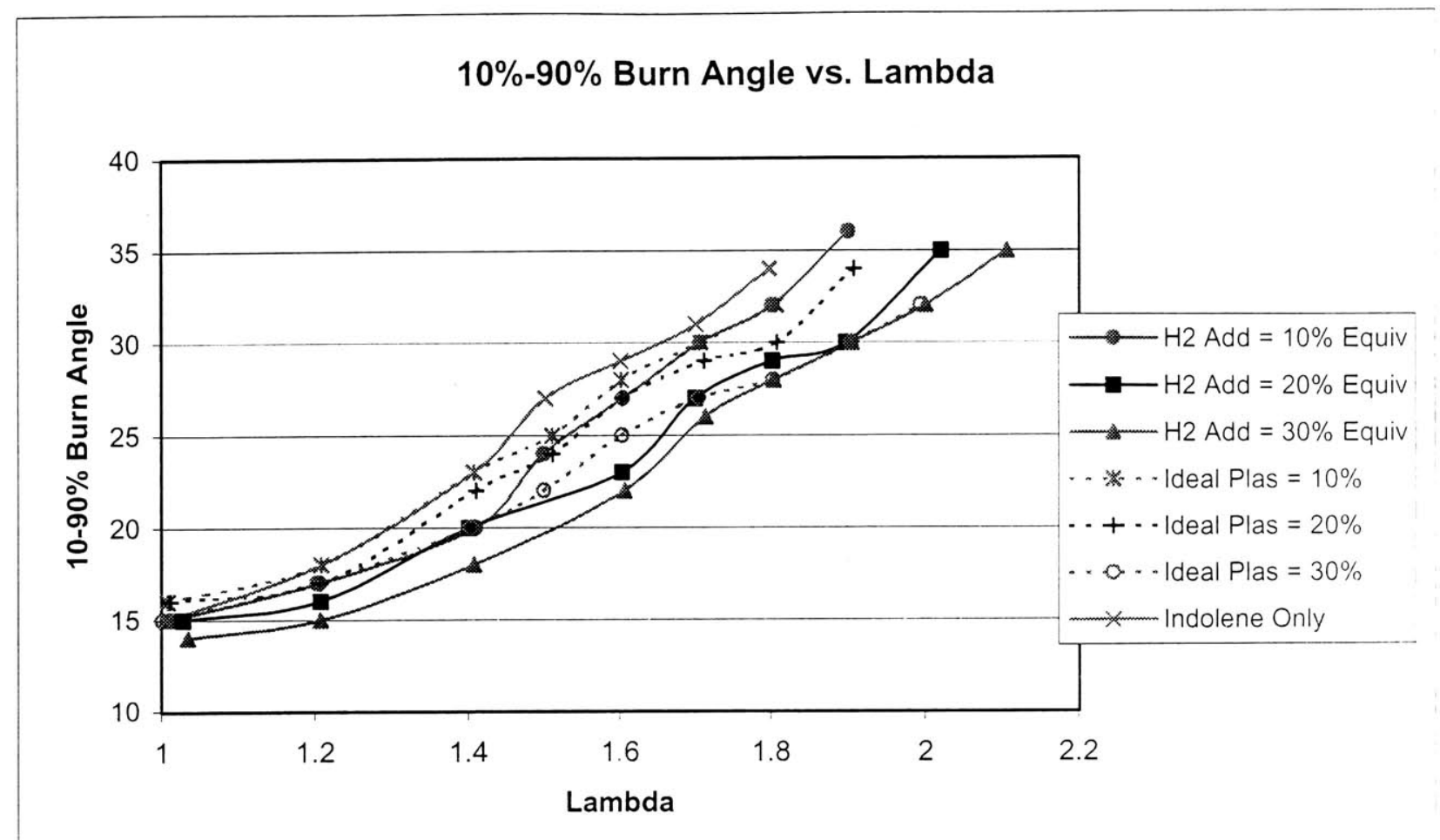

Figure 4.11 - 10\%-90\% Burn Duration Angle vs. Lambda - Ideal Plasmatron and Hydrogen Addition

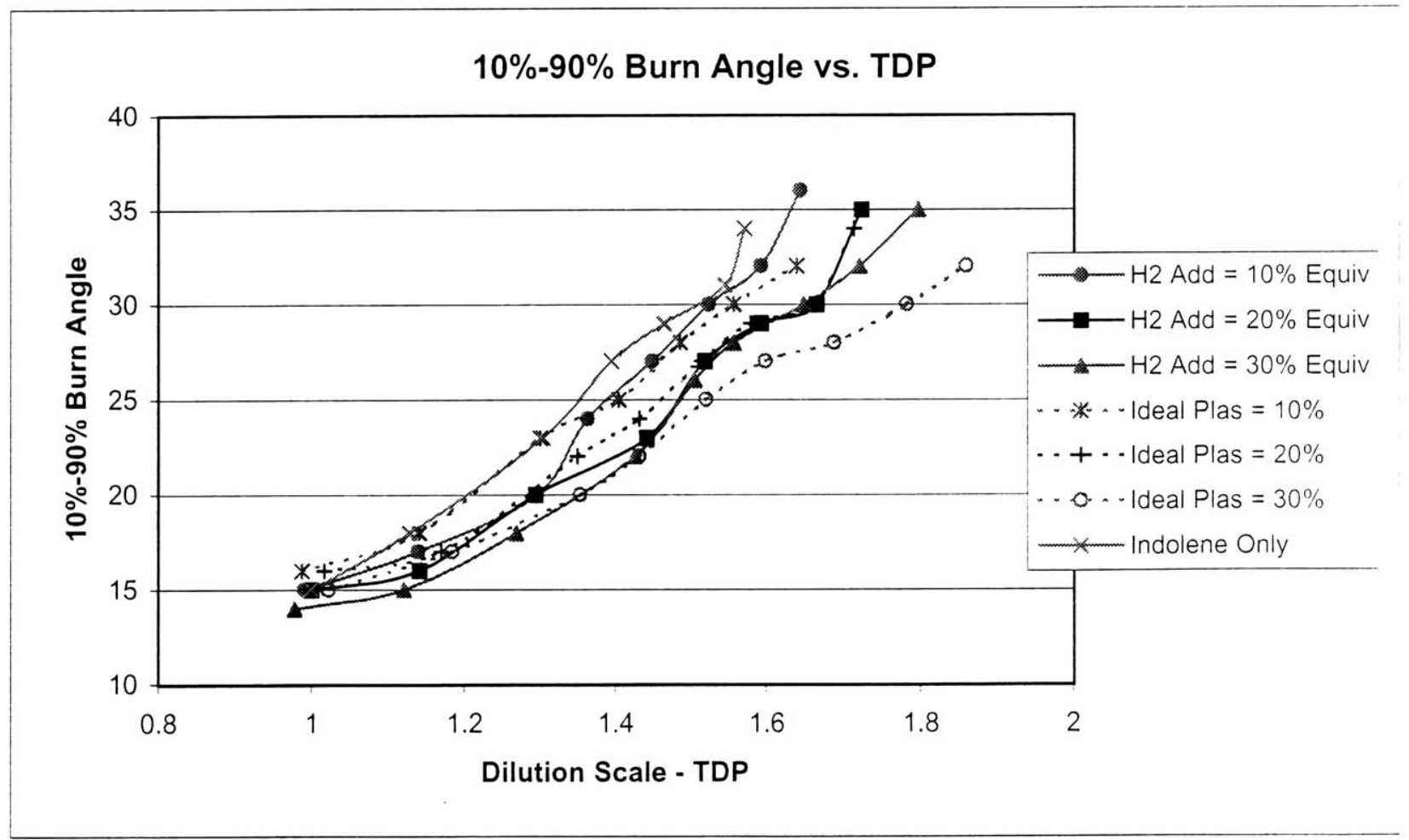

Figure 4.12 - 10\%-90\% Burn Duration Angle vs. TDP - Ideal Plasmatron and Hydrogen Addition 


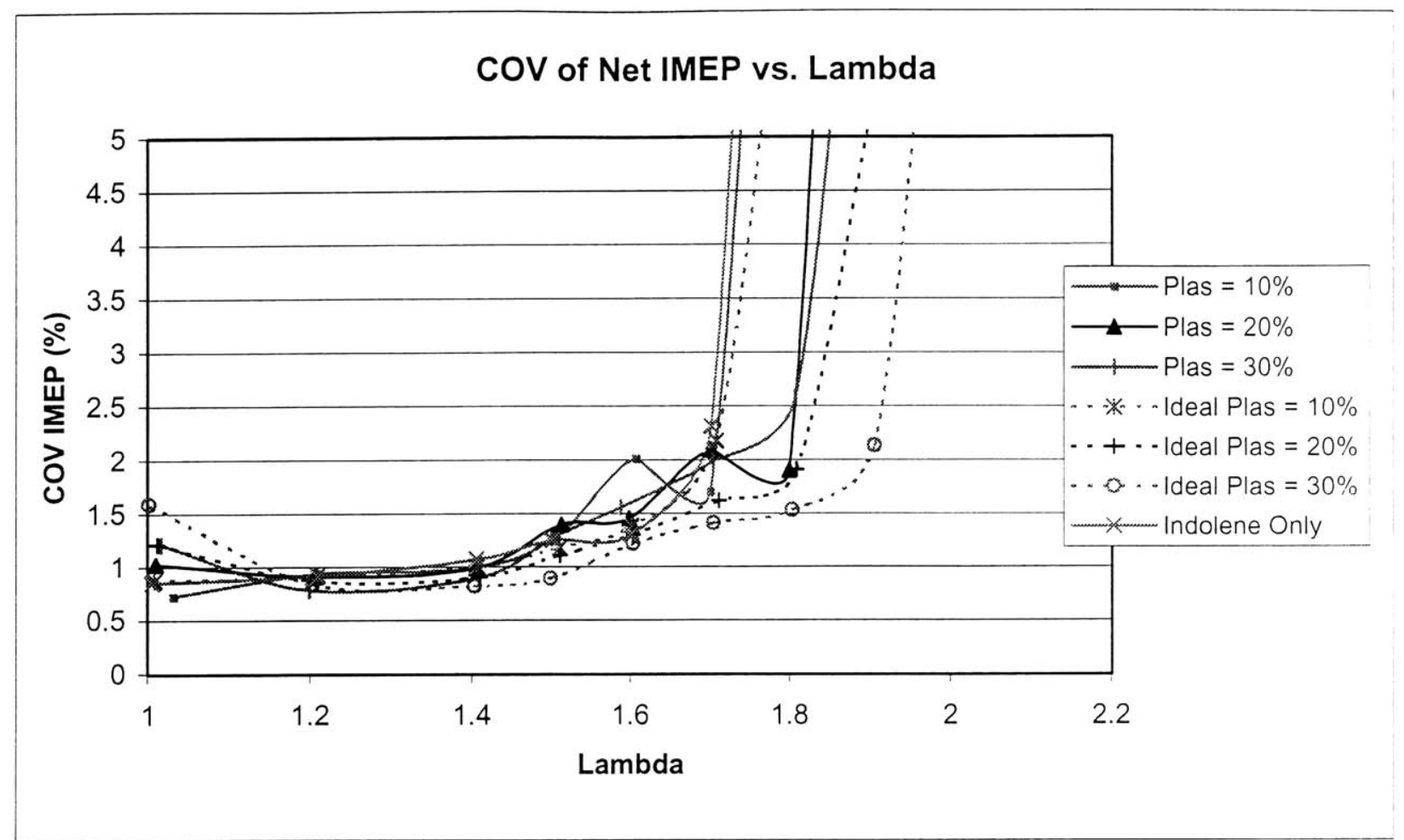

Figure 4.13 - COV of IMEP vs. Lambda - Typical Plasmatron and Ideal Plasmatron

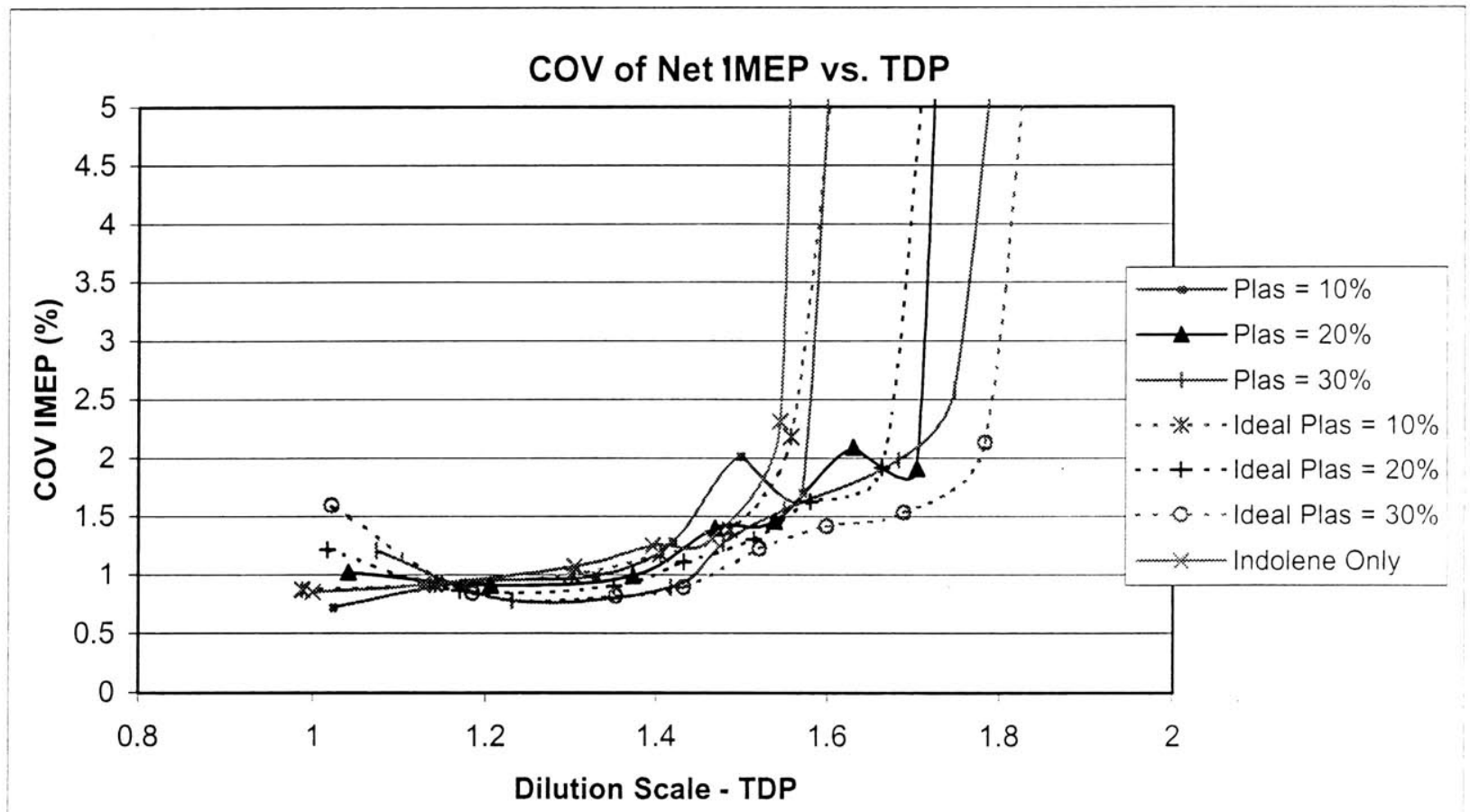

Figure 4.14 - COV of IMEP vs. TDP - Typical Plasmatron and Ideal Plasmatron 


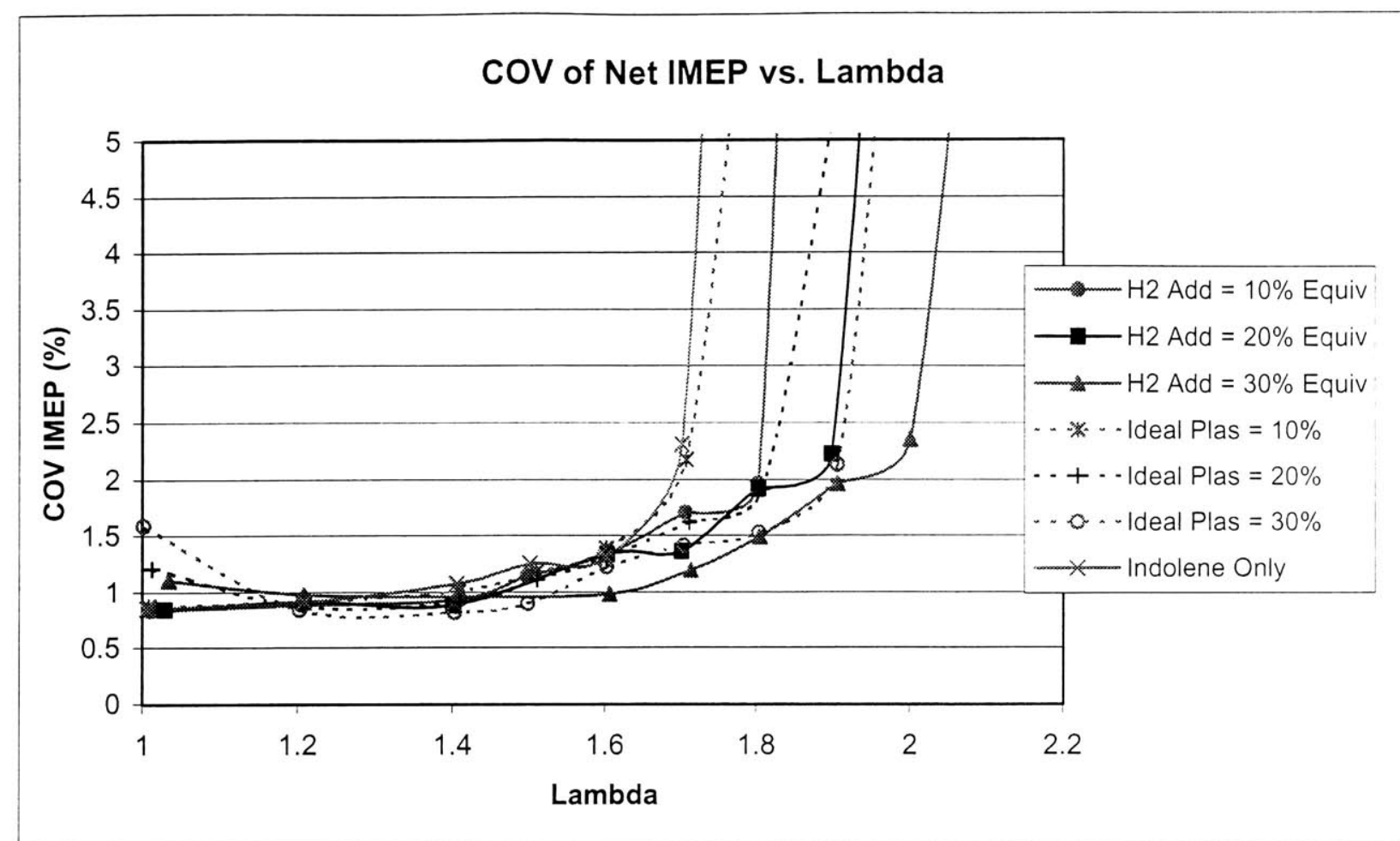

Figure 4.15 - COV of IMEP vs. Lambda - Ideal Plasmatron and Hydrogen Addition

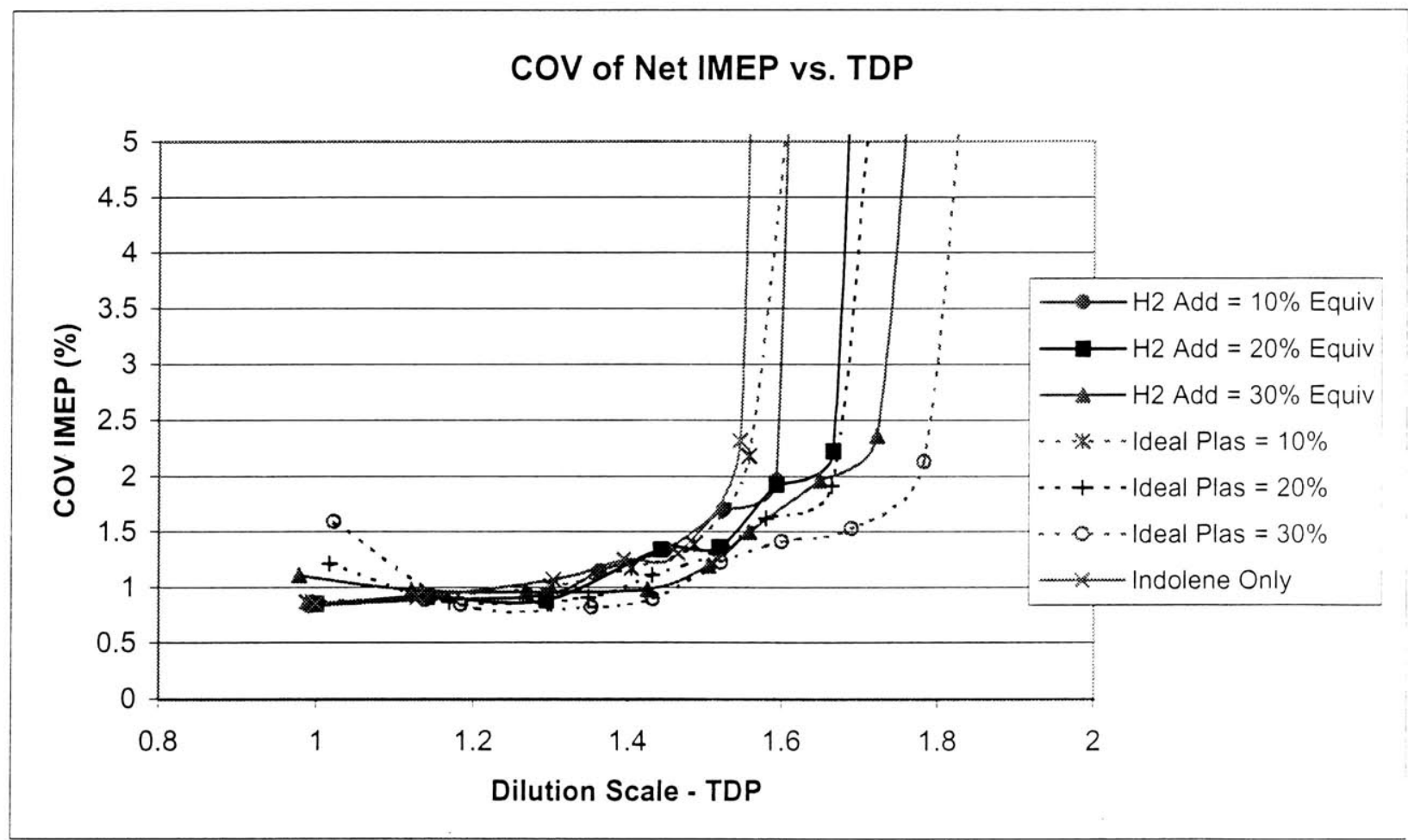

Figure 4.16 - COV of IMEP vs. TDP - Ideal Plasmatron and Hydrogen Addition 


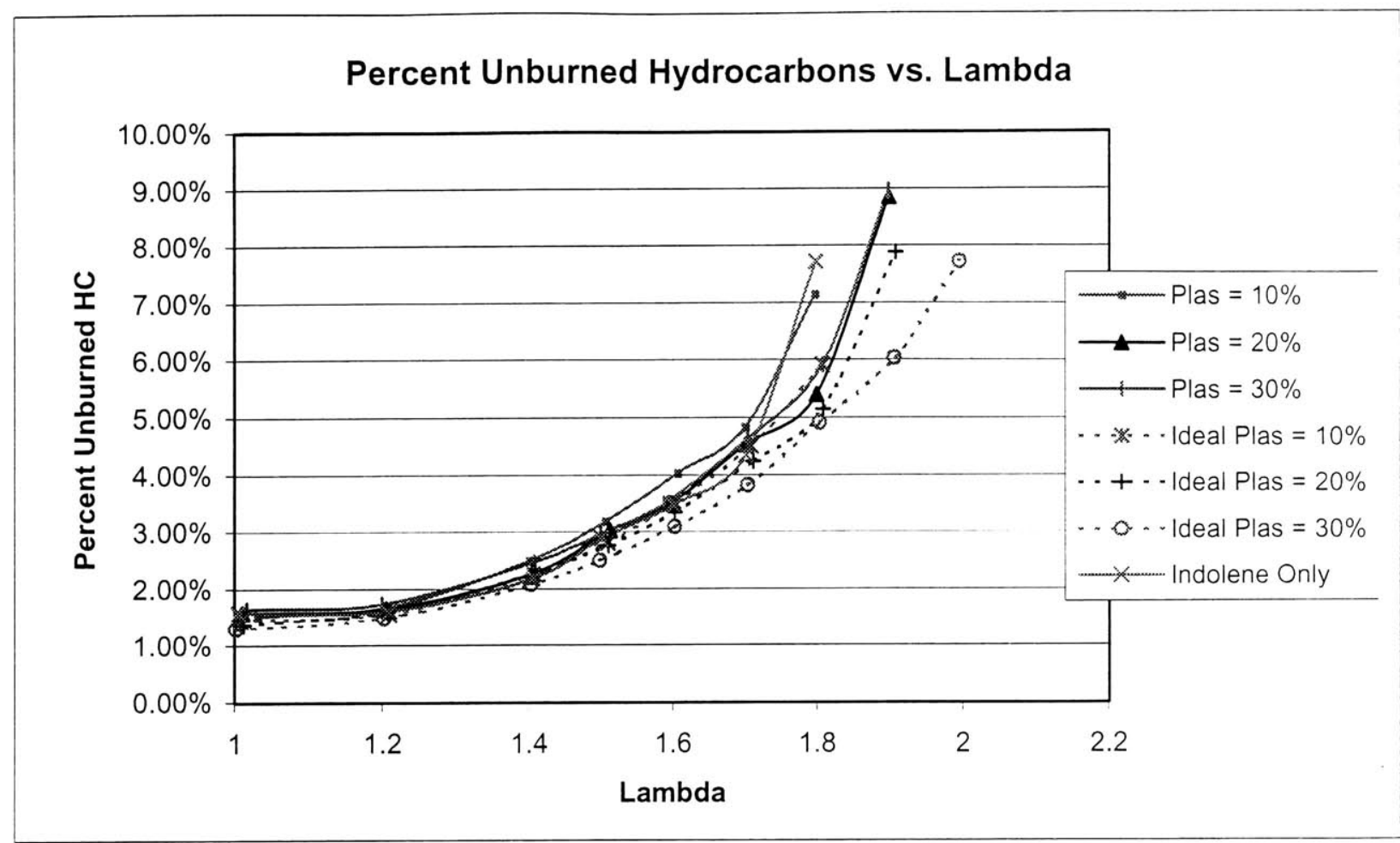

Figure 4.17 - Percent Unburned Hydrocarbons vs. Lambda - Typical and Ideal Plasmatron

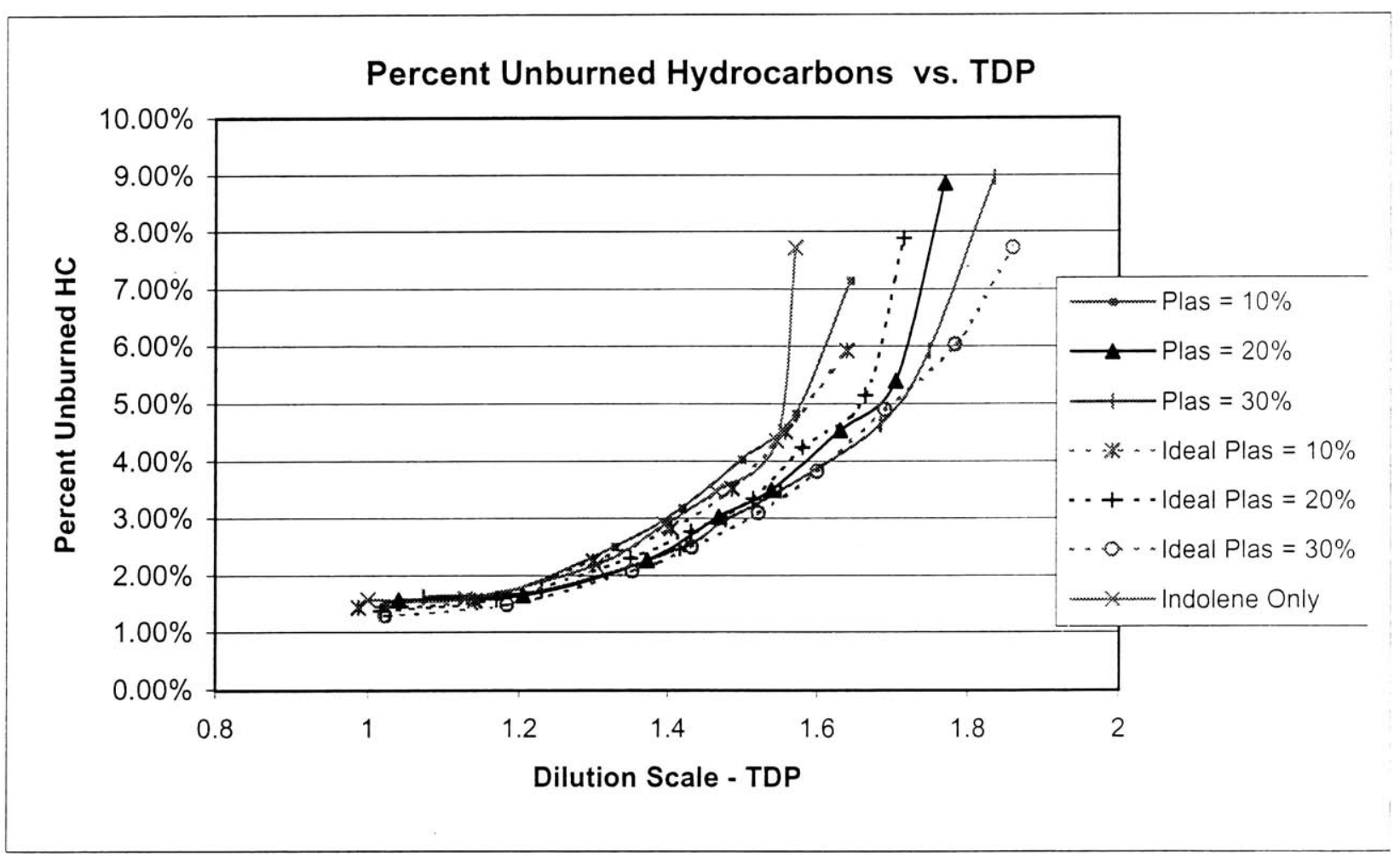

Figure 4.18 - Percent Unburned Hydrocarbons vs. TDP - Typical and Ideal Plasmatron 


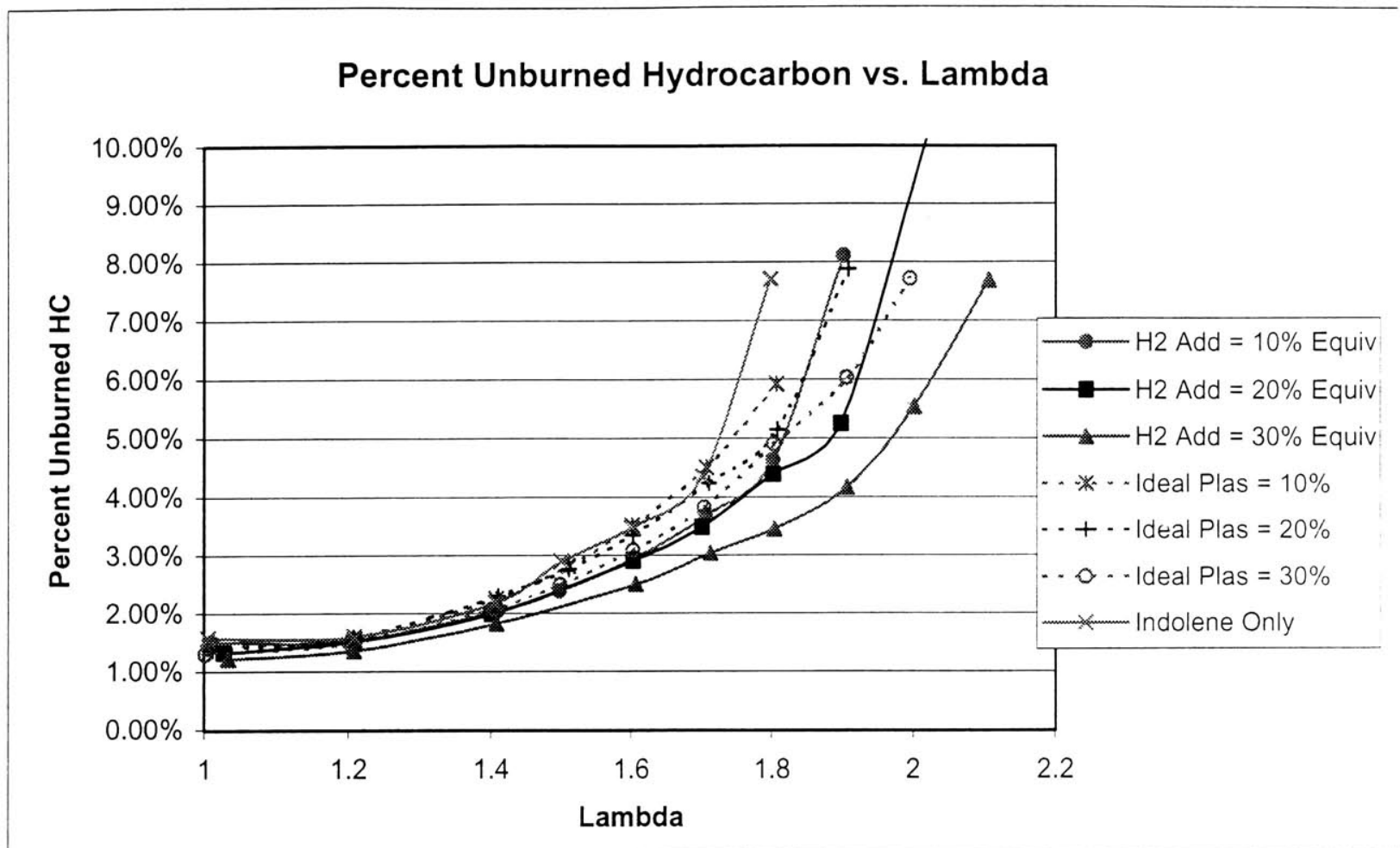

Figure 4.19 - Percent Unburned Hydrocarbons vs. Lambda - Ideal Plasmatron and Hydrogen Addition

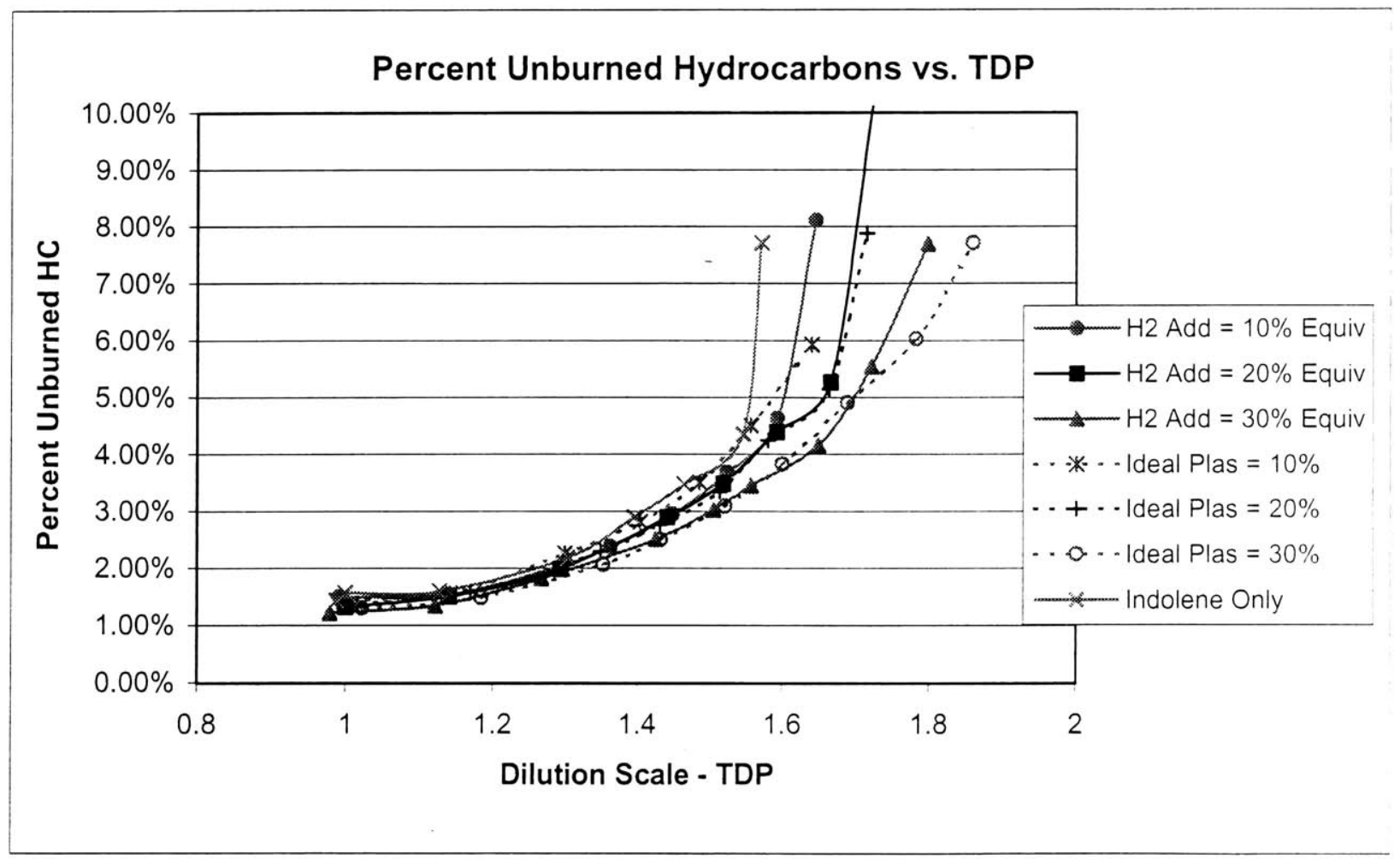

Figure 4.20 - Percent Unburned Hydrocarbons vs. TDP - Ideal Plasmatron and Hydrogen Addition 


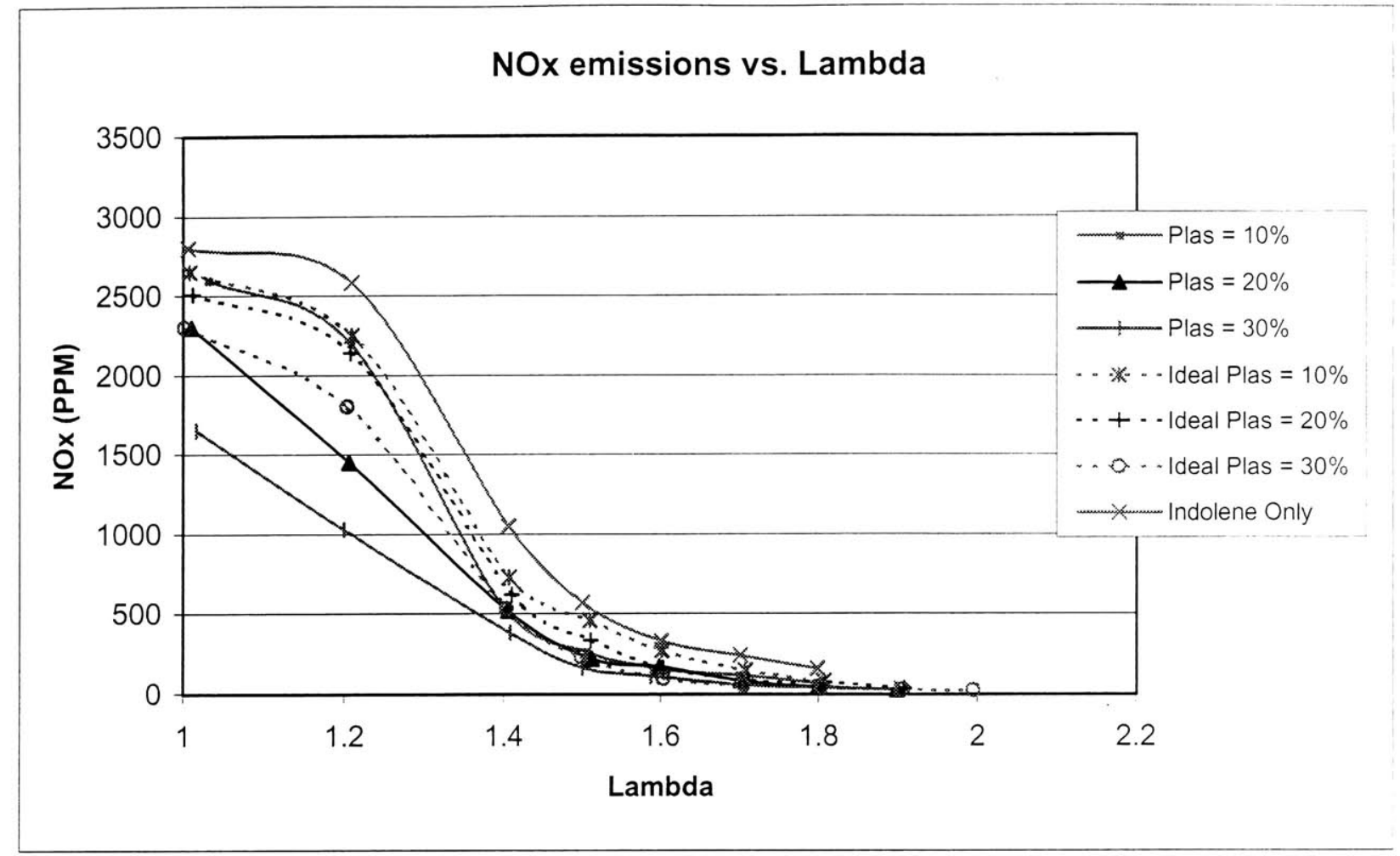

Figure 4.21 - NOx emissions vs. Lambda - Typical and Ideal Plasmatron

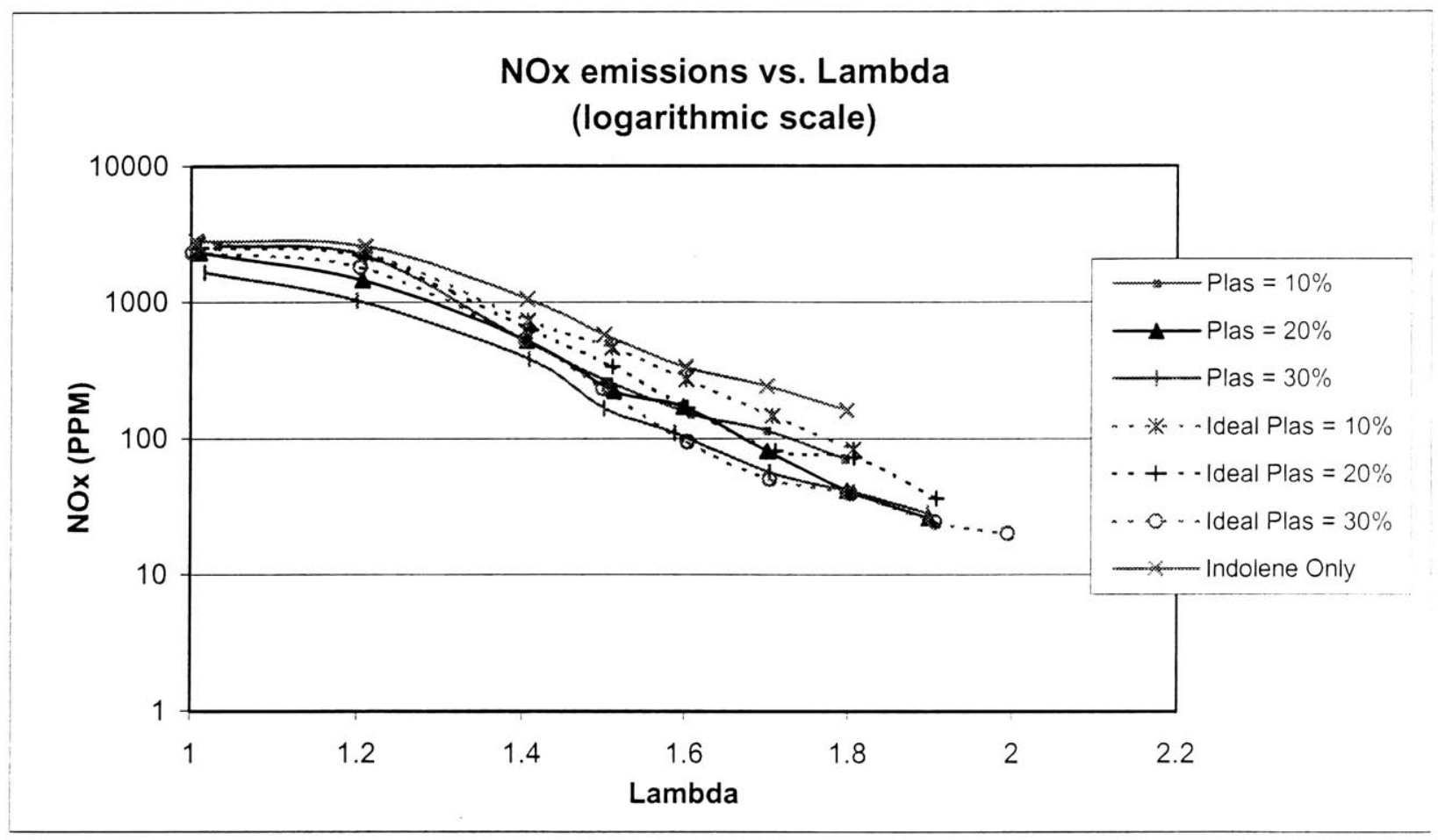

Figure 4.22 - Log Scale of NOx emissions vs. Lambda - Typical and Ideal Plasmatron 


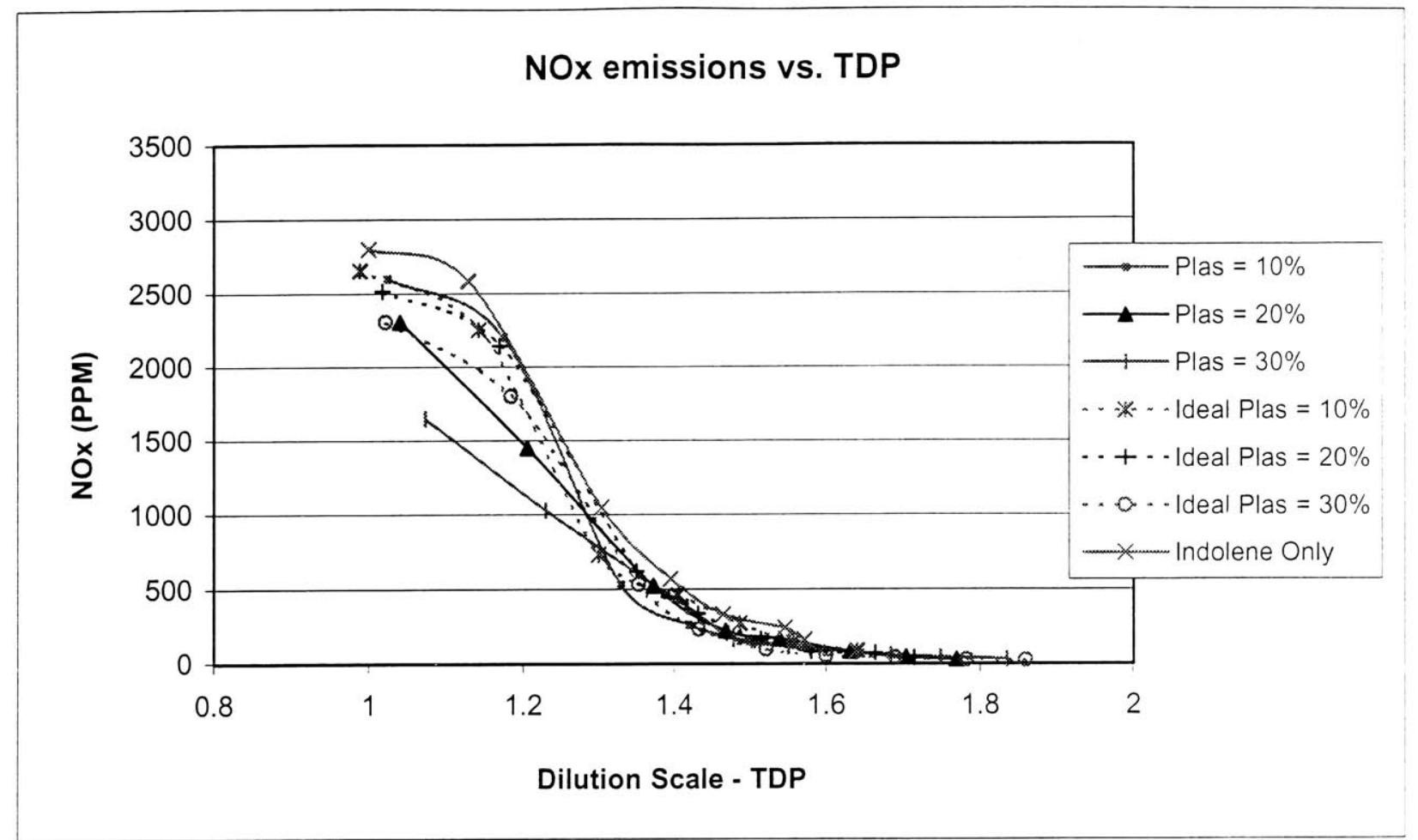

Figure 4.23 - NOx emissions vs. TDP - Typical and Ideal Plasmatron

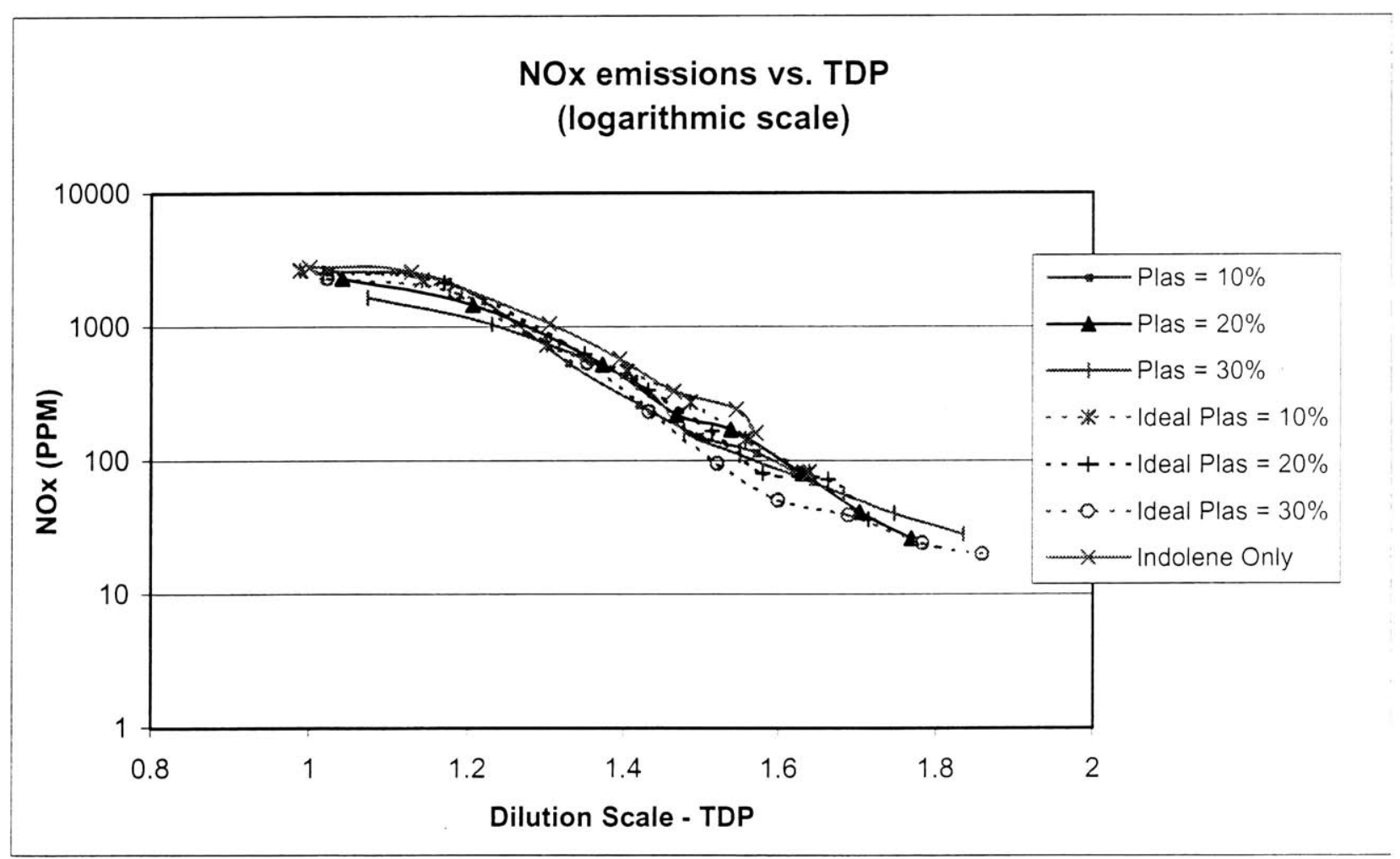

Figure 4.24 - Log Scale of NOx emissions vs. TDP - Typical and Ideal Plasmatron 


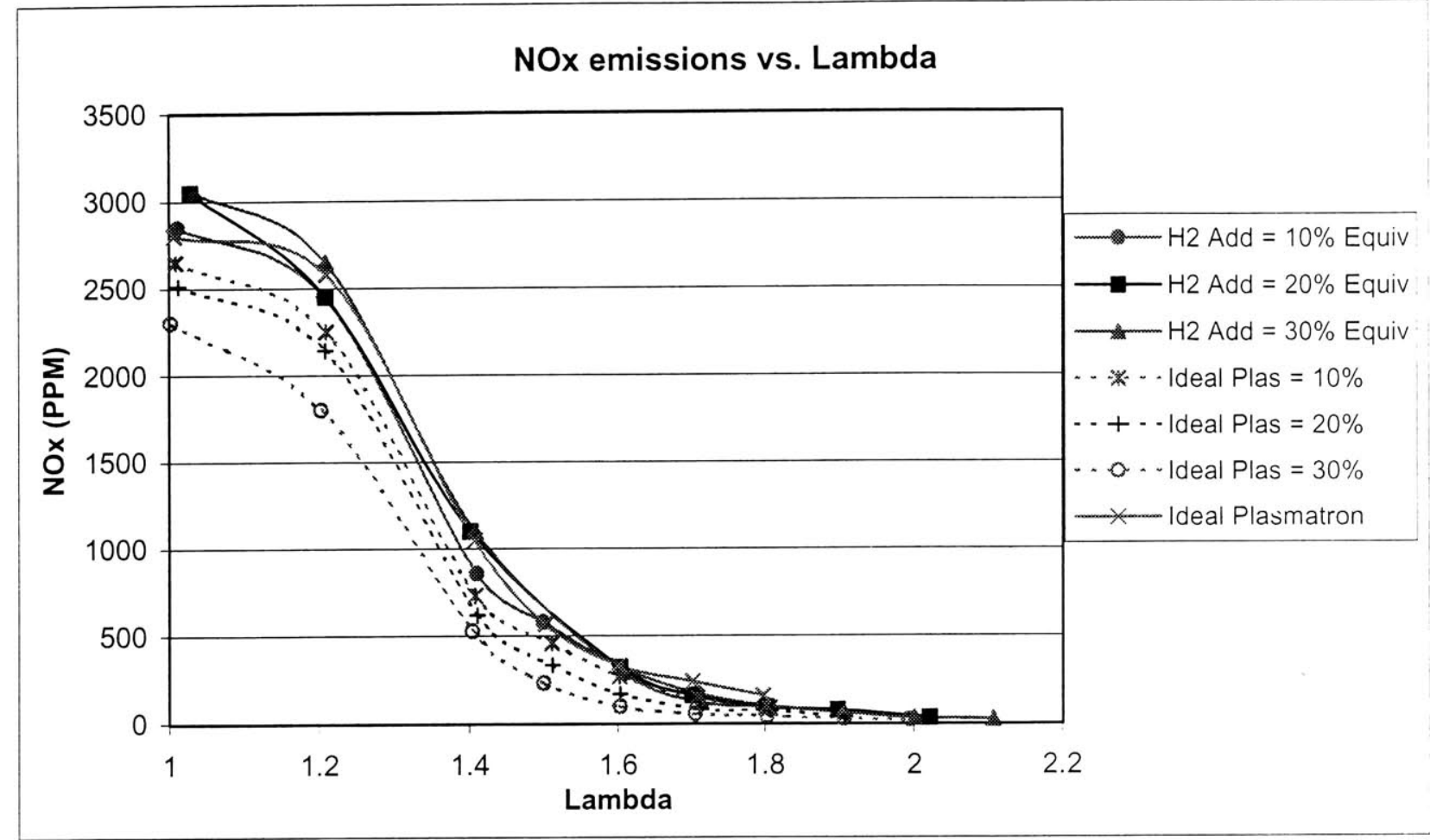

Figure 4.25 - NOx emissions vs. Lambda - Ideal Plasmatron and Hydrogen Addition

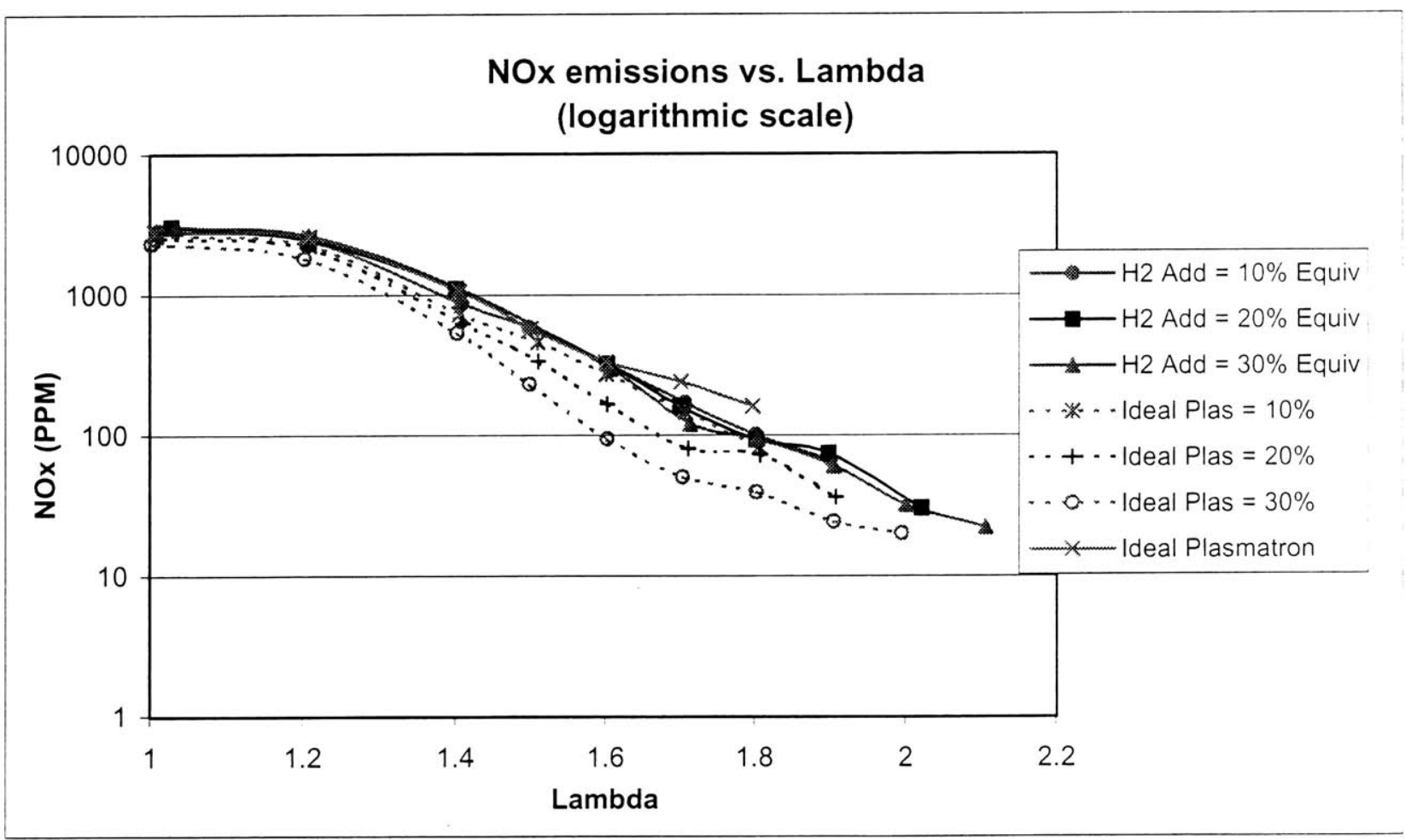

Figure 4.26 - Log Scale of NOx emissions vs. Lambda - Ideal Plasmatron and Hydrogen Addition 


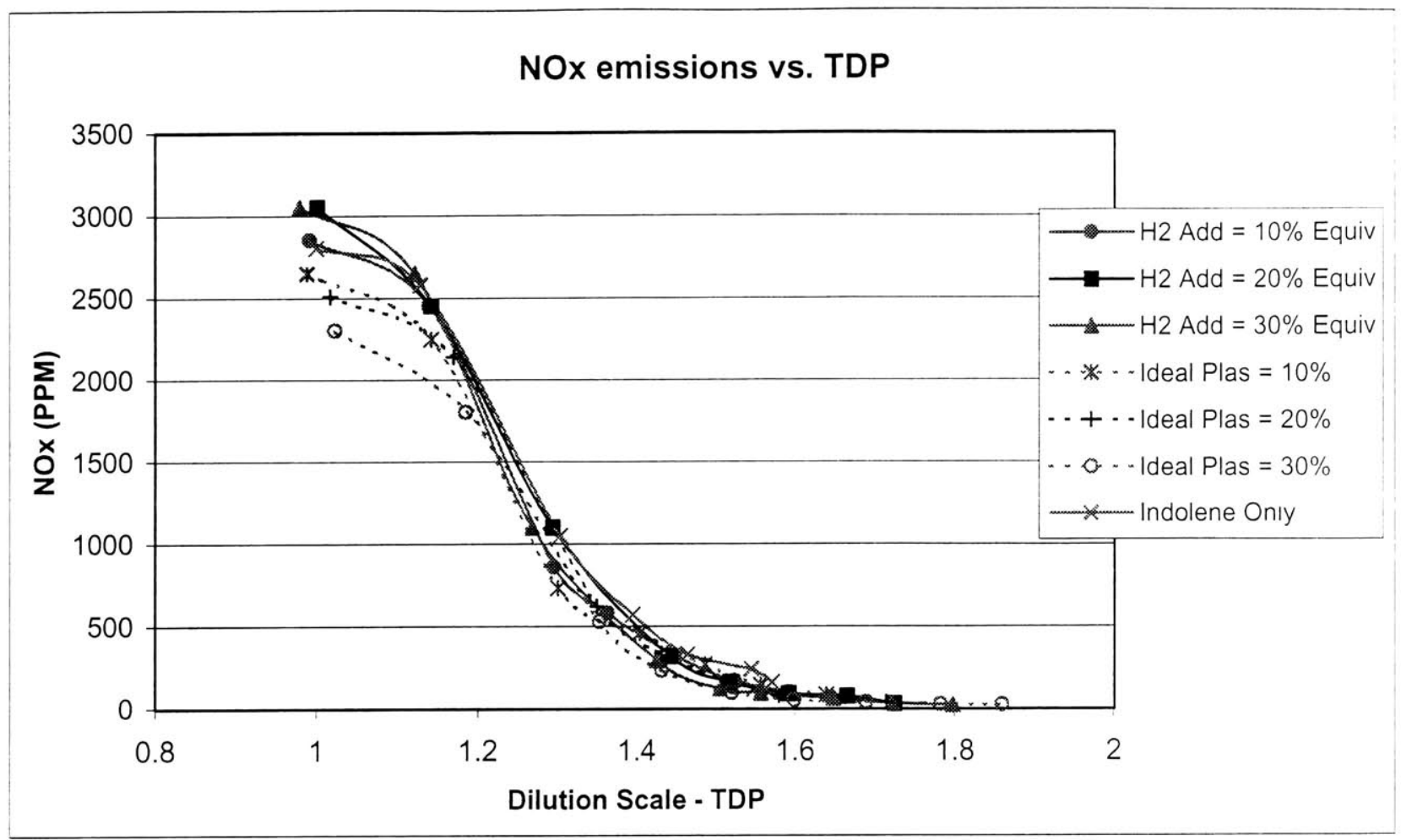

Figure 4.27 - NOx emissions vs. TDP - Ideal Plasmatron and Hydrogen Addition

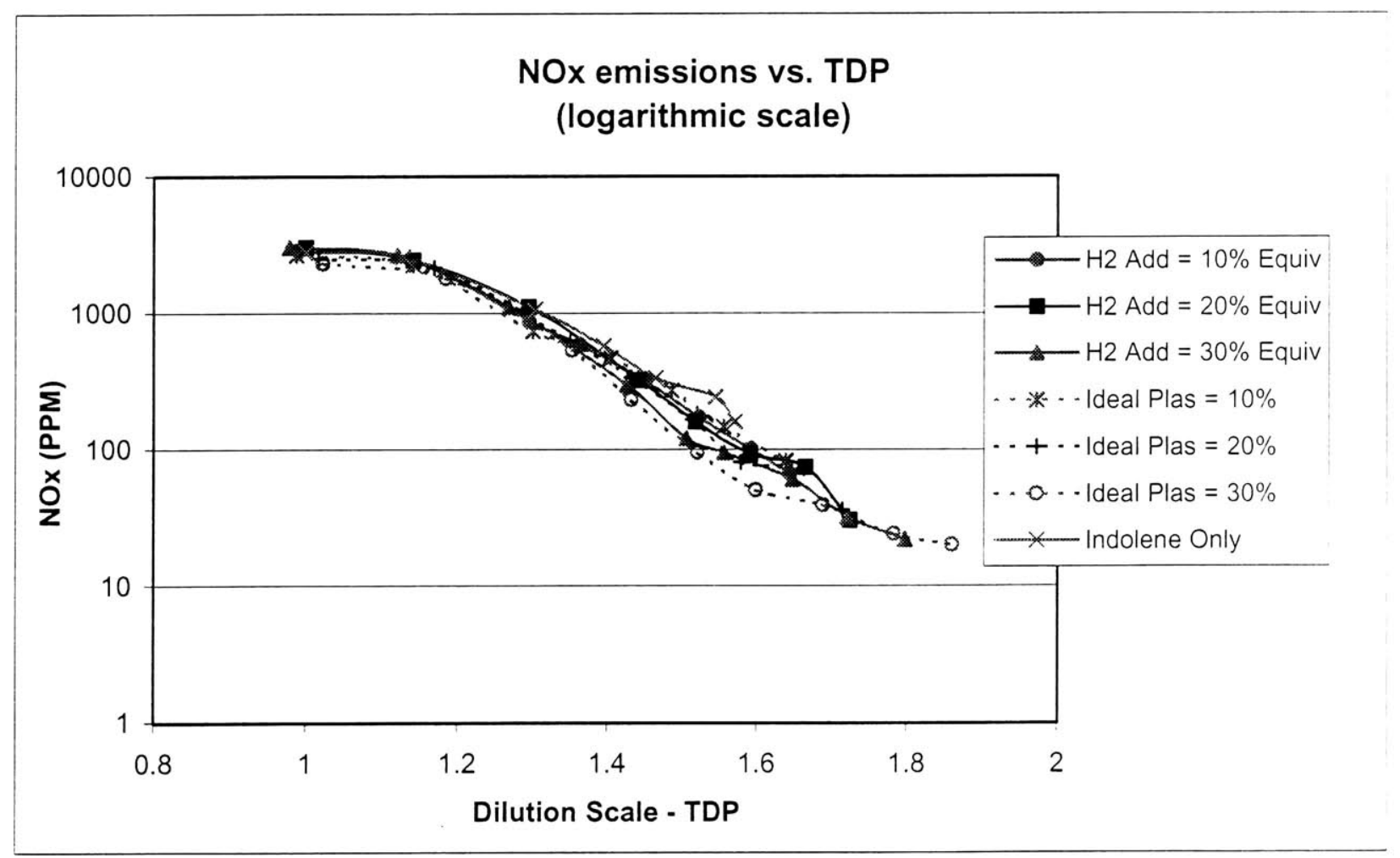

Figure 4.28 - Log Scale of NOx emissions vs. TDP - Ideal Plasmatron and Hydrogen Addition 


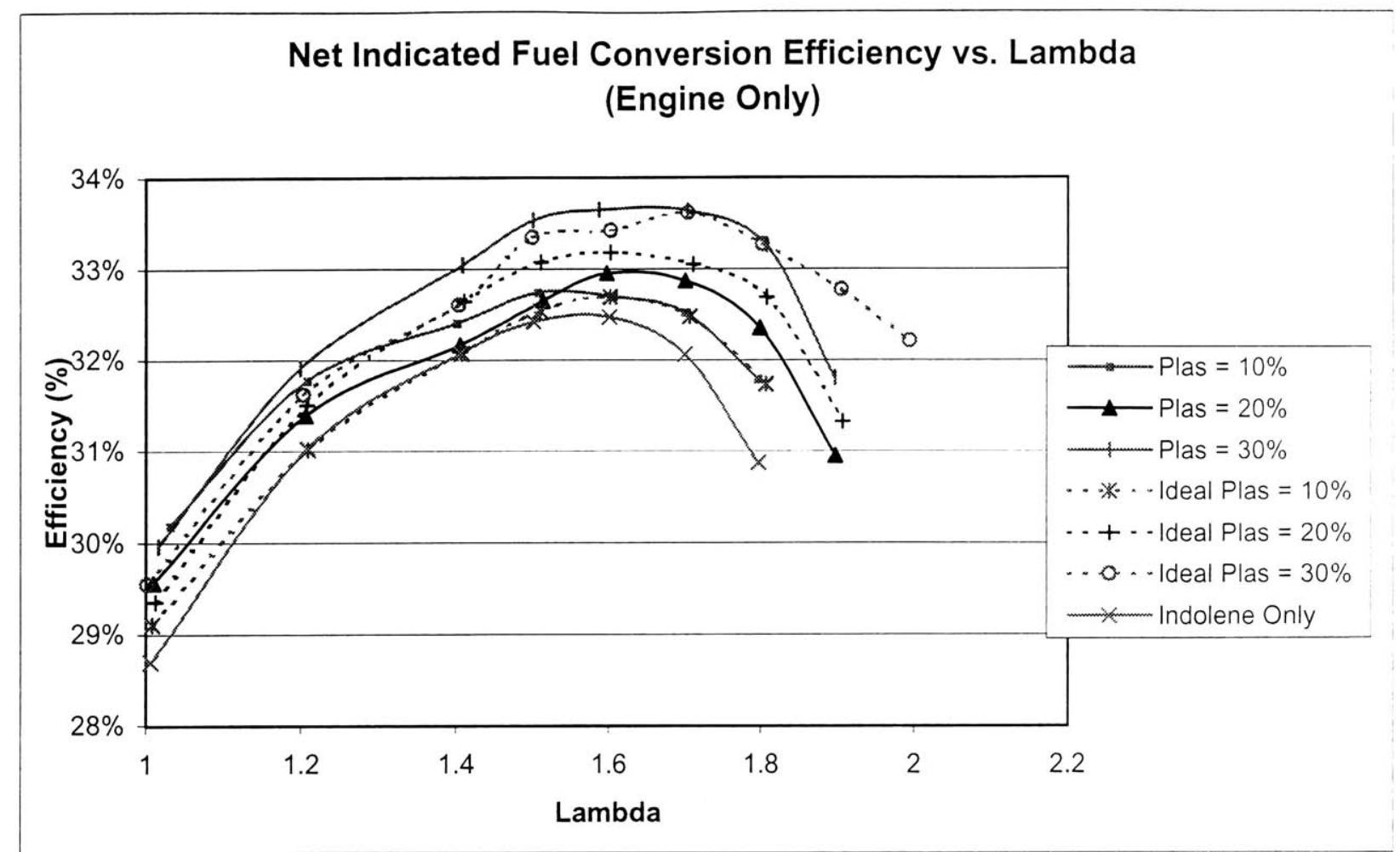

Figure 4.29 - Engine only Fuel Conversion Efficiency vs. Lambda - Typical and Ideal Plasmatron

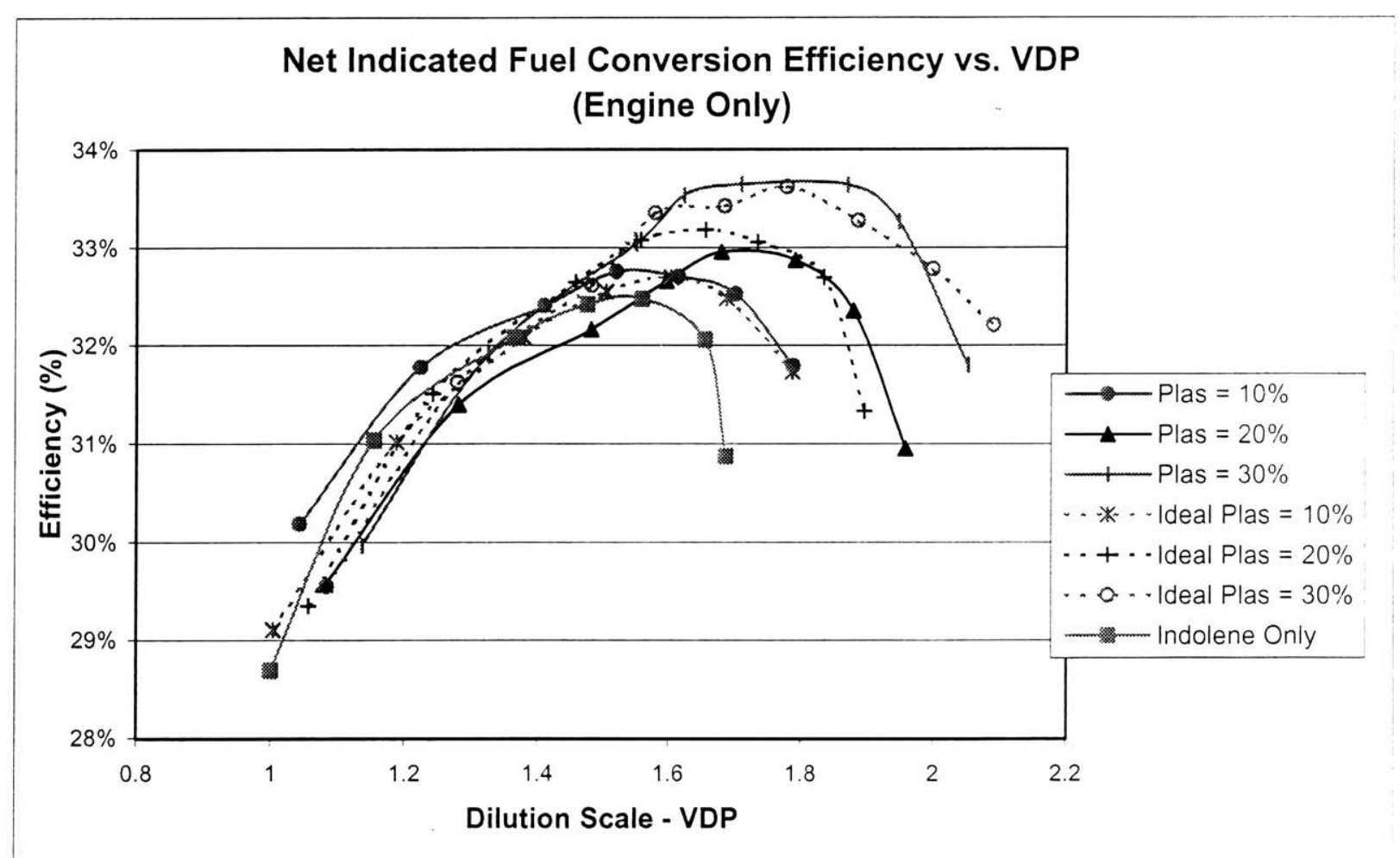

Figure 4.30 - Engine only Fuel Conversion Efficiency vs. VDP - Typical and Ideal Plasmatron 


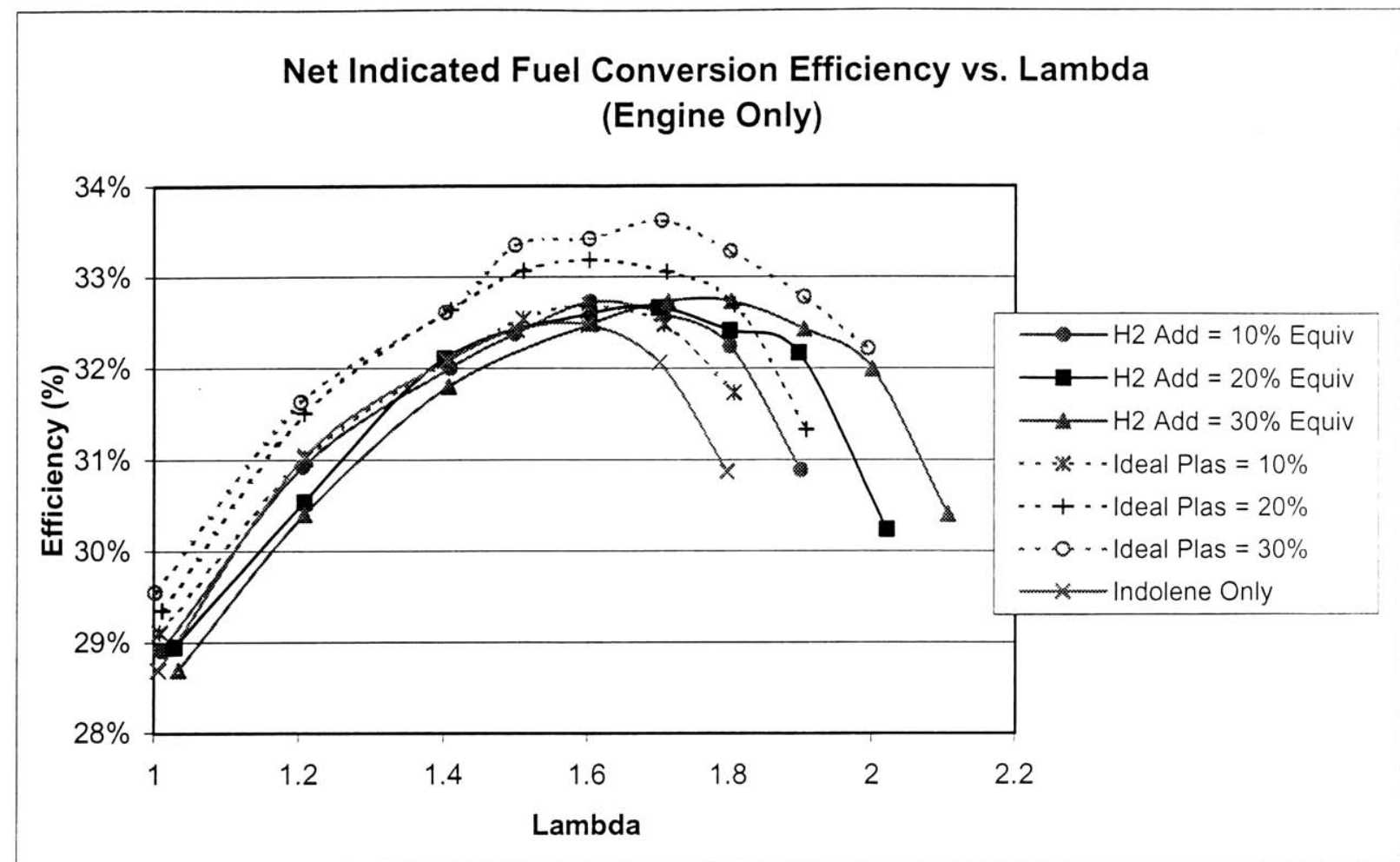

Figure 4.31 - Engine only Fuel Conversion Efficiency vs. Lambda - Ideal Plasmatron and Hydrogen

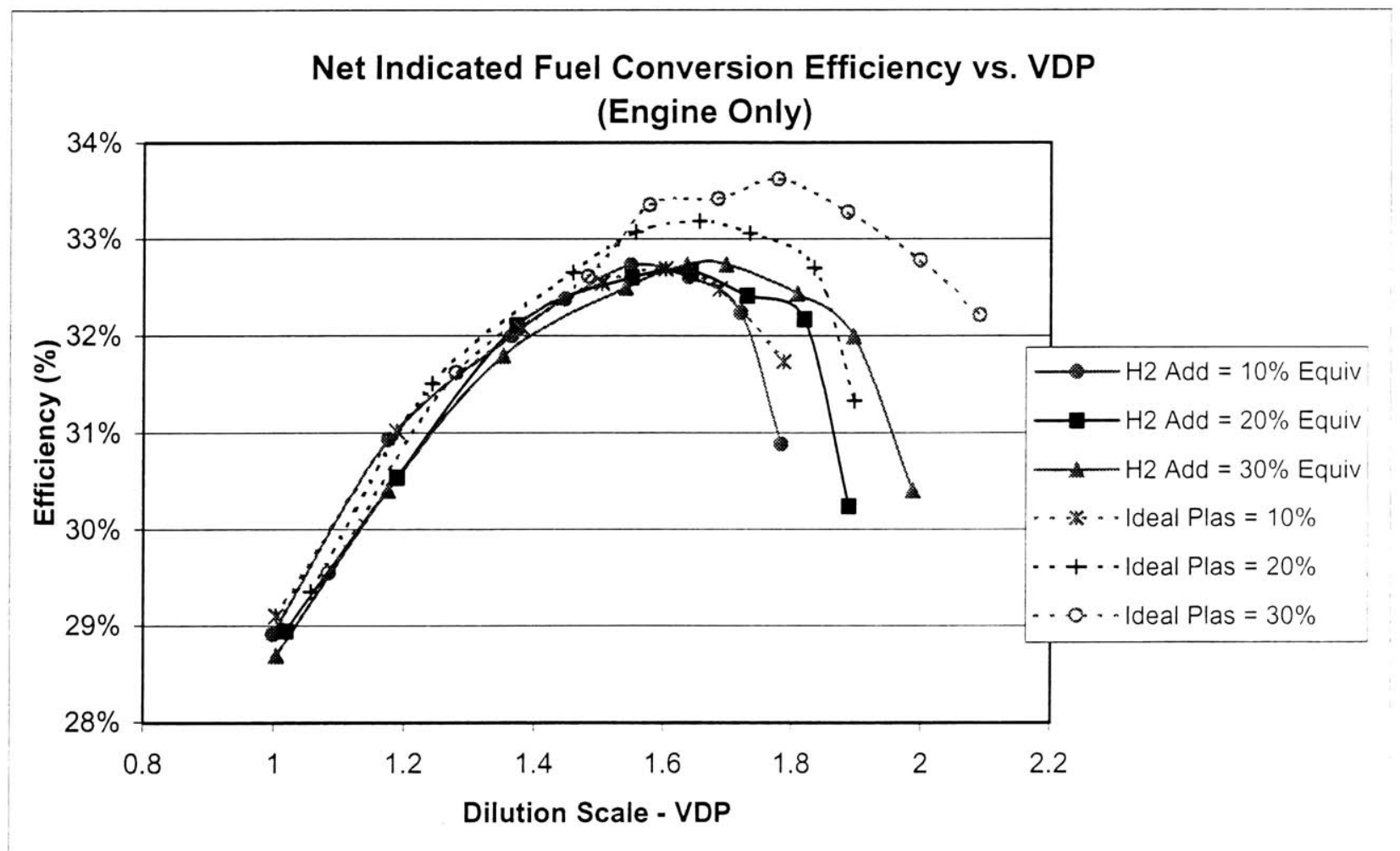

Figure 4.32 - Engine only Fuel Conversion Efficiency vs. VDP - Ideal Plasmatron and Hydrogen 


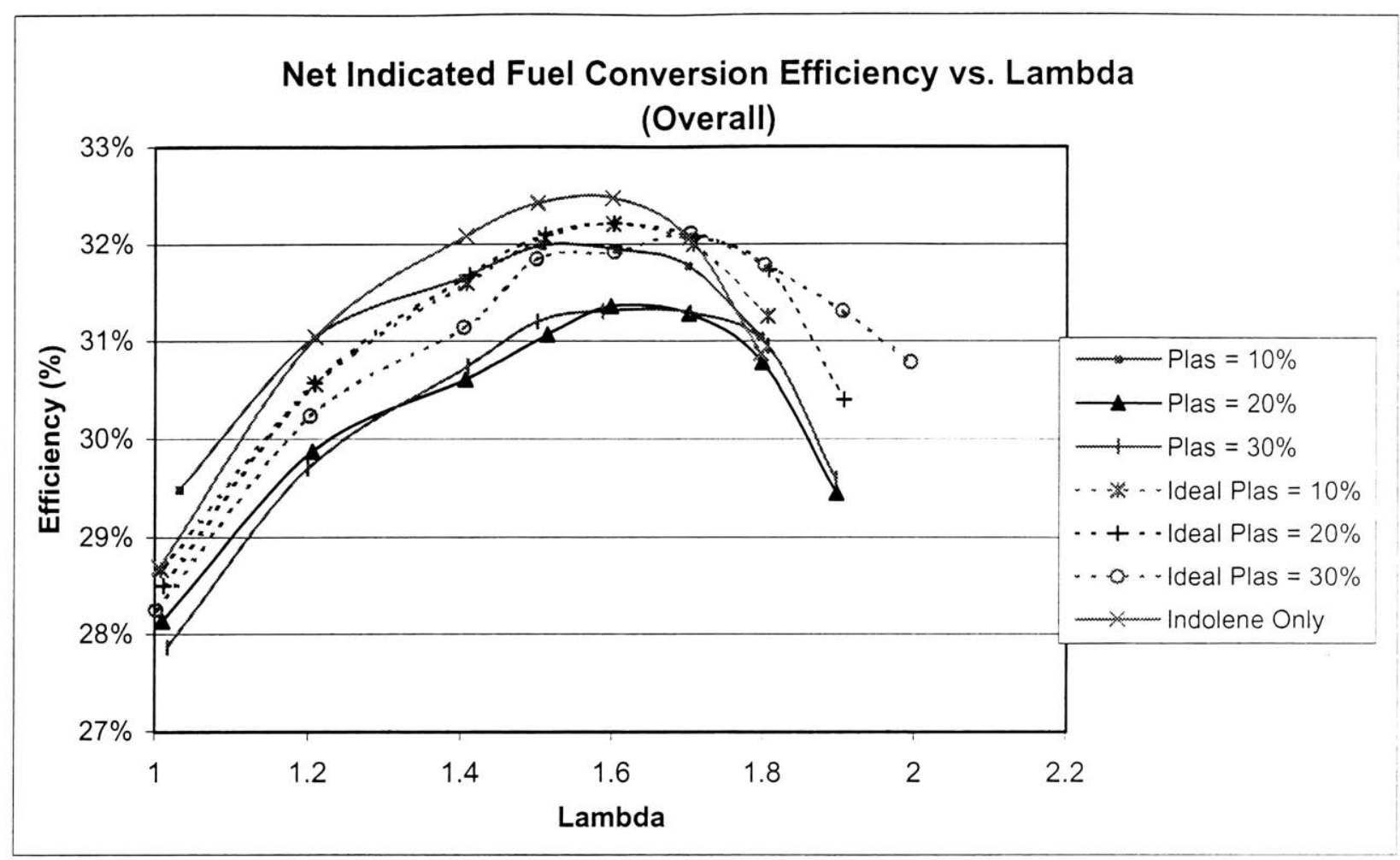

Figure 4.33 - Overall Fuel Conversion Efficiency vs. Lambda - Typical and Ideal Plasmatron

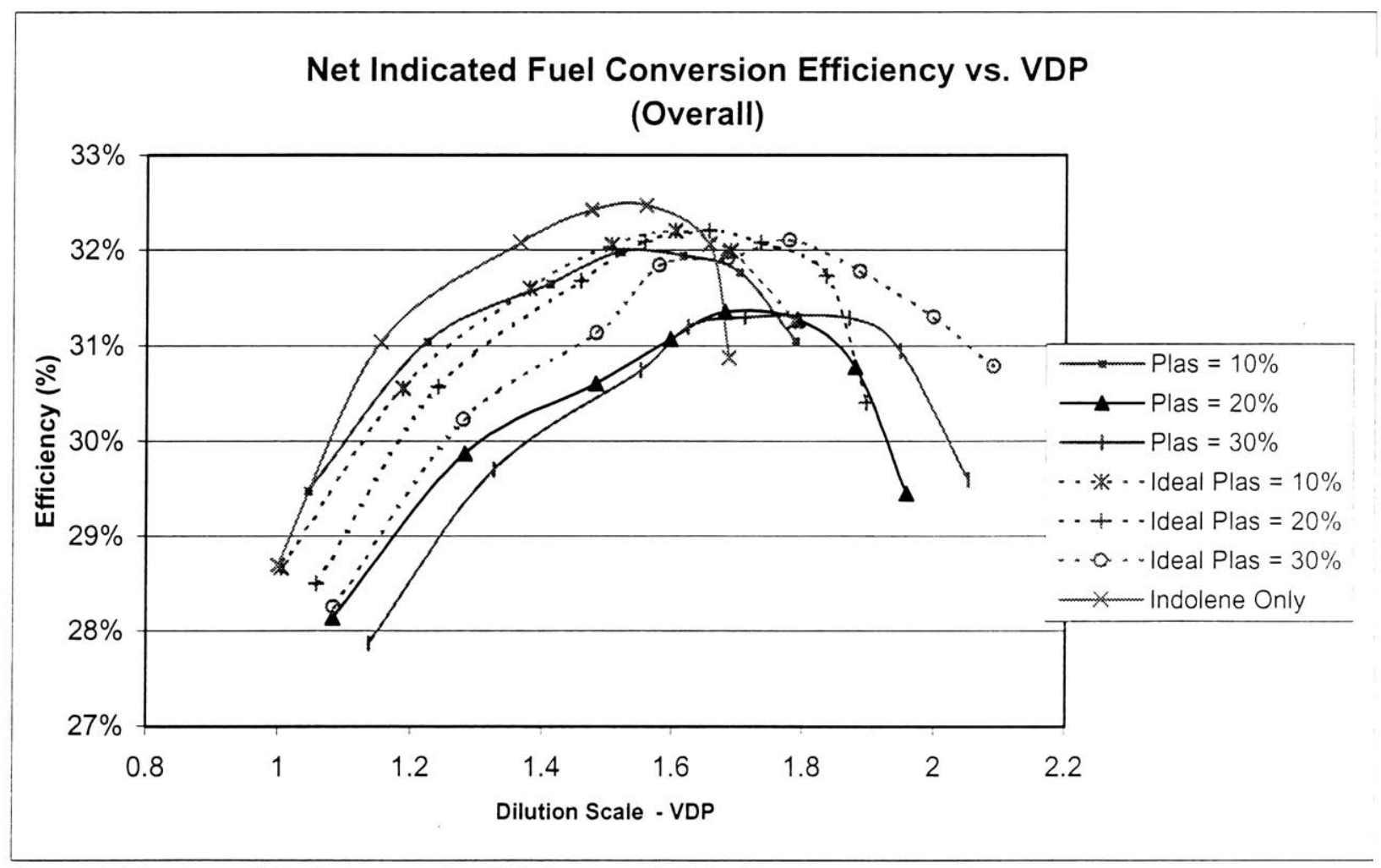

Figure 4.34 - Overall Fuel Conversion Efficiency vs. VDP - Typical and Ideal Plasmatron 


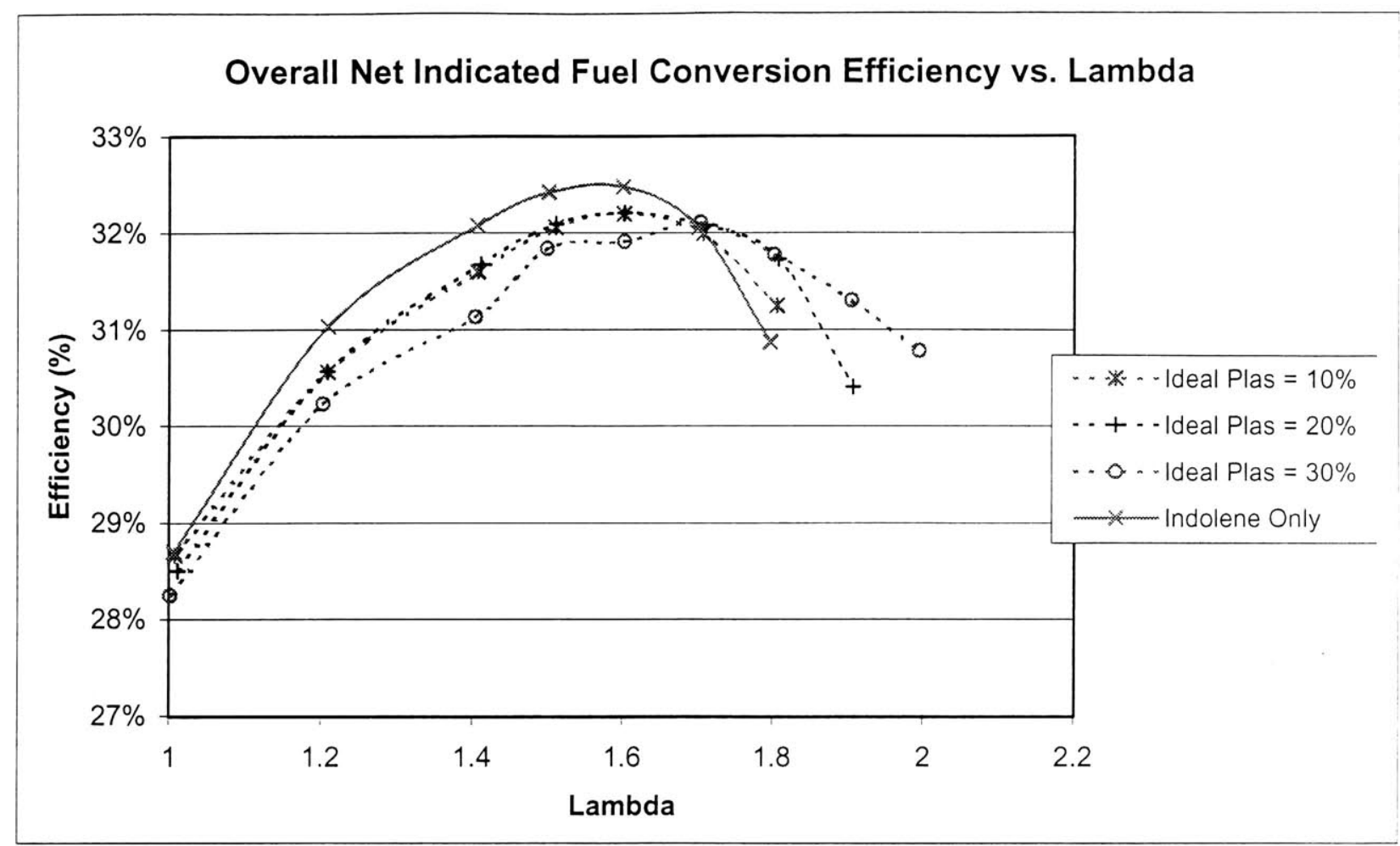

Figure 4.35 - Overall Fuel Conversion Efficiency vs. Lambda - Ideal Plasmatron and Hydrogen Addition

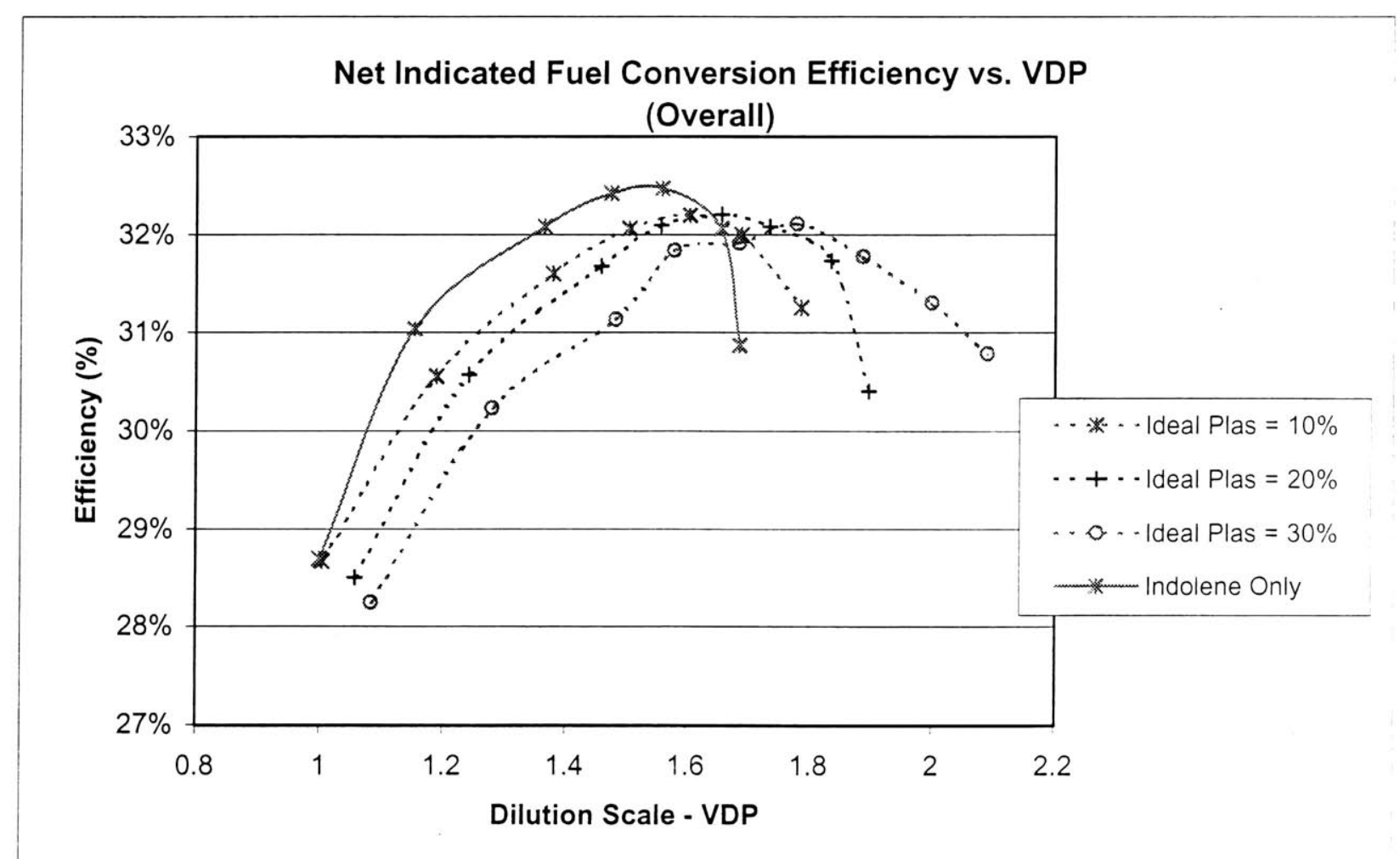

Figure 4.36 - Overall Fuel Conversion Efficiency vs. VDP - Ideal Plasmatron and Hydrogen Addition 


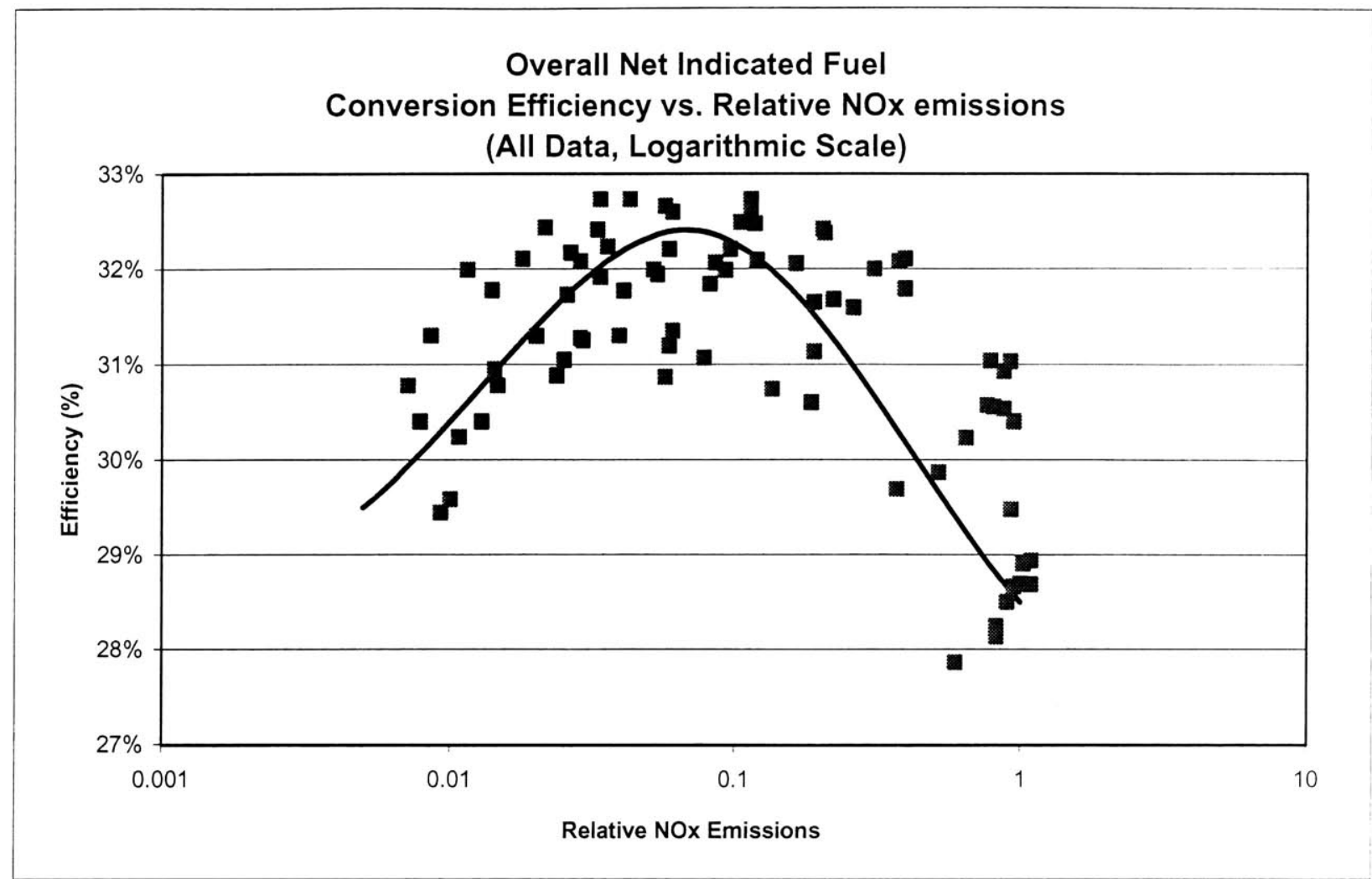

Figure 4.37 - Overall Net Indicated Fuel Conversion Efficiency vs. Normalized NOX Emissions - All Data

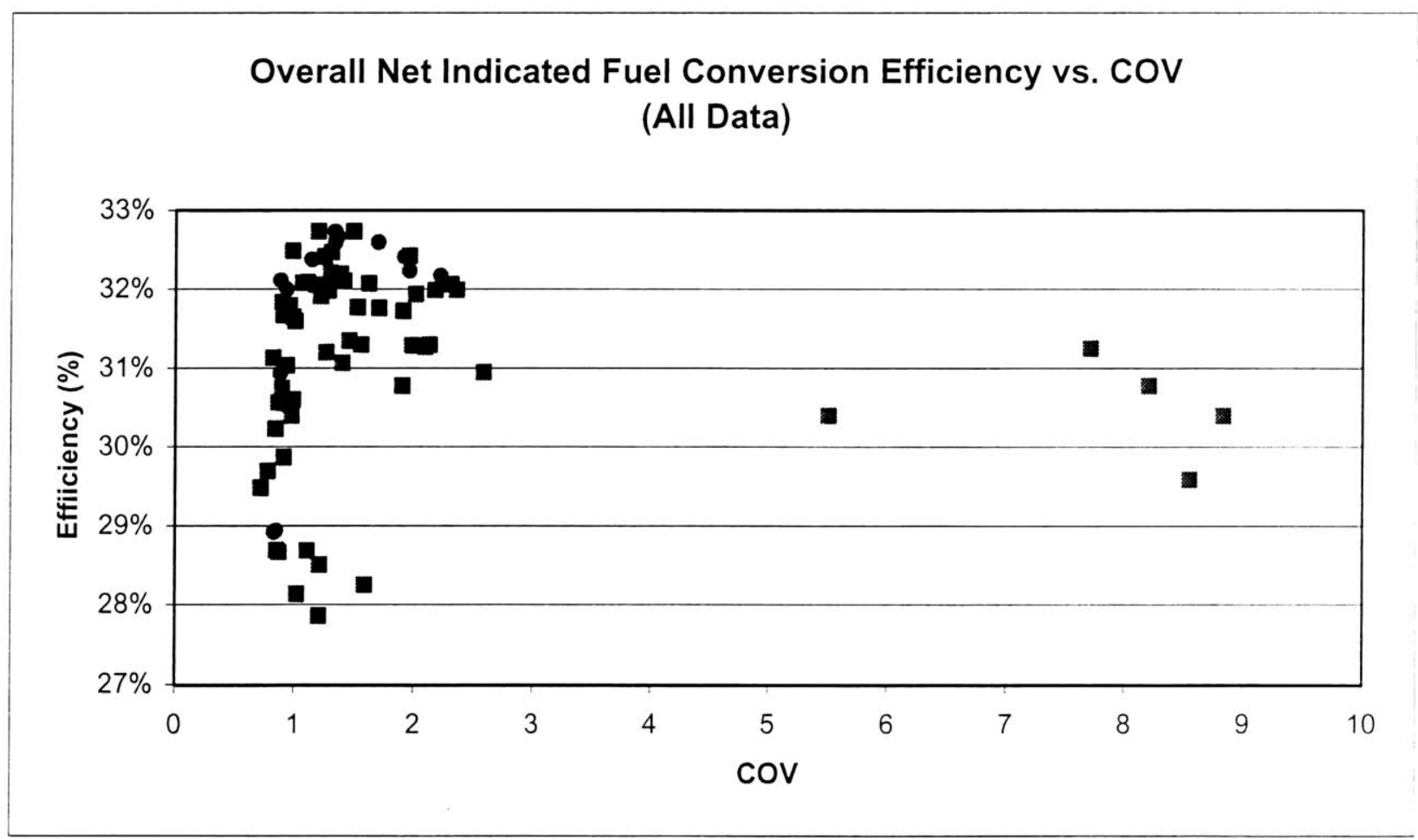

Figure 4.38 - Overall Net Indicated Fuel Conversion Efficiency vs. COV - All Data 


\section{Chapter 5 - Conclusion}

A number of conclusions can be drawn from this series of experiments:

1) There is the potential for a plasmatron fuel enabled lean SI engine to achieve significant gains in net indicated fuel conversion efficiency. All of the experiments were performed at a fixed load of $350 \mathrm{kPa}$ NIMEP and a fixed speed of 1500 RPM. For the ideal plasmatron addition $\left(\mathrm{H}_{2}, \mathrm{CO}\right.$, and $\mathrm{N}_{2}$ only) experiments the peak overall efficiency point occurred at $20 \%$ ideal plasmatron and lambda of 1.6. This corresponded to a value of 1.66 for the Volumetric Dilution Parameter (VDP). The VDP is an alternative dilution parameter to lambda and represents dilution based on the energy per unit volume of fuel air mixture. At this peak efficiency point the overall net indicated fuel conversion efficiency was increased $12 \%$ compared to the baseline case of the engine operating stoichiometrically on indolene only.

2) Substantial decreases in NOx emissions were observed when running at high dilution levels. At the peak efficiency point the NOx reduction was approximately $95 \%$. When higher levels of plasmatron gas were used the engine out NOx emissions were reduced by up to $99 \%$.

3) The percentage of unburned hydrocarbons increased as the mixture dilution increased. At low levels of dilution this number was independent of what fuel combination was used and was also independent of the amount of plasmatron gas added to the fuel/air mixture. In the upper dilution range the addition of more plasmatron gas reduced the percentage of unburned hydrocarbons due to higher dilution limits. A plasmatron enhanced engine would need a hydrocarbon aftertreatment system to meet emissions regulations.

4) Hydrogen addition experiments were performed to quantify the impact of the $\mathrm{CO}, \mathrm{CO}_{2}$, and $\mathrm{N}_{2}$ in the plasmatron gas. The fraction of the total energy that 
was supplied by the hydrogen was matched in order to make the comparison meaningful. A comparison of hydrogen addition experiments to the plasmatron gas addition experiments showed that the $\mathrm{CO}, \mathrm{CO}_{2}$, and $\mathrm{N}_{2}$ in the plasmatron gas had a slightly beneficial effect on combustion. This was reflected in the efficiency, emissions, and combustion stability data. The fact that $\mathrm{CO}$ has a higher dilution limit than indolene is thought to be the explanation for this observation.

5) In the analysis the relative air/fuel ratio was found to be an inadequate measure of mixture dilution. Two new dilution parameters were defined. The Volumetric Dilution Parameter, VDP, represents the heating value per unit volume of the air/fuel mixture. Pumping work reduction due to dilution correlate with VDP. The Thermal Dilution Parameter, TDP, represents the heating value per unit heat capacity of the fuel/air mixture. Combustion and emissions parameters correlate well with TDP.

6) Approximately $20 \%$ of the chemical energy of the fuel is lost when it is reformed in the plasmatron. These losses are significant and have a direct impact on the overall system efficiency. Increasing the efficiency of the plasmatron was shown to have a significant impact on the overall net indicated fuel conversion efficiency of the engine. 


\section{REFERENCES}

[1] N. Apostolescu, R. Chiriac

"A Study of Combustion of Hydrogen Enriched Gasoline in a Spark Ignition Engine", SAE Paper No. 960603, 1996

[2] I. Glassman

"Combustion", third edition

Academic Press, 1996

[3] J. B. Green Jr., N. Domingo, J. M. E. Storey, R. M. Wagner, J. S. Armfield

L. Bromberg, D.R. Cohn, A. Rabinovich, and N. Alexeev

"Experimental Evaluation of SI Engine Operation Supplemented by Hydrogen

Rịch Gas from a Compact Plasma Boosted Fuel Reformer”, SAE Technical Paper Series No. 2000-01-2206

[4] M. J. Grieve, J. E. Kirwan, A. A. Quader, Delphi Automotive Systems

"Integration of a small on-board reformer to a conventional gasoline internal combustion engine system to enable a practical and robust nearly-zero emission vehicle", 1999 Global Powertrain Conference; Stuttgart, Germany; October, 1999

[5] L. Bromberg, D.R. Cohn, A. Rabinovich

"Aftertreatment of Diesel Vehicle Emissions Using Compact Plasmatron Fuel Converter-Catalyst Systems", US Department of Energy Office of Heavy Vehicle Technologies Report, December 1999

[6] Chevron Phillips

UTG-96 Certificate of Analysis

[7] John B. Heywood

"Internal Combustion Engine Fundamentals"

McGraw-Hill, 1988

[8] Rosemont Analytical Inc.

Rosemont Analytical Model 402 Hydrocarbon Analyzer Instruction Manual

[9] Thermo Environment Instruments Inc.

Rack Mounted Chemiluminescence NO-NOx Gas Analyzer Instruction Manual

[10] H. M. Cheung, J. B. Heywood

"Evaluation of a One-Zone Burn Rate Analysis Procedure Using Production SI Engine Pressure Data", SAE Paper No. 932749, 1993 
[11] H. M. Cheung, J. B. Heywood "Estimating Heat Release and Mass-of-Mixture burned from Spark-Ignition Engine Pressure Data", Combustion Science and Technology 1987, Volume 54

[12] Evans, R.L.

"Combustion Chamber Design for a Lean-Burn SI Engine", SAE Paper No. 921545,1992 
APPENDIX 

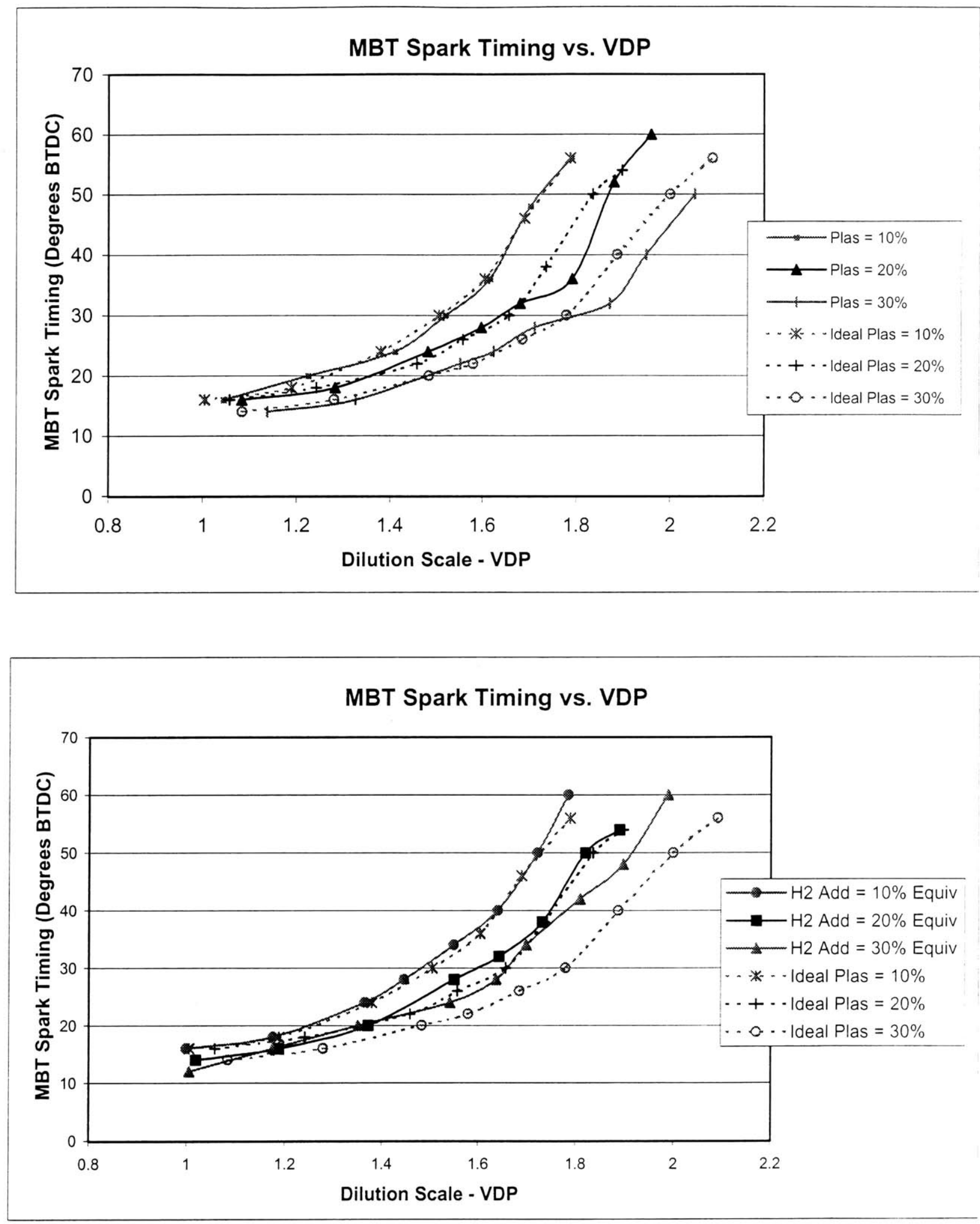


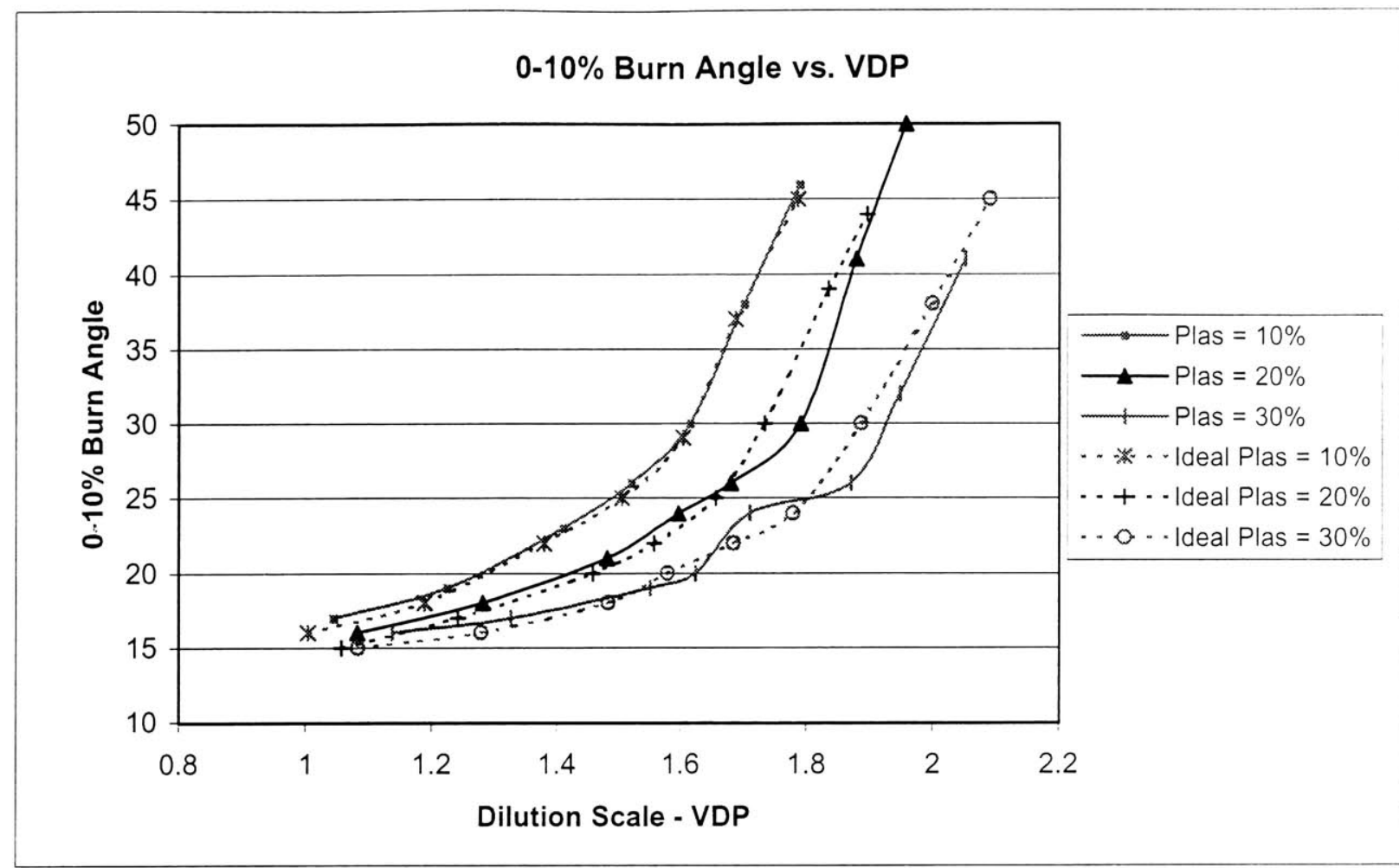

$10-90 \%$ Burn Angle vs. VDP

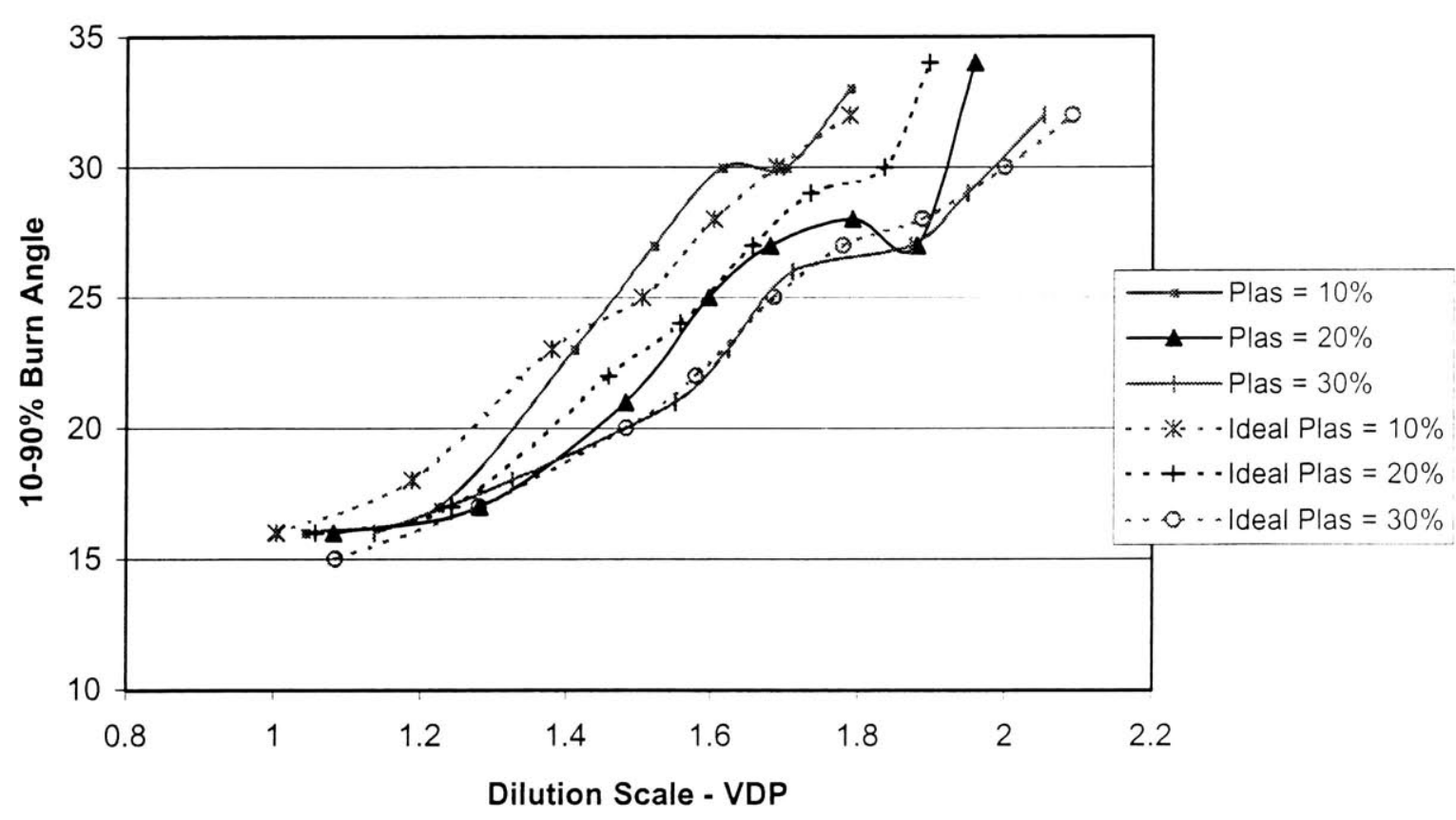



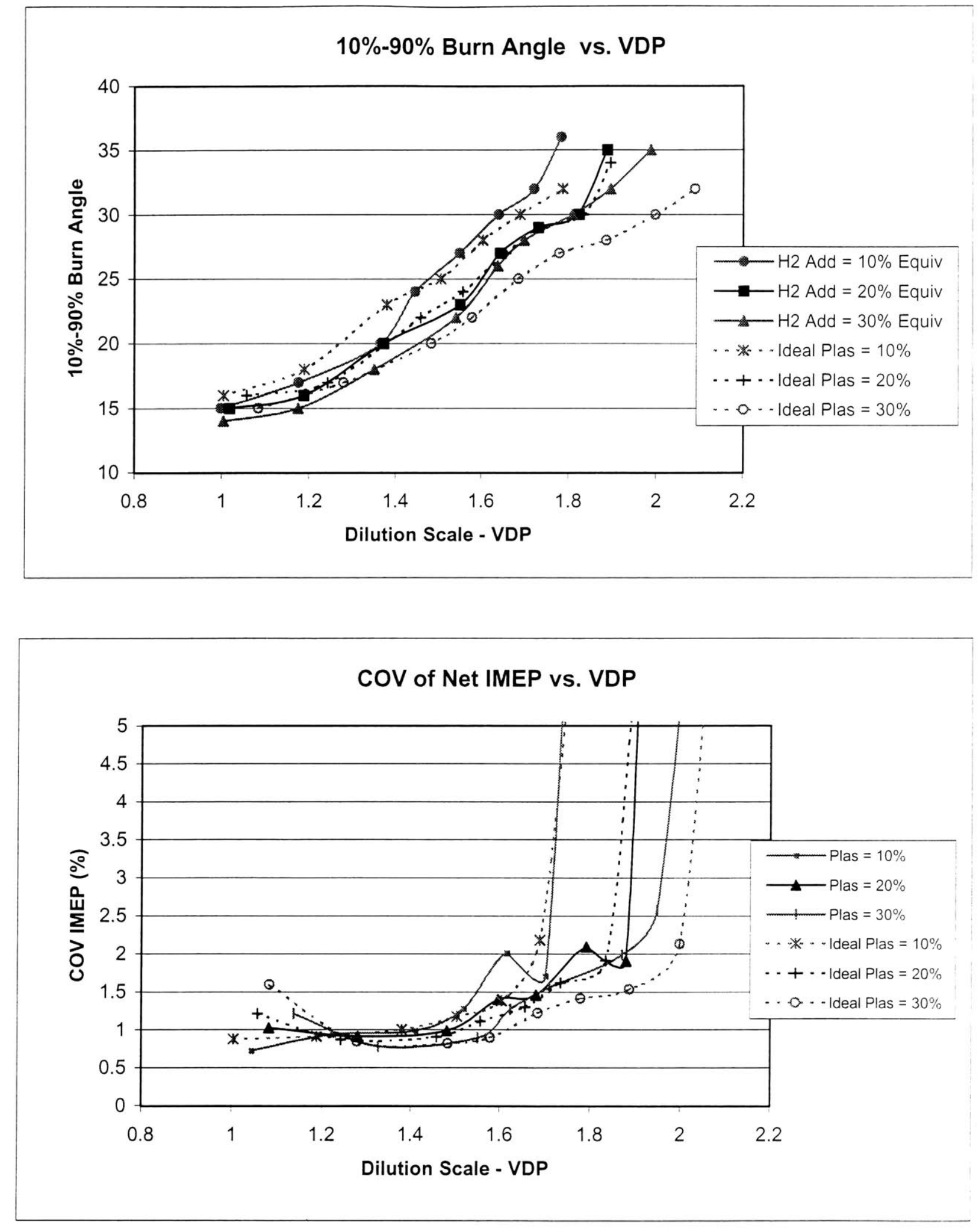

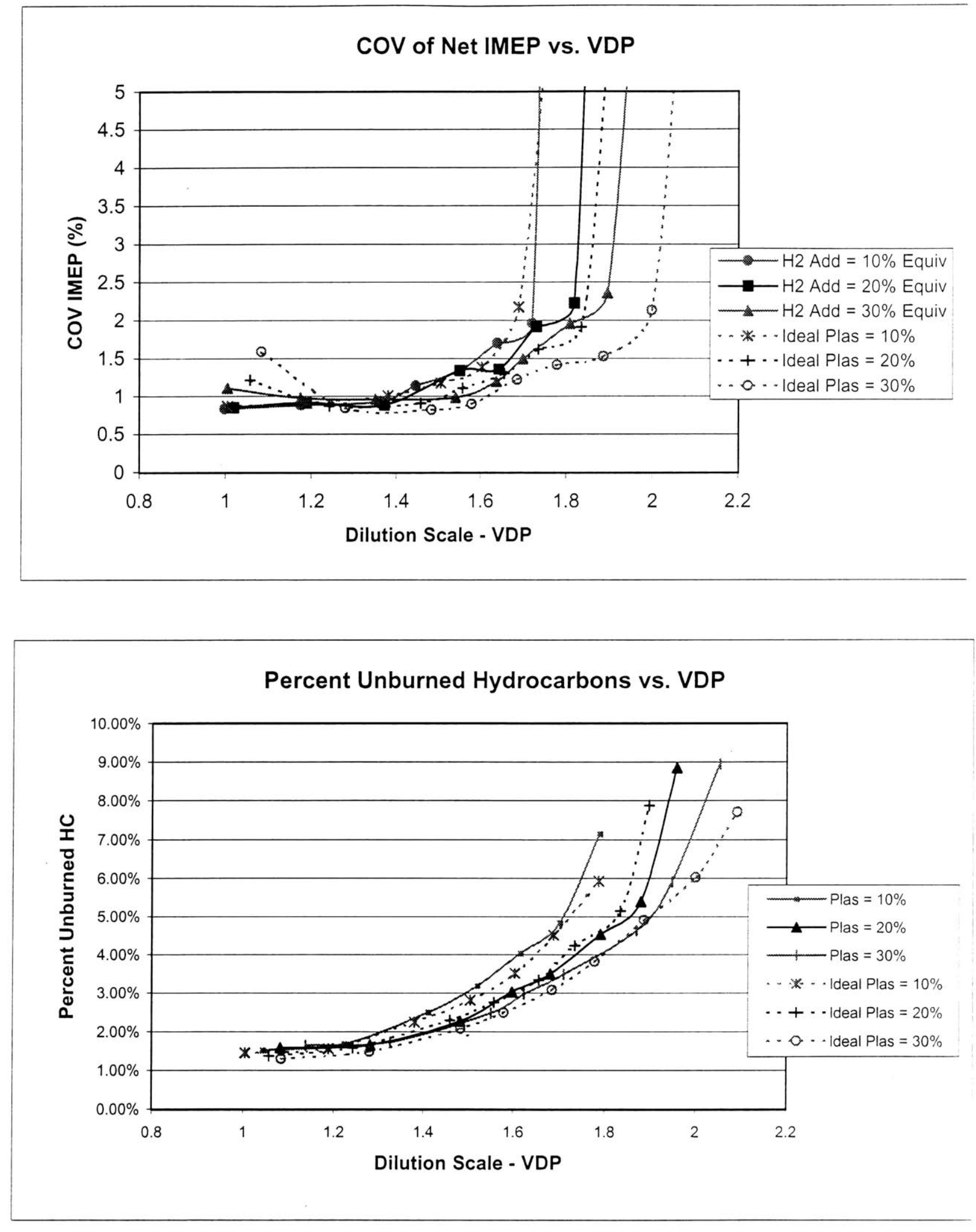

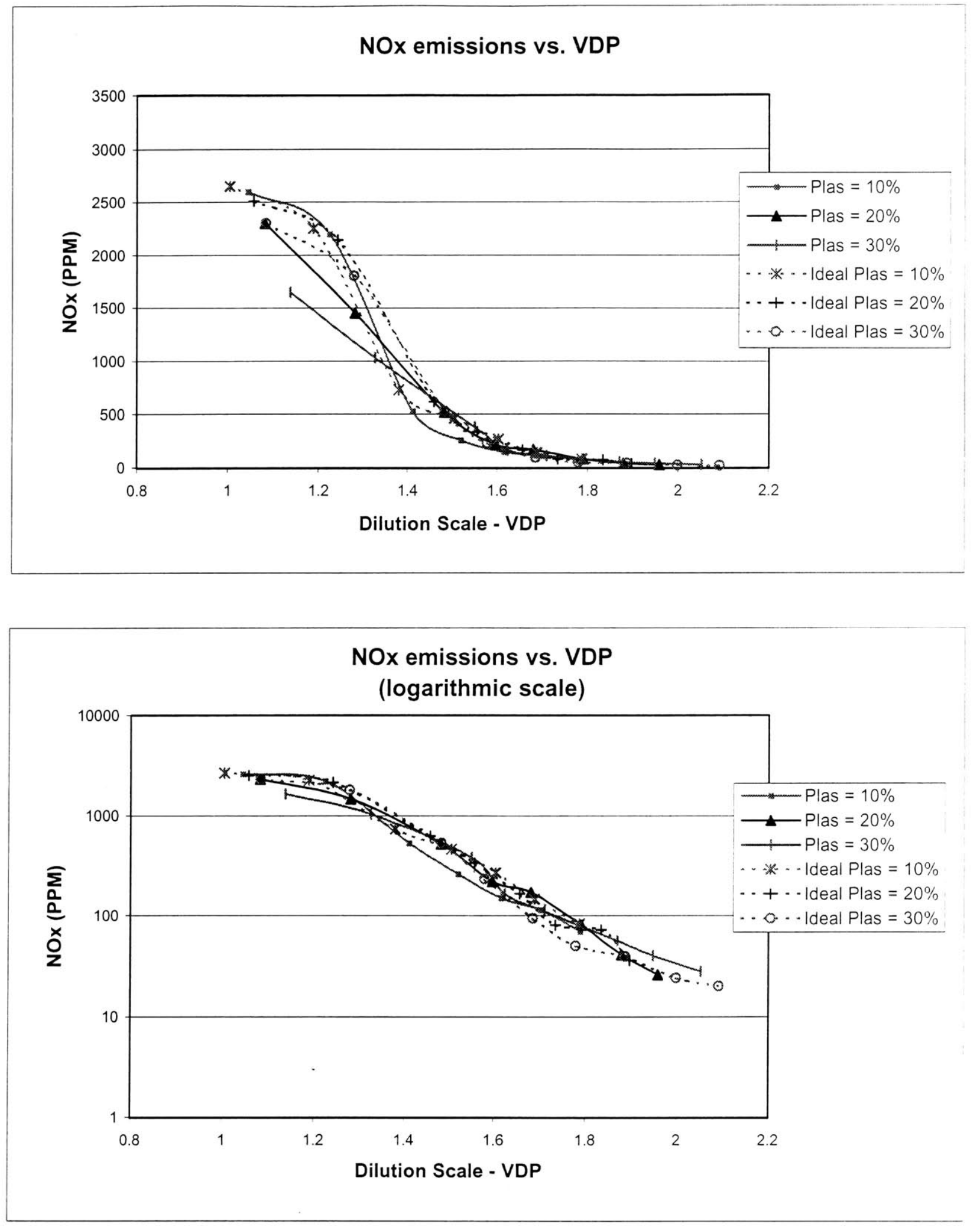

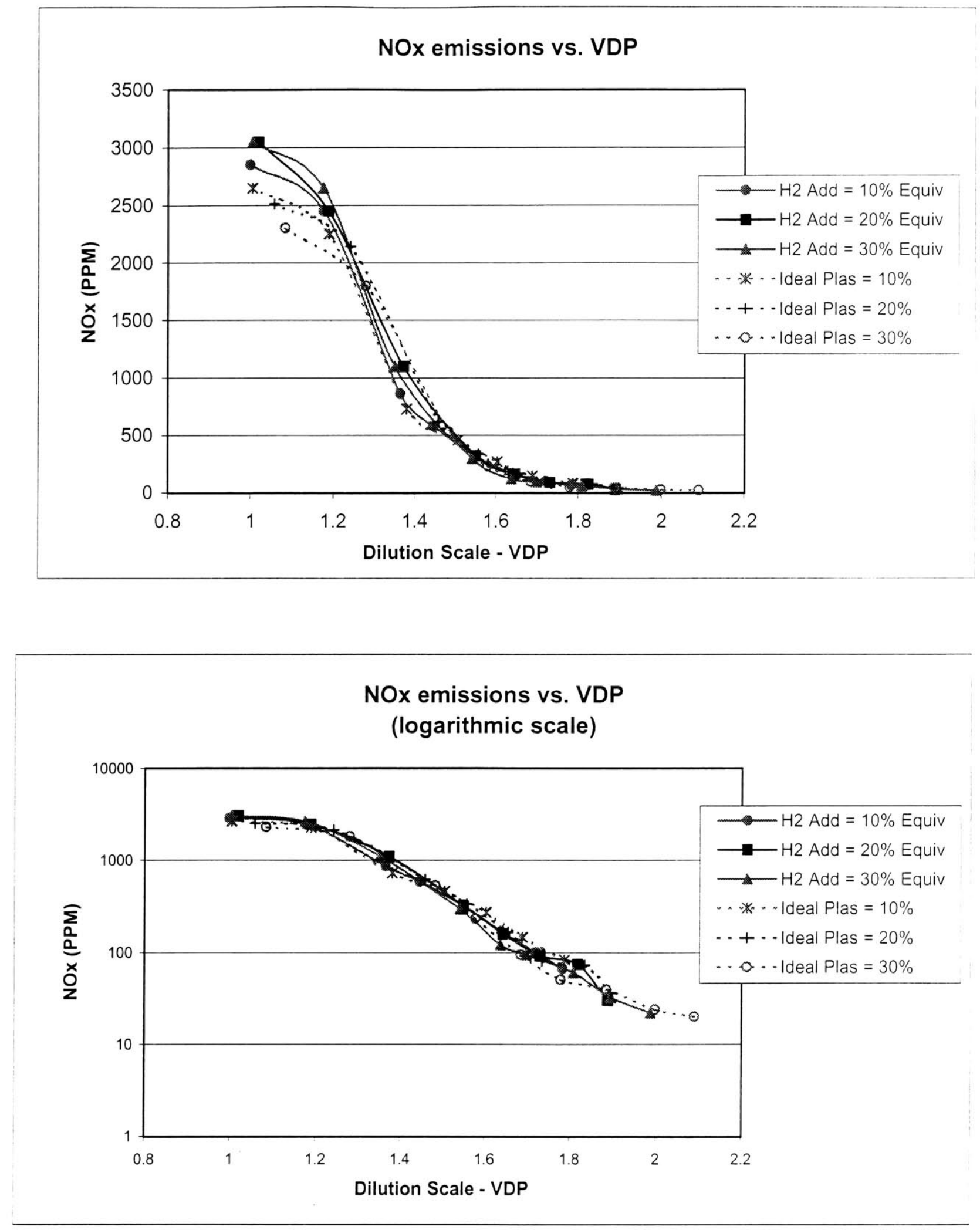

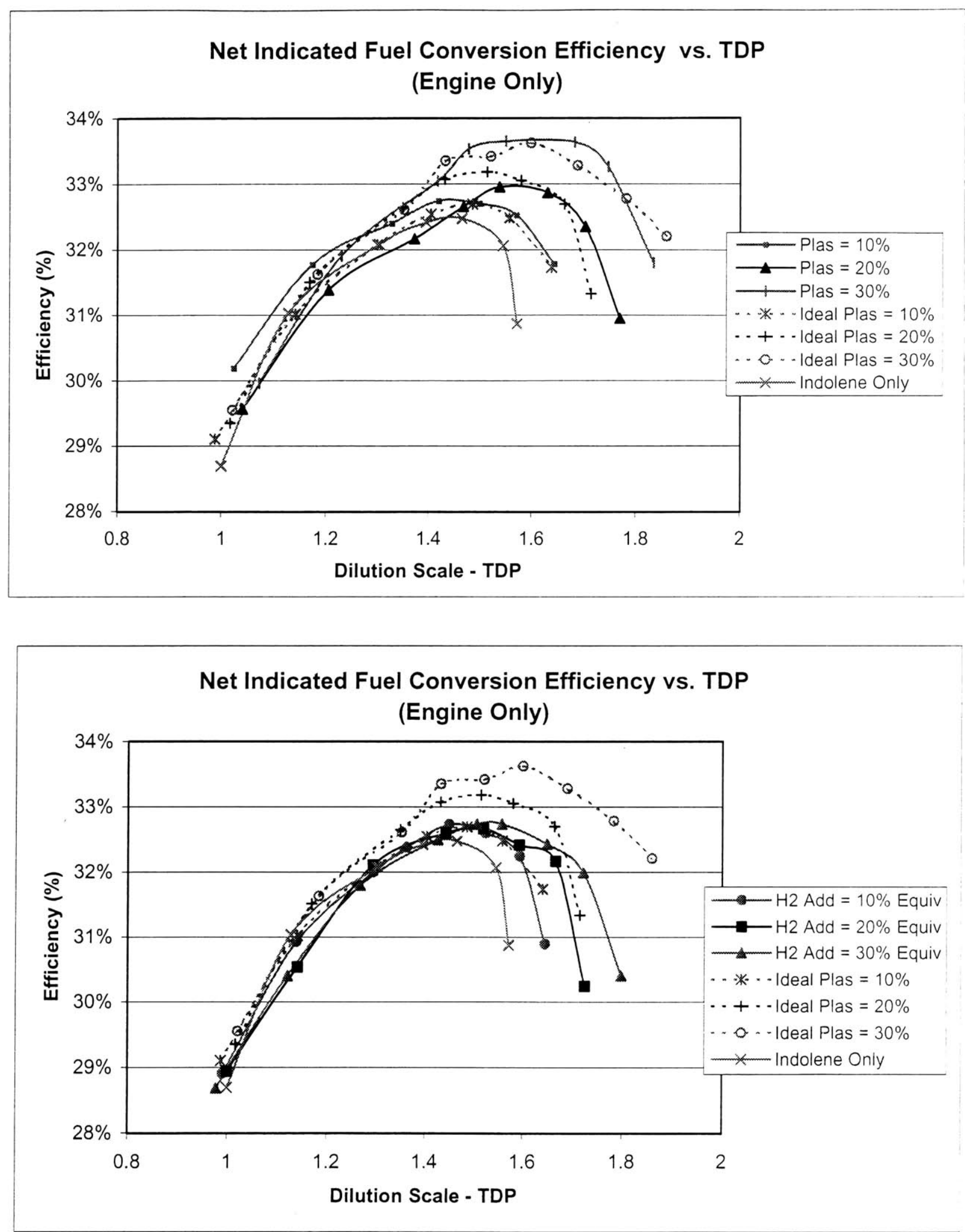

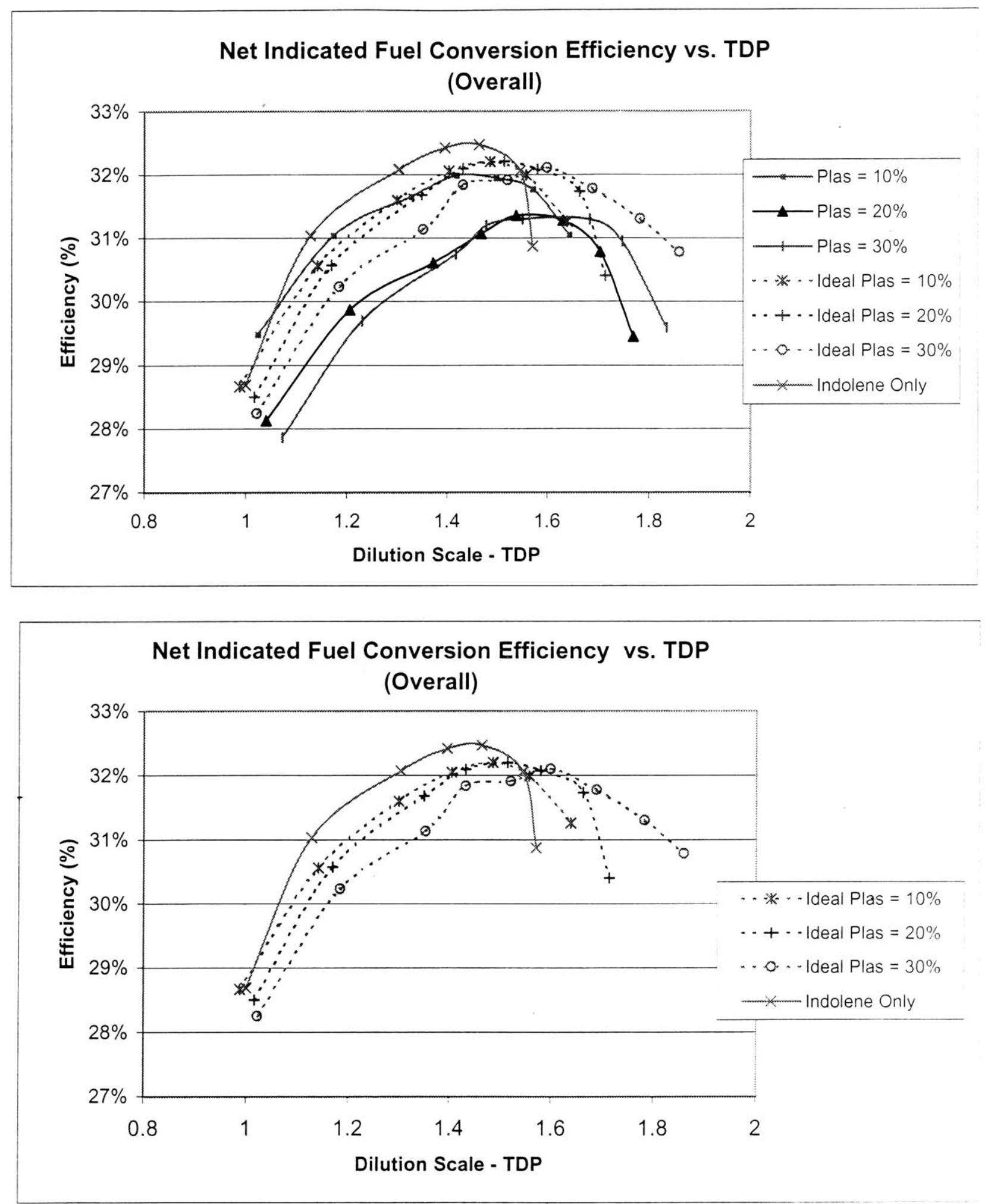